\title{
Desenvolvimento motor de lactentes expostos ao vírus da imunodeficiência humana (HIV)
}

Dafne Herrero

Dissertação apresentada ao Programa de Pós-graduação em Saúde Pública, para a obtenção do título de Mestre em Ciências.

Área de concentração Saúde, Ciclos de Vida e Sociedade.

Orientador: Prof. Dr. Luiz Carlos de Abreu

SÃO PAULO 
É expressamente proibida a comercialização deste documento, tanto na sua forma impressa como eletrônica. Sua reprodução total ou parcial é permitida exclusivamente para fins acadêmicos e cientificos, desde que na reprodução figure a identificação do autor, título, instituição e ano da tese/dissertação.

$$
54068 / 2012
$$


Dedico este trabalho a minha família, que no decorrer de sua realização, aumentou e se iluminou. 
Agradecimento especial aos que, durante a construção do mestrado, me fizeram sentir privilegiada pelo contato diário e pela oportunidade de ter estudado indivíduos que pouco medo têm de arriscar, repetem intensamente gestos e movimentos para se aprimorarem, e fazem das suas vontades 0 sentido de sua sobrevivência: estes são os bebês! 


\section{AGRADECIMENTOS}

Agradeço a quem não apenas me dá diariamente a força para querer ser uma pessoa melhor, mas também permitem que meus dias sejam mais intensos e repletos de momentos de observação, dedicação, aprendizado e felicidade plena: meus filhos Clara e Jorge.

Agradeço ao meu companheiro, parceiro, amigo e marido pelas horas de escuta, carinho e força incondicional: Daniel.

Agradeço à minha família que tenho orgulho de fazer parte e compartilhar desafios, conquistas, decisões, emoções e realizações: Mamuska, Andrine, Ramon, Ricardo, Jéssica, Raquel, Cleide e Paulo.

Agradeço aos professores que me guiam, inspiram, instigam e dividem de seu conhecimento com a intenção de propagar informação e auxiliar da melhor maneira possivel.

Agradeço aos amigos sempre presentes em minha jornada.

Obrigada! Sem o apoio de vocês não seria assim, não seria para mim, não seria... 


\section{RESUMO}

Herrero D. Desenvolvimento motor de lactentes expostos ao vírus da imunodeficiência humana (HIV). [Dissertação de Mestrado]. SP: Faculdade de Saúde Pública da USP; 2012.

Introdução: o desenvolvimento motor de lactentes tem sido discutido e abordado por teorias que buscam explicar se o que tem maior influência no seu curso é a maturação biológica ou a vivência no ambiente. Além da importância do vínculo inicial do lactente com o cuidador de referência e de fatores que possam interferir culturalmente e clinicamente no desenvolvimento infantil. Objetivo: avaliar o desenvolvimento motor de lactentes expostos ao HIV que fazem uso da medicação antirretroviral. Método: trata-se de um estudo transversal, conduzido no Centro de Referência e Treinamento de DST/AIDS de São Paulo, no período de novembro de 2009 a março de 2010, com amostra de conveniência composta por lactentes nascidos de mães infectadas, apresentando idade de um dia a 18 meses vida, parto único, a termo e que tivessem utilizado, ou utilizassem ainda, a medicação antirretroviral. Como instrumentos foram utilizados: roteiro estruturado (aspectos sócio-demográficos e médicoclínicos) e a Escala Motora Infantil Alberta. Resultados: predominantemente os lactentes apresentaram escore adequado para a idade, sendo que três possuiram percentil menor que o esperado e tiveram indícios de fatores socioambientais de risco para que houvesse o atraso. Ou seja, a maior parte dos lactentes corrobora para um resultado sem alteração do desenvolvimento motor neste grupo. Considerações finais: o fato de serem filhos de mães infectadas e fazerem uso de antirretrovirais não sobressaiu às outras variáveis que pudessem trazer consequências para a evolução do desenvolvimento motor.

Palavras-chave: desenvolvimento motor, avaliação, HIVIAIDS, intervenção precoce, fisioterapia. 


\begin{abstract}
Herrero D. Motor development of infants exposed to HIV. [Dissertation]. SP: Public Health School of USP, 2012.
\end{abstract}

Introduction: motor development has been discussed and tackled harder since the 70s. Theories try to explain what he has greater influence on its course is the biological maturation or living environment. Besides the importance of the initial bond with the infant's caregiver reference and factors that may affect culturally and clinically in child development. Objective: To determine the motor development of infants exposed to HIV that make use of antiretroviral medication. Method: This is a cross-sectional study conducted at the Center for Reference and Training for STD / AIDS in São Paulo, from November 2009 to March 2010, with a convenience sample consisting of infants born to infected mothers, with ages a day of life 18 months, only one delivery at term and who had used or still used, the antiretroviral medication. The instruments were used: structured questionnaire (socio-demographic and medical-clinical) and the Alberta Infant Motor Scale. Results: Predominantly the infants had a score for the suitable age, and possessed three percentile lower than expected and had evidence of social and environmental risk factors for the delay there. That is, the majority of infants to supports a result without alteration of the engine in this group. Final considerations: the fact of being children of infected mothers and to make use of antiretroviral drugs not excelled at other variables that could have consequences for the evolution of motor development.

Key words: motor development, evaluation, HIV / AIDS, early intervention, physiotherapy. 


\section{ÍNDICE}

1 Introdução

1.1 Referencial Histórico do desenvolvimento motor

1.2 Indicador de atraso do desenvolvimento

1.3 Vírus da imunodeficiência humana/ Aids: mães infectadas e filhos expostos

1.4 Diretrizes atuais no cuidado e proteção de recém-nascidos e 32 lactentes expostos

1.5 Follow-up

1.6 Justificativa

2 Objetivo

2.1 Objetivos específicos

3 Método

4 Resultados

4.1 Resultados dos três lactentes, acompanhados pelo Centro de Referência e Treinamento de HIVIAids de São Paulo em 2010, que apresentaram percentil $<10$.

4.2 Resultados dos nove lactentes, acompanhados pelo Centro de Referência e Treinamento de HIVIAids de São Paulo em 2010 , que tiveram o percentil $>10$

4.3 Resultado de todos os lactentes avaliados, acompanhados pelo Centro de Referência e Treinamento de HIVIAids de São Paulo, 2010 
5 Discussão.

5.1 Lactentes que apresentaram atraso do desenvolvimento 66 motor.

6 Conclusão.

76

7 Referências

78

Anexos. 


\section{LISTA DE TABELAS}

Tabela 1: Uso de droga por familiar dos lactentes acompanhados pelo Centro de Referência e Treinamento de HIVIAids de São Paulo em 2010, com percentil< 10

Tabela 2: Realização do pré-natal pelas mães dos lactentes acompanhados pelo Centro de Referência e Treinamento de HIVIAids de São Paulo em 2010, com percentil $<10$.

Tabela 3: Escolaridade da mãe dos lactentes acompanhados pelo Centro de Referência e Treinamento de HIVIAids de São Paulo em 2010, com percentil $<10$.

Tabela 4: Número de pessoas morando na casa dos lactentes acompanhados pelo Centro de Referência e Treinamento de HIVIAids de São Paulo em 2010, com percentil $<10$.

Tabela 5: Pais empregados dos lactentes acompanhados pelo Centro de Referência e Treinamento de HIVIAids de São Paulo em 2010, com percentil $<10$

Tabela 6: Frequência na creche dos lactentes acompanhados pelo Centro de Referência e Treinamento de HIVIAids de São Paulo em 2010, com percentil $<10$

Tabela 7: Local de permanência em casa dos lactentes acompanhados pelo Centro de Referência e Treinamento de HIVIAids de São Paulo em 2010, com percentil $<10$. 
Tabela 8: Uso de droga por familiar dos lactentes acompanhados pelo Centro de Referência e Treinamento de HIVIAids de São Paulo em 2010, com percentil >10

Tabela 9: Realização do pré-natal pelas mães dos lactentes acompanhados pelo Centro de Referência e Treinamento de HIVIAids de São Paulo em 2010, com percentil $>10$.

Tabela 10: Escolaridade da mãe dos lactentes acompanhados pelo Centro de Referência e Treinamento de HIVIAids de São Paulo em 2010, com percentil $>10$.

Tabela 11: Número de pessoas morando na casa dos lactentes acompanhados pelo Centro de Referência e Treinamento de HIVIAids de São Paulo em 2010, com percentil $>10$.

Tabela 12: Pais empregados dos lactentes acompanhados pelo Centro de Referência e Treinamento de HIVIAids de São Paulo em 2010, com percentil $>10$

Tabela 13: Frequência na creche dos lactentes acompanhados pelo Centro de Referência e Treinamento de HIVIAids de São Paulo em 2010, com percentil $>10$.

Tabela 14: Local de permanência em casa dos lactentes acompanhados pelo Centro de Referência e Treinamento de HIVIAids de São Paulo em 2010, com percentil >10......

Tabela 15: Escore na Escala Motora Infantil Alberta obtido pelos lactentes acompanhados pelo Centro de Referência e Treinamento de HIVIAids de São Paulo em 2010 


\section{LISTA DE FIGURAS}

Figura 1: Distribuição dos casos de AIDS entre 2000 e 2005............

Figura 2: Taxa de incidência de AIDS (por 100.000 habitantes) em menores de cinco anos, segundo região de residência por ano de diagnóstico

Figura 3: Gráfico de número de óbitos por cada 100.000 habitantes entre os anos de 1990 e 2000, enfatizando a introdução da terapia antirretroviral e, consequente, notória

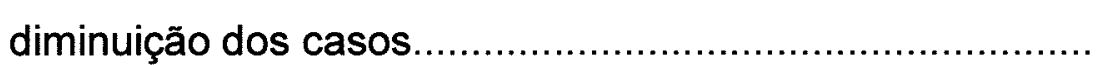




\section{LISTA DE ANEXOS}

Anexo 1: Roteiro Estruturado........................................................... 87

Anexo 2: Termo de Consentimento Livre e Esclarecido........................ $\quad 89$

Anexo 3: Aprovação nos comitês de ética............................................ 90

Anexo 4: Escala Motora Infantil Alberta............................................ 92

Anexo 5: Submissão do artigo da tese para European Journal of Medical Research

Anexo 6: Submissão do artigo da tese para International Breastfeeding Journal.................................................. 118 


\section{SIGLAS UTILIZADAS}

Aids: $\quad$ Síndrome da Imunodeficiência Adquirida

HIV: $\quad$ Vírus da Imunodeficiência Humana

OMS: $\quad$ Organização Mundial da Saúde

DST: Doenças Sexualmente Transmissíveis

SINAN: Sistema de Informação de Agravos de Notificação

SIM: $\quad$ Sistema de Informações de Mortalidade

SISCEL: Sistema de Controle de Exames Laboratoriais

SICLOM: Sistema de Controle Logístico de Medicamento

TV: $\quad$ Transmissão Vertical

UNAids: Programa Conjunto das Nações Unidas sobre HIVI Aids

OMS: $\quad$ Organização Mundial da Saúde

UNICEF: Fundo das Nações Unidas para a Infância

AZT: $\quad$ Zidovudine

ARV: $\quad$ Antirretroviral

AIMS: Escala Motora Infantil Alberta 


\section{INTRODUÇÃO}

O desenvolvimento motor tem sido discutido por teorias que buscam explicar se o que tem maior influência no seu curso é a maturação biológica ou a vivência no ambiente (Manoel, 2000), podendo ser acrescentada a importância do vínculo inicial do lactente com o cuidador de referência (Brum, 2004), além de outros fatores que possam interferir de maneira cultural e/ou clínica no desenvolvimento neuropsicomotor.

\subsection{HISTÓRICO DO DESENVOLVIMENTO MOTOR}

Connolly (2000) destaca tanto a necessidade de saber "o que muda", "quando muda" e "quanto muda" na sequencia que se tem no desenvolvimento motor, quanto a de identificar "como acontecem estas mudanças". Frente a esta abordagem sobre o assunto, a descrição do fenômeno passa a ser motivo de interesse para os pesquisadores da área.

Manoel (2000) aponta nas décadas de 30 e 40 as descrições clássicas de sequência de desenvolvimento motor apresentadas por Gesell e McGraw, e de desenvolvimento cognitivo por Piaget. Nos anos 60 , Bertalanfy caracteriza 0 desenvolvimento motor como a busca pela estabilidade e Prigogine insere os conceitos de sistemas em estados dependentes e independentes do tempo, respectivamente referentes, a uma estabilidade mantida e a uma estabilidade relativa. 
Já Bernstein (1967) propõe uma interação dinâmica entre restrição e liberação dos graus de movimento, permitindo assim um aprimoramento do controle motor pela variação nos padrões de movimento, enriquecendo o repertório de movimentação ao agregar questões quanto às reações de equilíbrio e endireitamento.

Esta forma de explicar o processo de evolução motora é a mais aceita na área da fisioterapia devido à difusão do método neuroevolutivo Bobath, desenvolvido pelo casal Karel e Bertha Bobath (1983), embasado nesta teoria.

$\mathrm{Na}$ década de 80 , Connolly conceitua como determinantes do desenvolvimento motor a presença de herança genética e ambiental. $E$ exemplifica como reação intrínseca a maturação e como reação extrínseca, a experiência. Já Gottlieb (1992) define o desenvolvimento motor pelo chamado "indeterminismo limitado", ou seja, por mais mudanças que ocorram nas etapas menos complexas no curso de evolução (o indeterminismo) há uma sequência geral de aquisições mais aprimoradas a ser seguida (limitada). Por exemplo: o lactente pode não engatinhar e adquirir a marcha, porém não consegue assumir a postura bipede sem que consiga rolar. Nesta abordagem há três etapas: ordem de acontecimentos, interdependência dos fatos e aparecimento de novas propriedades.

Valsiner (1997) acrescenta que o curso do desenvolvimento motor tem a mesma sequência nos indivíduos da mesma espécie. Para Connolly e Manoel (1997) à medida que uma etapa do desenvolvimento é alcançada, novos objetivos são estabelecidos. Como exemplifica Thelen (2000) na sua teoria de 
auto-organização inerente ao sistema muscular, "há uma estabilidade ou um curso linear inicial, que frente a uma perturbação provoca uma mudança qualitativa para readaptação" (apud Connolly, 2000).

Neste contexto, onde se sugere uma sequencia pré-determinada, é fundamental que haja o acompanhamento destas fases, e que os pais, por serem os principais cuidadores, respeitem a sua intuição e as suas próprias observações quanto aos aspectos motor, cognitivo, emocional ou comportamental (Brazelton, 1994). Estes aspectos também são citados por Perrotti e Manoel (2001) como determinantes para o desenvolvimento motor. 0 estudo do desenvolvimento oferece informações quanto à direção que se segue nas aquisições de posturas, reações de equilibrio e endireitamento, as mudanças de comportamento entre as fases, a busca pelo aprimoramento e refinamento da ação e o conhecimento dos principais marcos de aquisição motora. Este último tornando possivel a identificação de um provável atraso motor pelos próprios pais, cuidadores ou equipe clínica de acompanhamento, ou seja, permite que a sociedade como um todo participe de questões relacionadas aos marcos de desenvolvimento motor. 


\subsection{INDICADOR DE ATRASO DO DESENVOLVIMENTO}

A junção da suspeita de pais e profissionais, em um diálogo na avaliação, pode facilitar uma intervenção imediata. Segundo Bobath (1984, 1993), a principal queixa dos pais na procura por serviço especializado aparece por volta dos oito meses quando há um atraso na aquisição da postura sentada, que ocorre com aproximadamente seis meses. Este marco do desenvolvimento também é sugerido por Mustacchi (2000), como indicador de risco.

Os movimentos esperados ao nascimento estão dentro de um repertório motor espontâneo e ritmado, onde não há propósito, mas há ordem e padrão (Manoel, 2000). À medida que os lactentes observam a reação do outro perante suas manifestações, há o início da intenção de movimentar-se, que caracteriza a ação (movimento intencional). Por exemplo: quando o lactente bate no móbile para que balance e, frente aos estímulos visual e auditivo, passa a repetir o gesto por diversas vezes, evidencia a sua busca pela regularidade dos movimentos e seu aprimoramento (Manoel, 2000).

Desde o nascimento até os dois anos de vida existem as janelas do desenvolvimento, que são periodos propícios e determinantes para a vivência de experiências e aprendizados específicos (Jerusalinsky, 2002). É importante que se consiga estimular o lactente no período mais apropriado para cada aquisição, o que facilita seu aprimoramento. Para que o estímulo ocorra de forma cronologicamente adequada, este deve ser oferecido no período que a 
mãe/cuidador conhece como certo. Portanto faz-se necessária a apresentação e discussão deste tema.

No desenvolvimento motor há aspectos que podem ser determinantes para sua evolução ou atraso. Sabe-se que é na primeira semana que as causas de morbidade ligadas à gestação e ao parto surgem com maior intensidade e podem interferir em seu curso de evolução. Já no período neonatal tardio, as causas chamadas ambientais começam a aparecer com maior frequência, expressas principalmente pelas infecções. Das principais causas de morbidade e mortalidade, relacionadas ao lactente, estão a anóxia neonatal, o baixo peso ao nascer e as infecções congênitas (Rouquayrol, 2003), destacando-se dentre elas a Aids. 


\subsection{Vírus da imunodeficiência humanal AIDS: MÃES}

\section{INFECTADAS E FILHOS EXPOSTOS}

Até o final da década de 80 , acreditava-se que á infecção pelo vírus da Imunodeficiência Humana - HIV e a conseqüente Síndrome da Imunodeficiência Adquirida - Aids fosse restrita a um grupo específico de pessoas. Porém, nesta mesma década, os primeiros casos de crianças com este diagnóstico foram relatados, tornando essa infecção um dos maiores problemas de saúde pública, não só no Brasil (Figura 1), mas em todo o mundo. De acordo com a figura abaixo, se percebe uma desconcentração dos casos com o passar do tempo, caracterizando um fenômeno generalizado.

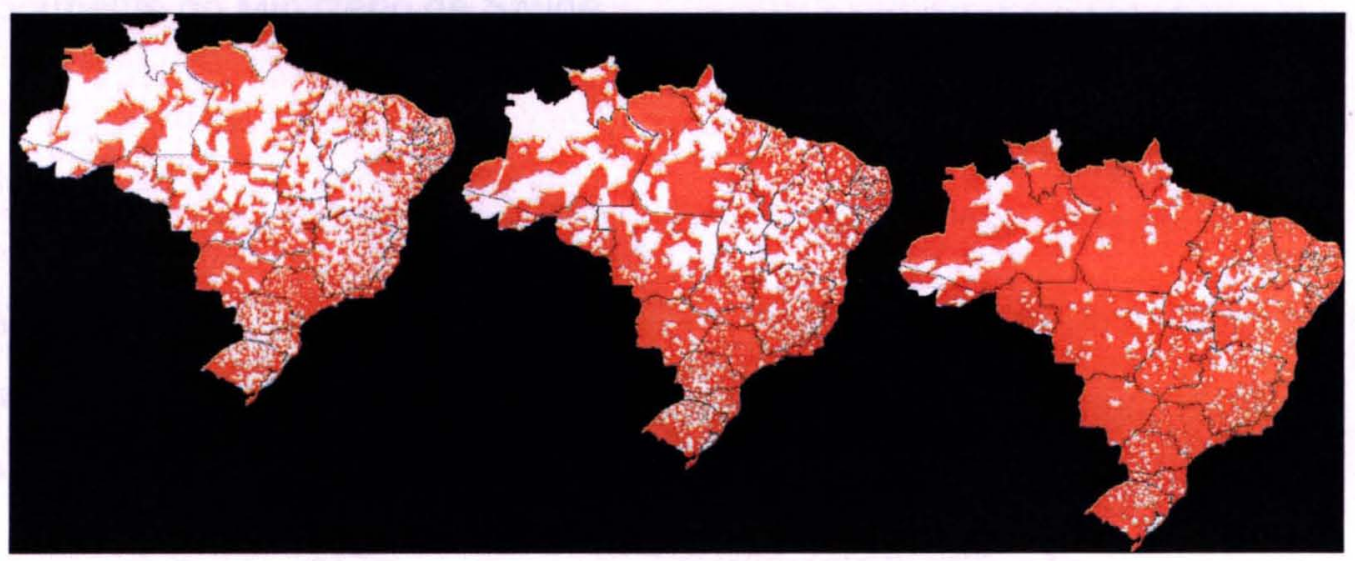

Figura 1: Distribuição dos casos de AIDS entre 2000 e 2005.

Estimativa: cerca de 600.000 infectados (2006)

Fonte: MS/SVS/PNDST/

AIDS e MS/SVS/DASIS/ Sistema de Informações sobre Mortalidade SIM

Casos notificados no Sinan, registrados no Siscel até 30/06/2006 e SIM de 2000 a 2005.

No Brasil, o número de casos da infecção pelo HIV apresenta maior crescimento nas regiões sul e sudeste, acomete mais os homens (sendo que esta diferença entre sexo masculino e feminino vem decrescendo), aponta faixa 
etária prevalente entre 30 e 40 anos e a raça branca como a de maior índice de infecção (Ministério da Saúde, 2011).

Os dados evidenciam que a incidência dos casos é um fator relevante à saúde pública, tendo o grupo de mulheres e crianças o maior crescimento dos índices nos últimos anos, suscetível às diversas consequências sociais, psicológicas e econômicas (Fernandes, 2000).

Entre as crianças de até cinco anos de idade a incidência mostra-se maior na região norte e em decréscimo nas demais regiões brasileiras (Figura 2). Sugere-se que este aumento notório de incidência na região norte também se deve ao crescimento das notificações obrigatórias pelos programas de monitoramento do Ministério da Saúde.

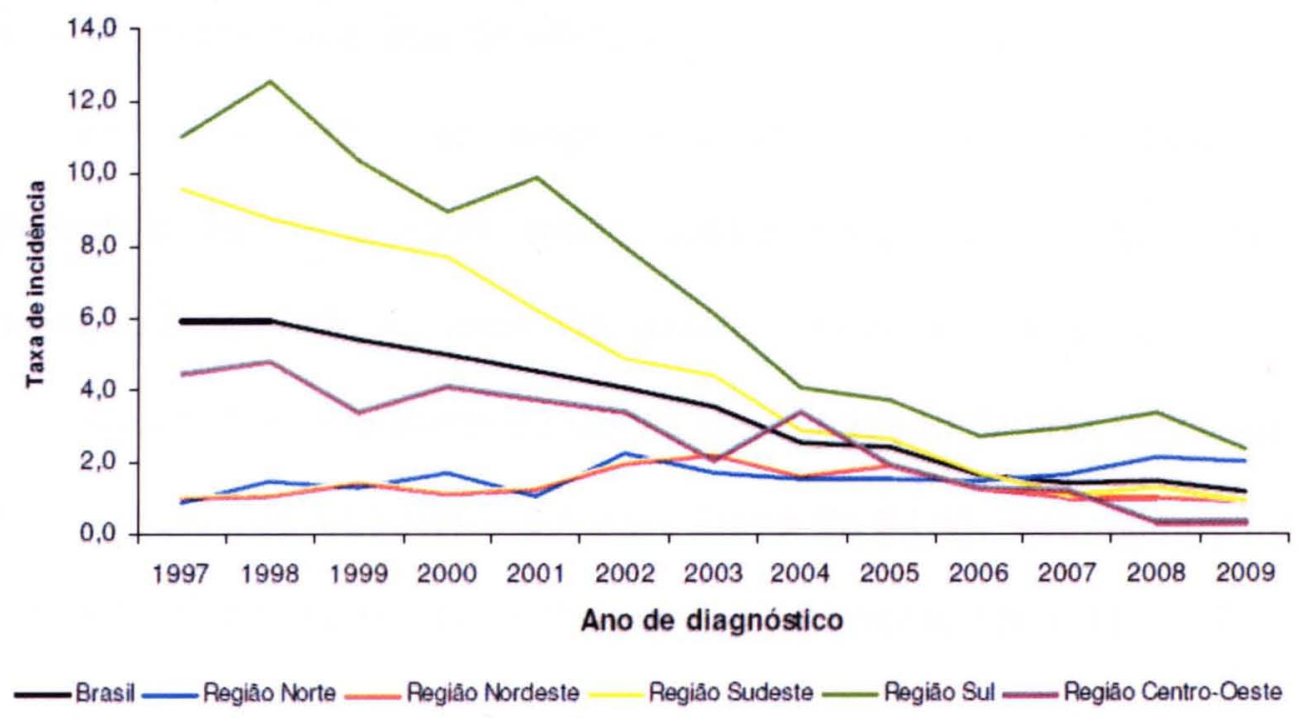

Figura 2: Taxa de incidência de Aids (por 100.000 habitantes) em menores de cinco anos, segundo região de residência por ano de diagnóstico.

Fonte: MS/SVS/Departamento de DST, Aids e Hepatites Virais.

NOTA: (1) Casos notificados no SINAN e registrados no SISCEL/SICLOM e SIM.

Dados preliminares para os últimos cinco anos. 
Em 1985 foi notificado, no Brasil pelo Ministério da Saúde, o primeiro caso de HIV em criança por transmissão vertical (TV), de mãe para filho, (Maturana et al., 2007; Newell, 2003; Moodley, 2000). Dados atuais indicam que esta taxa de transmissão é responsável pelo acometimento de $80-90 \%$ de lactentes e crianças infectados (Yoshimoto et al., 2005).

Nos países em desenvolvimento, destacando-se os paises da América Latina, as infecções pelo HIV se espalharam com mais intensidade entre as mulheres e, conseqüentemente, elevou-se a taxa de transmissão do tipo vertical.

Em Relatório Global sobre o HIV (OMS, 2007) estimava-se que, até a faixa etária de 15 anos de idade, existam 2,5 milhões de crianças vivendo com HIV e 420 mil novos casos de infecção.

Por outro lado, ao longo dos últimos anos, não houve aumento significativo de mortalidade, muito possivelmente devido às estratégias de prevenção e combate ao vírus. De acordo com dados da Secretaria de Estado de Saúde (2009), considerando dados da Fundação Seade, a transmissão de Aids no Estado de São Paulo diminuiu cerca de $64,4 \%$ nos últimos treze anos, após a introdução de Terapia Antirretroviral Altamente Ativa (HAART). 


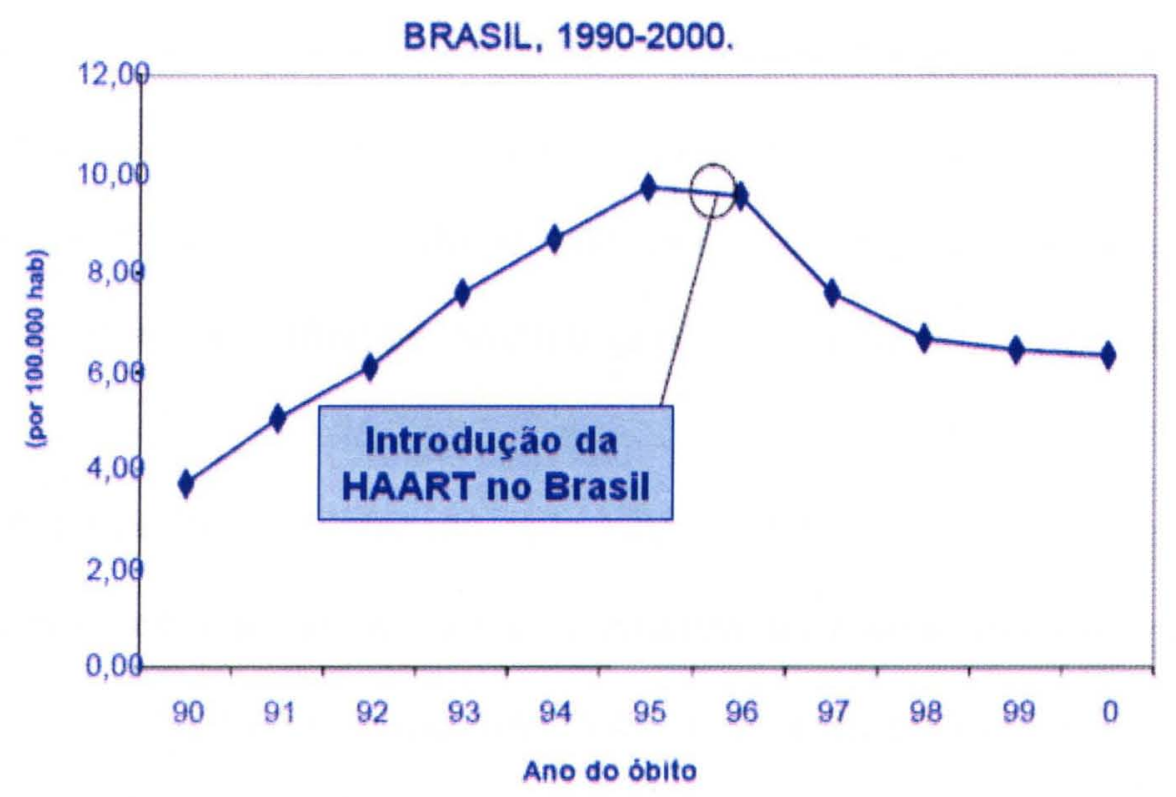

Figura 3: Óbitos por cada 100.000 habitantes entre os anos de 1990 e 2000, enfatizando a introdução da terapia antirretroviral.

Fonte: SIM/DATASUS

Alterações bioquímicas podem ocorrer em lactentes nascidos de mães infectadas pelo vírus da Aids e fazem uso de medicação antirretroviral, que tem como principal indicação evitar a infecção do tipo vertical. Dentre os principais achados clínicos estão o déficit pôndero-estatural (achado clínico em $69,5 \%$ dos casos antes de um ano de idade), anemia, hipocromia (palidez por deficiência de hemoglobina), macrocitose (aumento do tamanho das hemáceas), atipia linfocitária, linfopenia (diminuição do número de linfócitos) e monocitose (Silva et al., 2001), além da desnutrição materna presente durante o período gestacional deste grupo. Brandão et al. (2007) acharam em estudo que há um aumento de 11 para $29,3 \%$ nos casos de desnutrição entre as gestantes, no início e final da gestação, respectivamente. 
Durante a gravidez, os principais fatores etiológicos de acometimento do feto são infecções e parasitoses (rubéola, citomegalovírus, HIV, toxoplasmose), intoxicações (drogas, álcool, tabaco); radiações (diagnósticas ou terapêuticas); traumatismos (direto no abdome ou queda sentada da gestante) e fatores maternos (doenças crônicas, anemia grave, desnutrição e mãe idosa) (Rotta, 2002).

A prevenção da infecção pelo HIV, no feto e recém-nascido, baseia-se em medidas de intervenção como: a imunização desde antes da gravidez por parte da mãe infectada, o seguimento de orientação adequada para prevenção da transmissão vertical durante a gestação e parto, o diagnóstico imediato com exame de resultado rápido e tratamento com medicação antirretroviral (Rouquayrol, 2003).

A medicação antirretroviral teve importante papel na diminuição dos casos de Aids no Brasil, principalmente no que diz respeito às gestantes infectadas. Há uma estimativa/ano de cerca de 12.635 gestantes/parturientes portadoras do HIV, o que leva ao mesmo número de lactentes expostos por transmissão vertical (Bertolini, 2009).

Esta via de transmissão, vertical ou materno-infantil, pode ocorrer durante a vida intrauterina, no momento do parto, pós-parto ou durante $\circ$ aleitamento materno (Silva et al., 2001). Dados evidenciaram que aproximadamente $65 \%$ dos casos de TV ocorre durante o trabalho de parto e no parto, $35 \%$ ocorre intra-útero, principalmente nas últimas semanas de 
gestação e 7 a 22\% no aleitamento materno (Brito et al., 2006). Yoshimoto (2005) sugere que a transmissão ocorre principalmente durante o parto.

A patogênese da TV do HIV está relacionada a múltiplos fatores: virais (carga viral, genótipo e fenótipo viral); maternos (estado clínico e imunológico, presença de doenças sexualmente transmissíveis e outras co-infecções, o estado nutricional e o tempo de uso de antirretrovirais na gestação); comportamentais (uso de drogas e práticas sexuais desprotegidas); obstétricos (duração da ruptura das membranas amnióticas, a via de parto e presença de hemorragia intra-parto); do recém-nascido (prematuridade e baixo peso ao nascer) e aleitamento materno (300 mil lactentes morrem de Aids a cada ano depois de serem infectados ao receberem leite materno, segundo estimativa da ONU em 2009).

Estima-se que 20 a $25 \%$ dos lactentes, na ausência de terapia antirretroviral efetiva, tenham progressão precoce da doença. Porém, com o uso de antirretrovirais, este indice varia de 0 a $3 \%$ (Connor, 1994).

Apesar da disponibilidade dos insumos necessários à interrupção da TV nos serviços públicos de saúde (teste anti-HIV, drogas antirretrovirais, inibidor da lactação e fórmula infantil), estudos indicaram que apenas $52 \%$ das gestantes brasileiras receberam cobertura efetiva das ações de sua prevenção no pré-natal em 2006.

Em 1995, foi publicada uma norma específica sobre prevenção da transmissão vertical, indicada como uma das prioridades pelo Programa Nacional de DST e Aids (Veloso et al., 1999). Após esta publicação, o Estado 
de São Paulo criou as primeiras adaptações para a implantação do Protocolo ACTG-076.

Porém, estudos posteriores, que utilizavam o consumo de AZT injetável como indicador da implantação dessa conduta profilática, demonstraram que esse procedimento foi realizado apenas em $40 \%$ das gestantes soropositivas esperadas para o ano de 1998 (Marques et al., 2006).

Objetivando o fortalecimento dessa ação de controle, outra estratégia para avaliar a operacionalização do protocolo de profilaxia da transmissão vertical do HIV foi a inclusão da vigilância de gestantes HIV positivo e crianças expostas como agravos de notificação compulsória, desde 2000 (Portaria MS n 993/2000) (Brito et al., 2006).

Após a implantação destas medidas epidemiológicas, observou-se uma diminuição de cerca de $70 \%$ dos casos de TV (Herdy et al., 2003) e aparecimento de mudanças significativas no prognóstico clínico das crianças, diminuindo o índice de morbidade e mortalidade por infecções oportunas.

Segundo o Ministério da Saúde (2009), o acompanhamento dado a este grupo de lactentes expostos ao HIV deve ser mensal nos primeiros seis meses de vida e bimestral a partir do segundo semestre até completar dois anos, quando passa a ser anual. Algumas das revisões tomadas como referência pelo Ministério da Saúde, 2009, apontam o acompanhamento do lactente exposto ao HIV como obrigatório no primeiro ano de vida, havendo uma posterior adaptação, de acordo com o serviço de atendimento local. 
Nas consultas periódicas são essenciais o registro de peso, comprimento e perímetro cefálico, verificando a velocidade de ganho de peso e crescimento que poderá alterar o curso de desenvolvimento adequado. $\mathrm{A}$ anamnese dos lactentes expostos deve ser tão detalhada quanto à avaliação dos infectados.

Os lactentes expostos ao HIV por nascerem de mães infectadas têm a chance, durante o tratamento com ARV na gravidez e no pós-parto (42 dias), de manterem suas cargas virais indetectáveis (Brasil, 2009). A atenção maior deve ser dada ao aparecimento de toxicidade mitocondrial, que tem sua gravidade igualmente proporcional ao aparecimento de anormalidades neurológicas (encefalopatias, convulsões febris, atraso do desenvolvimento, sintomas cardiacos, gastrointestinais atribuídos a hepatite, miopatia, retinopatia, pancreatite e acidose láctica).

Quanto ao exame físico, devem-se avaliar o sistema retículo-endotelial, alteração de perímetro cefálico, atraso de crescimento e desenvolvimento (tendo o desempenho motor acompanhado através dos marcos de aquisição de postura e habilidades citados no cartão da criança), candidíase oral e/ou genital.

O grupo de Estudos da Coorte Perinatal Francesa descreve um aumento no índice de convulsões febris em lactentes expostos em comparação com os não expostos aos antirretrovirais, risco este cumulativo do primeiro episódio de convulsão febril até 18 meses de idade de 1,1\% em expostos, comparado com 0,4\% de não expostos. King (2004) e Barret (2003) colocam que este achado ainda é controverso em relação à exposição aos ARV. 
O esquema medicamentoso preconizado durante a gravidez é a associação de três ou mais tipos de drogas antirretrovirais para potencializar ao máximo os seus efeitos e reduzir a carga viral a niveis indetectáveis (Watts, 2002; Magder et al., 2005; Brocklerhurst et al., 2005). O Grupo Assessor de Terapia Antirretroviral em Crianças recomenda a combinação de duas drogas da classe de Inibidores de Transcriptase Reversa Análogo de Nucleosídeo (ITRN) com uma droga da classe de Inibidores da Transcriptase Reversa Nãoanálogo de Nucleosídeo (ITRNN).

A aplicação destas drogas combinadas é inquestionável para a profilaxia da transmissão vertical, lembrando que a utilização em gestantes reflete uma abordagem nova, devendo os medicamentos serem empregados de forma bem criteriosa por motivo de preocupação e atenção (Ministério da Saúde, 2009). O momento de risco maior é durante a gravidez, pela homeostase que ocorre constantemente para o desenvolvimento do feto (Marques, 2006).

O uso de medicamentos na gravidez é recente e a maior parte dos estudos foi feito em animais (1200 teratógenos foram identificados em animais e 30 , em humanos). O uso do $A Z T$, por exemplo, ocorre há pouco mais de 15 anos (Marques, 2006).

O Centro Regulador de Medicamentos dos EUA (Food and Drug Administration - FDA) desenvolveu uma classificação para os antirretrovirais em categorias: $A, B, C, D$ e $X$, onde $A$ é o grupo mais seguro na gravidez e não demonstra risco ao feto, B não demonstra risco ao feto de animais, C demonstra risco ao feto de animais ou não foi determinado por falta de estudos, 
D há evidência de risco fetal $\mathrm{e}, \mathrm{X}$ os riscos superam os benefícios. Nos dias atuais, as drogas utilizadas estão nos grupos B, C ou D (Ministério da Saúde, 2009).

Alguns estudos referidos pelo Ministério da Saúde em 2009 mostram que drogas especificas, como tenofovir, usadas em macacas grávidas, causam a diminuição de porosidade óssea nos fetos. E em lactentes, há a desmineralização óssea com o seu uso prolongado.

Marques (2006) acrescenta que nos recém-nascidos expostos ao tratamento com uso de antirretroviral intra-útero onde pode haver uma redução dos niveis séricos de insulina, sugerindo ainda que os inibidores de protease estão relacionados com o surgimento de intolerância à glicose e casos de diabetes (não especificado se tipo I ou II) neste grupo.

Na edição de 2009 das Recomendações para profilaxia da transmissão vertical do HIV e tratamento antirretroviral em gestantes, a escolha é pelo lopinavir e ritonavir, onde não há descrição de teratogenicidade em humanos (Ministério da Saúde, 2009). Os lactentes expostos recebem o antirretroviral apenas durante a gestação e nos primeiros 42 dias de vida, não recebendo aleitamento materno.

O objetivo principal do tratamento HAART (terapia antirretroviral altamente ativa) é suprimir a replicação do HIV, preferencialmente de forma indetectável (situação esperada no grupo de lactentes expostos), pelo maior tempo possivel, prevenindo ou interrompendo a progressão da doença e 
minimizando o risco de resistência aos antirretrovirais (Ministério da Saúde, 2009; Marques, 2006). 


\subsection{DIRETRIZES ATUAIS NO CUIDADO E PROTEÇÃO DE RECÉM-NASCIDOS E LACTENTES EXPOSTOS}

A atualização de dados e orientações quanto aos cuidados e tratamento da criança exposta e infectada é freqüente. Com o intuito de melhorar as condições de saúde e salvar vidas, as novas diretrizes da OMS (2009) recomendam pela primeira vez o aleitamento materno dos lactentes por suas mães portadoras do vírus da Aids, usuárias de terapia antirretroviral no período de amamentação.

Tais recomendações estão baseadas em dados atualizados disponíveis e transmitem a mensagem de que a amamentação é saudável ainda que por mães infectadas, nos casos em que haja acesso aos antirretrovirais e não esteja disponível e garantida a fórmula infantil (2009).

Dentre as novas diretrizes está o uso de antirretroviral mais cedo na gravidez, a partir da $14^{\mathrm{a}}$ semana de idade gestacional até o final do periodo de amamentação (OMS, 2009). O tempo de amamentação é elevado até que o lactente complete 12 meses de idade, com a condição de ambos estarem em tratamento com antirretrovirais. Segundo a OMS (2009), este processo com o uso adequado da medicação reduzirá o risco de transmissão do HIV durante a amamentação e melhorará a chance de sobrevivência do lactente.

Autoridades nacionais de saúde são encorajadas pela OMS para identificar a prática de alimentação mais adequada do lactente (aleitamento materno com antirretrovirais ou uso de fórmula infantil) para suas comunidades. 
A prática escolhida deverá ser utilizada como único padrão de atendimento do país.

Segundo orientação da UNICEF (2009), a fórmula infantil deve ser oferecida gratuitamente, podendo a oferta ao lactente ocorrer com o envolvimento e entrega emocional que aconteceria em uma situação de aleitamento materno exclusivo. Além disto, a gestante HIV positivo recebe o “Guia Prático de Alimentos para Crianças Menores de 12 meses que não podem ser Amamentadas" pelo Ministério da Saúde nos postos e hospitais de atendimento. A orientação indica que a lactação da mãe soropositiva deve ser inibida pós-parto por enfaixamento ou uso de inibidor de lactação. E acrescenta também a importância do auxílio da equipe médica e familiares para apoiar a mãe nesta decisão, sem discriminação.

Visando alcançar a máxima diminuição da taxa de TV junto ao Programa Estadual de DSTIAIDS de São Paulo, o Ministério da Saúde (2009) orienta que não ocorra amamentação, mas sim, a sua substituição pela fórmula infantil após aconselhamento. Contraindica também o aleitamento misto, o aleitamento cruzado (amamentação por outra nutriz) ou pasteurização domiciliar do leite humano. A fórmula infantil é determinada através de licitações realizadas pelo Ministério da Saúde, no momento do estudo era distribuído o Nestogeno.

O lactente nascido de mãe infectada tem o direito de receber a fórmula láctea infantil até os seis meses de idade, pelo menos. Em alguns Estados, este prazo é de até doze meses (Ministério da Saúde, 2009). 
Somada à condição nutricional, Marques (2006) destaca itens relevantes referentes ao tempo de sono, rotina, comportamento e intercorrências infecciosas ou não como determinantes para o acompanhamento dos lactentes expostos.

Tais questōes podem comprometer a oportunidade de vivenciar 0 movimento, o que se encontra intimamente ligado ao desenvolvimento de um lactente em sua totalidade (físico, mental, emocional e social) (Bobath, 1993). 


\subsection{FOLLOW-UP}

O desenvolvimento neuropsicomotor do lactente é aspecto importante do desenvolvimento infantil. As aquisições motoras no primeiro ano de vida são fator relevante no prognóstico do desenvolvimento integral da criança, pois o período compreendido entre o nascimento e o final do primeiro ano de vida é considerado como um dos mais críticos para o desenvolvimento infantil (Bobath, 1993).

Escalas são utilizadas para o follow-up adequado e maior objetividade das informações. Uma destas é a Escala Motora Infantil Alberta (Piper e Darrah, 2004), cujos objetivos são: (1) identificar restrição do desenvolvimento neuromotor dos lactentes; (2) informar aos pais sobre as atividades motoras que $\circ$ bebê realiza, que $\circ$ lactente não realiza e atividades que estão se desenvolvendo; (3) analisar o desenvolvimento motor em determinado tempo ou pré e pós internação; (4) mensurar mudanças no desenvolvimento motor bastante pequenas que não podem ser identificadas por métodos mais tradicionais e (5) agir como instrumento de pesquisa para identificar eficácia em programas de estimulação para lactentes com distúrbios motores. As autoras acharam uma confiabilidade interobservador de 0,99 e, no teste-reteste, a confiabilidade foi de 0,99 .

O foco desta avaliação é aprimorar a observação do desenvolvimento sequencial no controle postural referente às posições supina (barriga para cima), prona (barriga para baixo), sentada e ortostática (em pé). A 
administração do teste envolve uma avaliação observacional com o mínimo de manuseio e tempo de aproximadamente 20 minutos para avaliação.

A validação brasileira da Escala Alberta foi iniciada por Saccani e Valentini (2010). Os lactentes eram frequentadores de Creches, Escolas de Educação Infantil, Unidades Básicas de Saúde e Entidades da Região Sul-riograndense. As pesquisadoras concluíram que a sensibilidade da avaliação foi maior para o primeiro ano de vida, sendo poucos os itens para diferenciar os lactentes com desenvolvimento a partir dos doze meses.

No primeiro ano de vida o desenvolvimento motor apresenta ritmo acelerado de mudanças que culminam nas funções de mobilidade, com a aquisição do engatinhar e da marcha independente, respectivamente aos nove e 12 meses de idade (Mancini, 1992). Os movimentos, mesmo in útero, mostram que o feto não apenas chupa o dedo, mas também pressiona a parede uterina e outras partes de seu próprio corpo ao movimentar seus membros, que Ihe proporcionam retroalimentação tátil e proprioceptiva. Um recém-nascido ou lactente privado de mobilidade, com dificuldade de se movimentar e explorar seu corpo e o ambiente, ou que possa movimentar-se apenas de um modo desordenado, terá dificuldade em desenvolver a percepção corporal, ou só poderá consegui-lo com muita dificuldade e depois de muito tempo (Bobath, 1984, 1993).

A saúde integral do lactente e da criança deve contemplar questões presentes desde a assistência ao nascimento (como acesso, qualidade de atendimento e cobertura), programas de aleitamento (incentivo à amamentação 
e/ou oferecimento de fórmula infantil nos casos de mães infectadas), controle de vacinas (conseqüente controle de morbidade e mortalidade infantil), acompanhamento de crescimento e desenvolvimento (auxílio no diagnóstico de atraso e alterações no curso do desenvolvimento adequado a cada idade), além do atendimento especializado nas redes públicas de saúde em caso de encaminhamentos para especialidades médicas necessárias (Ministério da Saúde, 2004).

Nos casos de lactentes expostos ao HIV materno há necessidades específicas e acompanhamento peculiar que devem ser respeitados na sua total realização, sem que haja o descaso em relação à gravidade de transmissão vertical e insuficiência de informação no momento de seguimento pré-natal, parto e pós-parto.

Um acompanhamento médico e terapêutico adequado deve aumentar substancialmente a qualidade de vida (Turner et al., 1996), tendência esta que se mantém até hoje em casos de infectados por HIV. No entanto, a específica ação das drogas antirretrovirais sobre o desenvolvimento e crescimento dos lactentes expostos ao HIV materno ainda é controversa. 


\subsection{JUSTIFICATIVA}

Justifica-se o estudo do desenvolvimento motor de lactentes expostos ao vírus da imunodeficiência materno pelo fato deste grupo poder apresentar: condição de intercorrências clínicas (anemia, porosidade óssea, toxicidade mitocondrial), alterações de comportamento (maior incidência de episódios de convulsão), questões relacionadas à dificuldade de ganho de peso e estatura e histórico recente de administração medicamentosa durante o período gestacional. 


\section{OBJETIVO}

Avaliar o desenvolvimento motor de lactentes expostos ao vírus da imunodeficiência humana (HIV) materno e que fazem uso de medicação antirretroviral.

\subsection{OBJETIVOS ESPECÍFICOS}

- Investigar fatores biológicos e socioambientais com interferência no desenvolvimento motor dos lactentes expostos ao HIV materno;

- Caracterizar estímulos para a movimentação durante o processo de avaliação deste grupo etário;

- Investigar a especificidade da Escala Motora Infantil Alberta (AIMS), aplicada pelo profissional de fisioterapia, no contexto de follow-up para este grupo de lactentes.

- Descrever diretrizes de cuidado e proteção dos lactentes expostos ao HIV materno. 


\section{MÉTODO}

Trata-se de estudo transversal realizado durante os meses de novembro de 2009 a março de 2010 no Centro de Referência e Treinamento de Aids em São Paulo (CRT), o qual se constitui em um ambulatório especializado no atendimento a pacientes com HIVIAids.

O convite aos pais para participarem da pesquisa foi realizado durante as visitas de acompanhamento de rotina ao serviço do CRT de Aids, visto que os lactentes já eram acompanhados clinicamente pela médica infectologista. Os critérios de inclusão foram: recém-nascido de termo, apresentar APGAR adequado (>7), mãe com diagnóstico positivo de HIV, ter utilizado medicação antirretroviral em alguma fase do desenvolvimento do lactente, estar inserido no programa DST/Aids, ter idade entre um dia e 18 meses de vida e ter o termo de consentimento livre e esclarecido assinado pelos responsáveis.

Os critérios de exclusão foram: carga viral positiva ao primeiro exame de detecção, doença neurológica, prematuridade, alteração genética, baixo peso ao nascimento, ausência de informações no período pré-natal, permanência no hospital por mais de quatro dias ou utilização de UTI neonatal.

A amostragem foi constituída por conveniência, com número de 31 lactentes avaliados e 30 inseridos no estudo. A perda amostra ocorreu pelo fato de um dos lactentes ter apresentado carga viral detectável.

Para avaliação do desenvolvimento motor do lactente, utilizou-se a Escala Motora Infantil Alberta (Piper e Darrah, 1994). A classificação do 
desempenho motor foi feita segundo valores de percentis: <5: atraso do desenvolvimento; $\geq 5$ e <10: risco para atraso do desenvolvimento motor, denotando necessidade de maior atenção no acompanhamento deste lactente; $\geq 10$ e <72: desempenho adequado; $\geq 72$ : lactentes com excelente desempenho para a faixa etária.

A estimulação para a movimentação, trocas posturais e manutenção na postura indicada pela escala foi realizada com auxílio de brinquedos coloridos, sonoros e que permitissem coordenação mão-olho (encaixe).

As variáveis biológicas e socioambientais foram obtidas ou por meio de questionário com as mães ou por pesquisa dos prontuários. 0 formulário continha perguntas fechadas correspondentes a aspectos sócio-demográficos (sexo, idade, cor e data de nascimento) e médico-clínicos (peso e comprimento atual e ao nascer, nota de APGAR, usọ de medicação antirretroviral, tipo de alimentação nos primeiros meses de vida, época do diagnóstico do HIV materno, contagem de Linfócitos CD4 e carga virais iniciais, bem como condição sorológica atual).

A pesquisa foi realizada após aprovação pelo Comitê de Ética em Pesquisa do Centro de Referência e Treinamento de AIDS (número 010/2009) em São Paulo e pelo Comitê de Ética da Faculdade de Saúde Pública da USP (número 1991), seguindo as normas que regulamentam pesquisas em seres humanos contidas nas Resoluções n 196/96 e n² 251/97 do Conselho Nacional de Saúde (Anexo 3). 
Os objetivos da pesquisa, bem como os procedimentos, foram previamente explicados a todos os pais ou representantes legais. Somente depois de obtidos termos de consentimento dos seus responsáveis é que a pesquisa foi realizada.

Os dados da pesquisa estão inseridos no prontuário dos lactentes e sob a guarda do Centro de Referência e Treinamento de HIVIAids de São Paulo. 


\section{RESULTADOS}

A amostra dos 30 lactentes foi constituída por 20 do sexo masculino e 10 do sexo feminino. O limite inferior de idade foi de 11 dias e o limite superior de 18 meses de vida.

O escore apresentado na Escala Motora Infantil Alberta (AIMS) pelos lactentes foi: três abaixo do percentil $10(0,1$ e 9) e 27 dentro do percentil esperado para a idade.

Nas tabelas (1 a 15), os lactentes apresentam-se identificados por números, indicando a ordem em que foram avaliados. E estão especificadas as características daqueles que têm seu percentil<10 ou adequado para a idade, ou seja, desenvolvimento atípico $(<10)$ ou típico $(\geq 10)$.

Os itens identificados como associados aos fatores biológicos foram: realização de pré-natal, mãe usuária de droga, idade gestacional (todos eram termo) e peso ao nascer (todos adequados).

Já os fatores ambientais analisados foram: a escolaridade materna, número de pessoas moradoras na casa, pais empregados, frequência em creche e o local de permanência dos lactentes no domicílio.

Além dos itens avaliados na escala e a entrevista para investigação de aspectos clínicos do lactente, também se observou, durante a avaliação, o contato visual com a avaliadora, o interesse do lactente pelo brinquedo, 0 contato com o cuidador durante a estimulação e a resposta por som, sorriso ou balbucio, o conhecimento dos cuidadores quanto às capacidades dos lactentes, 
sua comparação com outros lactentes e sua intenção em querer se informar mais sobre os meios de estimulação e desenvolvimento integral de seu filho.

Das três mães que tinham recebido escore abaixo do esperado para idade de seus filhos, duas não achavam que seus filhos estavam atrasados. Uma delas referiu que sua filha apresentava desenvolvimento com ritmo de evolução igual ao da sua irmã mais velha. Porém em conversa, após a entrevista, a mãe informou que sua primogênita estava com dificuldade de acompanhar as atividades escolares e havia sido agendada uma reunião com professores e diretora para sugerir que fizesse a transferência para uma escola especial. Foi explicado que este tipo de situação era identificado como atraso do desenvolvimento e que deveria passar por uma avaliação mais minuciosa e talvez precisasse de um acompanhamento periódico para que não fosse necessária escola especial, visto que esta prática não é mais indicada em nenhum caso de atraso do desenvolvimento.

Os lactentes que possuiram percentil menor que o esperado mostraram menor intenção ao procurar o objeto (neste contexto, fez-se necessário apresentar mais de uma vez o modelo do que iriam fazer para repetir e conseguir intenção no movimento). Uma delas (percentil $=0$ ) teve dificuldade de focar por mais de alguns segundos o objeto, o que talvez possa ter dificultado o acompanhamento e deslocamento motor, além de mostrar que não tinha a estimulação necessária para vivenciar o seguimento.

Foi notado que os cuidadores queriam que seus lactentes obtivessem o maior escore e mostrassem tudo o que faziam em casa. Assim, ajudavam 
durante a avaliação para que o lactente se movimentasse com dicas sobre: "ele gosta mais desta música", "ele adora barulho de beijo", "para este lado é mais dificil dele virar mesmo..."

Apenas um dos cuidadores desconhecia informações básicas sobre o lactente e não lembrava dados como a data de nascimento, como prefere ficar em casa, quais brinquedos chamam sua atenção ou qual sua última aquisição mais importante. Porém o lactente teve seu escore adequado.

Dentre os lactentes que apresentaram percentil $>71$ houve um que mostrou maior capacidade de resiliência (superar os fatores adversos ao desenvolvimento), pois há fatores adversos ao desenvolvimento que se fizeram presentes. Seu escore foi muito bom para a idade. Seu contato visual, interesse pelo brinquedo e intenção comunicativa foram significativos naquele momento, recebendo os cuidados de sua mãe adotiva, que se mostrou interessada e extremamente engajada em estimulá-lo. Durante a avaliação, o pai adotivo ligou e perguntou se estava tudo bem com o lactente, demonstrando atenção ao seu desenvolvimento e saúde. 


\subsection{RESULTADOS DOS TRÊS LACTENTES, ACOMPANHADOS} PELO CENTRO DE REFERÊNCIA E TREINAMENTO DE HIVIAIDS DE SÃo PAULO EM 2010, QUE APRESENTARAM PERCENTIL $<10$

Tabela 1: Uso de droga por familiar dos lactentes acompanhados pelo Centro de Referência e Treinamento de HIVIAids de São Paulo em 2010, com percentil< 10 .

\begin{tabular}{ccc}
\hline Usuário de droga na família & $\mathbf{n}$ & $\%$ \\
\hline Sim & 1 & 33,5 \\
Não & 2 & 66,5 \\
\hline Total & $\mathbf{3}$ & $\mathbf{1 0 0}$ \\
\hline
\end{tabular}

Dos três lactentes que apresentaram percentis $<10$, um apresentou usuário de droga na familia.

Tabela 2: Realização do pré-natal pelas mães dos lactentes acompanhados pelo Centro de Referência e Treinamento de HIVIAids de São Paulo em 2010, com percentil <10.

\begin{tabular}{ccc}
\hline Pré-natal & $\mathbf{n}$ & $\%$ \\
\hline Sim & 3 & 100 \\
Não & 0 & 0 \\
\hline Total & 3 & 100 \\
\hline
\end{tabular}


O pré-natal, com uma média de oito consultas até o nascimento, foi realizado por todo o grupo destes três lactentes. Em algumas consultas o pai acompanhava, outras a avó materna e, predominantemente apenas a mãe acompanhava o lactente.

Tabela 3: Escolaridade da mãe dos lactentes acompanhados pelo Centro de Referência e Treinamento de HIVIAids de São Paulo em 2010, com percentil $<10$.

\begin{tabular}{ccc}
\hline Escolaridade materna & $\mathbf{n}$ & $\%$ \\
\hline Primeiro grau incompleto & 1 & 33,3 \\
Segundo grau completo & 1 & 33,3 \\
Superior completo & 1 & 33,3 \\
\hline Total & 3 & 100 \\
\hline
\end{tabular}

A escolaridade apresentada pelas mães era de, no mínimo, primeiro grau completo. Todas sabiam ler e diziam compreender adequadamente o que lhes era dito e orientado. 
Tabela 4: Número de pessoas morando na casa dos lactentes acompanhados pelo Centro de Referência e Treinamento de HIVIAids de São Paulo em 2010, com percentil $<10$.

\begin{tabular}{ccc}
\hline Número de pessoas & $\mathbf{n}$ & $\%$ \\
\hline 4 & 1 & 33,5 \\
6 & 2 & 66,5 \\
\hline Total & 3 & 100 \\
\hline
\end{tabular}

O número de moradores manteve-se entre 4 e 6 nas casas dos três lactentes. Dentre os moradores haviam avós, tios separados ou solteiros e o núcleo familiar principal (mãe, lactente, pai e irmãos).

Tabela 5: Condição laboral dos pais empregados de lactentes acompanhados pelo Centro de Referência e Treinamento de HIVIAids de São Paulo em 2010, com percentil $<10$.

\begin{tabular}{ccc}
\hline Pais empregados & $\mathbf{n}$ & $\%$ \\
\hline Sim & 3 & 100 \\
Não & 0 & 0 \\
\hline Total & 3 & 100 \\
\hline
\end{tabular}

A condição laboral dos pais era estável e, os três, não tinham pretensão de fazer mudança imediata para outro emprego ou cargo na própria empresa. Um deles era autônomo (mecânico). 
Tabela 6: Frequência na creche dos lactentes acompanhados pelo Centro de Referência e Treinamento de HIVIAids de São Paulo em 2010, com percentil $<10$.

\begin{tabular}{ccc}
\hline Creche & $\mathbf{n}$ & $\%$ \\
\hline Sim & 2 & 33,5 \\
Não & 1 & 66,5 \\
\hline Total & 3 & 100 \\
\hline
\end{tabular}

A creche era frequentada por dois dos três lactentes. Era vista pelas mães como sendo um lugar de exploração e descobertas. Ambas achavam que meio período já era suficiente, pois os filhos ainda eram "muito pequenos".

Tabela 7: Local de permanência em casa dos lactentes acompanhados pelo Centro de Referência e Treinamento de HIVIAids de São Paulo em 2010, com percentil <10.

\begin{tabular}{ccccc}
\hline $\begin{array}{c}\text { Local de } \\
\text { permanência em }\end{array}$ & $\mathbf{n}$ & $\%$ & Local de & $\%$ \\
casa & & & permanência & ideal para a \\
& & & idade & \\
\hline Chão & 2 & 33 & 3 & 100 \\
Colo & 1 & 67 & 0 & 0 \\
\hline Total & 3 & 100 & 3 & 100 \\
\hline
\end{tabular}


As oportunidades de movimentação em casa eram dadas aos lactentes no colo e no chão. Sendo que o local ideal, para as idades em questão, era o chão. O chão proporciona liberdade de movimentação, superfície adequada para apoio e aquisição de equilíbrio e menor chance de quedas mais perigosas. 


\subsection{RESULTADOS DOS LACTENTES, ACOMPANHADOS PELO CENTRO DE REFERÊNCIA E TREINAMENTO DE HIVIAIDS DE SÃo PAULO EM 2010, QUE TIVERAM O PERCENTIL $\geq 10$}

Tabela 8: Uso de droga por familiar dos lactentes acompanhados pelo Centro de Referência e Treinamento de HIVIAids de São Paulo em 2010, com percentil $>10$.

\begin{tabular}{ccc}
\hline Usuário de droga na família & $\mathbf{n}$ & $\%$ \\
\hline Sim & 7 & 25 \\
Não & 20 & 75 \\
\hline Total & 27 & 100 \\
\hline
\end{tabular}

Neste caso, os usuários apareceram em número significativo e com parentesco muito próximo aos lactentes (pai, mães, avó materna e tio). Porém a maioria entre todos os 27 lactentes que tiveram seu escore adequado para a idade não está em contato com usuários de droga.

Tabela 9: Realização do pré-natal pelas mães dos lactentes acompanhados pelo Centro de Referência e Treinamento de HIVIAids de São Paulo em 2010, com percentil $>10$.

\begin{tabular}{ccc}
\hline Pré-natal & $\mathbf{n}$ & $\%$ \\
\hline Sim & 25 & 92 \\
Não & 2 & 8 \\
\hline Total & 27 & 100 \\
\hline
\end{tabular}


Mais de $90 \%$ das mães fizeram o acompanhamento adequado durante $\circ$ pré-natal. Das mulheres que não frequentaram as consultas: uma mãe não revelou o motivo pelo qual não o fez. E a outra, ocultou a gravidez da família e apenas revelou quando não foi mais possivel justificar as mudanças de seu corpo.

Tabela 10: Escolaridade da mãe dos lactentes acompanhados pelo Centro de Referência e Treinamento de HIVIAids de São Paulo em 2010, com percentil $>10$.

\begin{tabular}{ccc}
\hline Escolaridade materna & $\mathbf{n}$ & $\%$ \\
\hline Não estudou & 1 & 3 \\
Segundo grau incompleto & 8 & 30 \\
Segundo grau completo & 12 & 45 \\
Superior completo & 3 & 11 \\
Superior incompleto & 3 & 11 \\
\hline Total & $\mathbf{2 7}$ & $\mathbf{1 0 0}$ \\
\hline
\end{tabular}

Mais de $50 \%$ das mães possuia grau de instrução adequado segundo critérios como tempo (anos) de estudo, compreensão das orientações médicas e do porquê devem ser seguidas (importância para qualidade de vida e visão futura dos benefícios de tê-la). 
Tabela 11: Número de pessoas morando na casa dos lactentes acompanhados pelo Centro de Referência e Treinamento de HIVIAids de São Paulo em 2010, com percentil $>10$.

\begin{tabular}{ccc}
\hline Número de pessoas & $\mathbf{n}$ & $\%$ \\
\hline 3 & 8 & 30 \\
4 & 7 & 26 \\
5 & 4 & 15 \\
6 & 4 & 15 \\
8 & 3 & 11 \\
12 & 1 & 3 \\
\hline Total & $\mathbf{2 7}$ & $\mathbf{1 0 0}$ \\
\hline
\end{tabular}

As moradias abrigavam mais de um núcleo familiar. Os moradores contribuíam com serviço em casa ou renda por trabalhar fora, as casas eram espaçosas (em quatro casos) e cinco das mães relatavam vontade de ir morar com marido e filhos em um lugar menor, porém com menos pessoas.

Tabela 12: Condição laboral dos pais de lactentes acompanhados pelo Centro de Referência e Treinamento de HIVIAids de São Paulo em 2010, com percentil $>10$.

\begin{tabular}{ccc}
\hline Pais empregados & $\mathbf{n}$ & \% \\
\hline Sim & 25 & 93 \\
Não & 2 & 7 \\
\hline Total & $\mathbf{2 7}$ & $\mathbf{1 0 0}$ \\
\hline
\end{tabular}


Com exceção do pai que estava recluso da sociedade e o casal aposentado, todos possuíam vínculo empregatício. E a mãe, que relatou a prisão do companheiro, recebe ajuda governamental e trabalha como diarista.

Tabela 13: Frequência na creche dos lactentes acompanhados pelo Centro de Referência e Treinamento de HIVIAids de São Paulo em 2010, com percentil $>10$.

\begin{tabular}{ccc}
\hline Creche & $\mathbf{n}$ & $\%$ \\
\hline Sim & 7 & 26 \\
Não & 20 & 74 \\
\hline Total & 27 & 100 \\
\hline
\end{tabular}

Sete dos lactentes são freqüentadores de creches, próximas as suas casas, e seis ficam com a mãe ou avó materna durante o dia. 
Tabela 14: Local de permanência em casa dos lactentes acompanhados pelo Centro de Referência e Treinamento de HIVIAids de São Paulo em 2010, com percentil $>10$.

\begin{tabular}{ccccc}
\hline $\begin{array}{c}\text { Local de } \\
\text { permanência } \\
\text { em casa }\end{array}$ & $\mathbf{n}$ & $\%$ & $\begin{array}{c}\text { Local de } \\
\text { permanência ideal } \\
\text { para a idade }\end{array}$ & $\%$ \\
\hline Chão & 14 & 52 & 19 & 70 \\
Carrinho & 7 & 26 & 4 & 15 \\
Berço & 5 & 19 & 4 & 15 \\
Colo & 1 & 3 & 0 & 0 \\
\hline Total & $\mathbf{2 7}$ & $\mathbf{1 0 0}$ & $\mathbf{2 7}$ & $\mathbf{1 0 0}$ \\
\hline
\end{tabular}

As idades destes lactentes indicavam que a maioria poderia brincar no chão e aproveitar as vivências e deslocamentos que são oferecidos nesta condição postural. No entanto, quatro deles, poderiam ficar no carrinho, e quatro no berço, pois tinham idade inferior a cinco meses de vida e não é interessante uma vulnerabilidade térmica e/ou de estabilidade na superfície. 


\subsection{RESULTADO DE TODOS OS LACTENTES AVALIADOS,} ACOMPANHADOS PELO CENTRO DE REFERÊNCIA E TREINAMENTO DE HIVIAIDS DE SÃO PAULO, 2010.

Tabela 15: Escore na Escala Motora Infantil Alberta obtido pelos lactentes acompanhados pelo Centro de Referência e Treinamento de HIVIAids de São Paulo em 2010.

\begin{tabular}{ccc}
\hline AlMS & $\mathbf{n}$ & $\%$ \\
\hline Desenvolvimento adequado & 27 & 90 \\
Atraso do desenvolvimento & 3 & 10 \\
\hline Total & 30 & 100 \\
\hline
\end{tabular}

Dentre os lactentes avaliados, $10 \%$ (três) apresentou atraso do desenvolvimento motor e $90 \%$ (vinte e sete) teve sua performance motora considerada adequada para a idade. Dos três lactentes com desenvolvimento atípico, um apresentou percentil zero na escala, um pontuou no percentil um e o terceiro, percentil de nove. 


\section{DISCUSSÃO}

No Brasil, há média de 30 mil novos casos de Aids a cada ano, sendo principalmente em mulheres e pessoas acima de 50 anos. Mundialmente, cerca de 2000 crianças são infectadas por dia e 95\% pela via de transmissão vertical (UNAids, 2008).

São levados em consideração para determinar o grupo como "vulnerável": aspectos sociais, político institucionais e comportamentais. Analisados em conjunto com aspectos individuais e condições especificas (Instituto de Saúde, 2010).

Assim, os chamados grupos de risco para o aparecimento da Aids, antes formados por jovens homossexuais masculinos e usuários de droga, iniciam em 1990 um processo de "feminização" e atingem as famílias (mães, lactentes e crianças) (Negrini, 2004; Machado, 2010). Tal fato implicou em um aumento do que chamamos transmissão vertical ou materno-infantil, evidenciado pelo crescente número de lactentes e crianças acompanhados nos serviços de saúde (Machado, 2010).

Norteia-se, então, a preocupação maior com os lactentes expostos ao medicamentos em razão da toxicidade mitocondrial. Acredita-se numa incidência do agravo de $0,26 \%$ deste medicamento aos 18 meses de idade (Ministério da Saúde, 2009) com efeitos adversos de anemia, neutropenia e elevação das enzimas hepáticas (Bertolini, 2009), porém não há informações que o AZT leve à alteração de crescimento ou desenvolvimento (Marques, 
2006). Os lactentes expostos podem apresentar, ao nascimento, peso ligeiramente mais baixo, contudo há uma recuperação rápida demonstrando que não há diferença significativa entre lactentes expostos ou não na faixa etária de 18 meses de idade (Beitune, 2004; Culname, 1999; Zuccotti, 1999).

Mesmo com os avanços alcançados em tratamentos nos adultos, algumas drogas não possuem composição farmacológica adequada para crianças. Associa-se a este fato, o pouco conhecimento sobre os potenciais efeitos dessas drogas neste grupo. Seu uso prolongado tem criado uma situação desafiadora para o desenvolvimento normal destes pequenos usuários.

Nos paises em desenvolvimento a taxa de transmissão persiste aumentada por fatores como: dificuldade do diagnóstico durante a gestação, o não seguimento do tratamento com antirretrovirais ou a profilaxia, e a não substituição total do leite materno pela fórmula infantil (Fernandes et al., 2010; Matida et al., 2007). Ressalta-se que em 1999, $39 \%$ dos lactentes ainda recebiam aleitamento materno e Silva et al. (2001) afirmam que no estudo feito com dois grupos de lactentes, infectados e não infectados, a amamentação aparece como risco adicional para transmissão perinatal.

O enfrentamento a esta situação se dá por ações intersetoriais nas três esferas de gestão, instituições não governamentais e movimentos sociais (Brasil, 2007; Instituto de Saúde, 2010).

A população formada por mães infectadas e lactentes expostos ao HIV, durante a gestação e aleitamento materno, traz, de forma específica ou global, 
certas demandas que abarcam fatores ambientais e biológicos relacionados ao desenvolvimento infantil, que estão em contexto adverso ou facilitador deste processo (Negrini, 2004).

Neste aspecto, pode-se citar: pais impossibilitados de cuidar de seus filhos devido situação econômica e/ou de saúde, situação de institucionalização (separação entre irmãos, orfandade), reclusão penitenciária de cuidadores, estresse familiar (expresso pela espera do resultado de exame sorológico do lactente), número de filhos acima da média, renda familiar, escolaridade materna, substituição do aleitamento materno pelo uso de fórmula infantil, peso ao nascer, idade gestacional e uso de drogas (Lemes et al., 2009; Negrini, 2004; Paiva, 2010).

Segundo a identificação das variáveis biológicas e ambientais descritas por Marcondes (1991), o presente estudo relata: acompanhamento pré-natal, intercorrências na gestação, intercorrências no parto, idade gestacional e carga viral detectável para o HIV como as variáveis biológicas.

E idade dos pais, escolaridade materna, internação pós-alta, adesão ao tratamento, $\mathrm{AZT}$ via oral, condições de moradia, sol no ambiente que permanece o recém-nascido e lactente, número de moradores na casa, vínculo empregatício dos familiares, uso de álcool e drogas, frequência na creche, local de permanência do lactente, cuidador durante o dia, prática de aleitamento materno ou uso de fórmula infantil como as variáveis ambientais.

Cabe ressaltar que apenas apresentar um dos fatores em questão, ambiental ou biológico, sendo considerado de risco, ainda assim é insuficiente 
para determinar interferência ou prognóstico do desenvolvimento infantil (Pedromônico, 2002). A soma ou combinação de dois ou mais fatores podem trazer consequências para alterar o curso do desenvolvimento esperado.

Segundo Amorim (2010), uma nutrição adequada, a estimulação ambiental, o elevado padrão cultural, sócio-econômico e educacional da família interferem positivamente no desenvolvimento. Exemplifica, ainda, que a estimulação ambiental é um dos fatores mais importantes, pois especialmente nos primeiros meses e anos de vida, é um período de acelerado crescimento. Em contrapartida, lembra que este se torna um ponto de vulnerabilidade para o lactente, caso não seja dada sua devida importância.

Eventos significativos nos primeiros anos de vida ocorrem na interação com o meio. Neste propósito de interação, há o estímulo para a movimentação e a apropriação do próprio corpo por parte do lactente, o que podemos chamar de processo de constituição do eu. Soma-se então a parte genética, onde há o que chamamos de "janelas" de desenvolvimento, ou seja, momentos propícios para algumas aquisições (Jerusalinsky, 2002). Lopes e Tudella (2004) ainda acrescentam os momentos que chamamos "platôs" de aprimoramento, que são como fases de aperfeiçoamento de uma aquisição para sua sedimentação.

Ribeiro e Beltrane (2010) relatam que fatores de risco biológico podem interferir no desenvolvimento neuromotor, principalmente se houver histórico de risco na idade até 18 meses. Já Pretti et al. (2010) defendem fatores de risco ambiental como principais efeitos adversos para o desenvolvimento motor, por 
exemplo: interação com cuidadores, problemas respiratórios, postura ao dormir e estresse materno.

Reforçados por Maria-Mengel e Linhares (2007), que sugerem que as crianças serem cuidadas pelos pais biológicos em uma união estável, contar com estímulos positivos no lar e ter nivel superior de escolaridade podem ser considerados fatores de proteção ao desenvolvimento infantil. Sendo que neste contexto as primeiras interações do lactente em seu meio social são de fundamental importância para conexões neurais e construção de rede de relações ao longo dos três primeiros anos de vida.

A menção aos fatores de proteção dá-se pela existência do que se pode denominar resiliência, citada anteriormente como a capacidade do lactente de sobressair-se dos seus fatores adversos e seguir com seu desenvolvimento típico (Maria-Mengel, 2007). Tal fato pode apresentar-se frente à infecção pelo HIV e a peculiar situação familiar.

Amorim (2009) sugere que a presença materna pode agir como um fator de proteção para a aquisição de habilidades motoras, como as referentes ao equilíbrio estático.

Em uma revisão de literatura, Goldstein e Campbell (2008) comentam o quanto é importante a estreita relação entre pais e filhos e quanto este fato desperta o interesse por parte dos pais em saberem mais sobre o desenvolvimento, suas características e tendências para a estimulação dos lactentes. Assim, o conhecimento aparece como facilitador do desenvolvimento e estimulação de suas aquisições motoras (Goldstein e Campbell, 2008). O 
artigo expõe ainda que a orientação clínica aos pais tem maior eficácia e facilidade de memorização se for dada de forma escrita.

Neste binômio, Spitz nos propõe o uso do termo "provocar" como: a intenção consciente da mãe, ou seja, sua presença como uma oportunidade de estímulo ao lactente (Brum, 2004). O ato de provocar pela simples presença da mãe desafia e oportuniza ao lactente descobertas e vivências.

A relação da mãe com o filho é tida como fator determinante no pleno desenvolvimento infantil e envolvimento familiar nos cuidados dedicados ao lactente. Paiva et al. (2010) nos mostram que a comunicação não verbal, presente na situação da mãe com HIV e seu filho, traz à cena o apego ao lactente (que aparece intensificado em casos de descoberta recente do diagnóstico) e a possibilidade de identificar anormalidades em seu desenvolvimento (situação que envolve aspectos diversos como: atenção, culpa e percepção). A incerteza perante a espera pelo resultado da sorologia e a superproteção de seus filhos são citadas por Galvão et al. (2010), como alguns dos dilemas e conflitos presentes na vida da mãe infectada. Ao longo da vida da criança há a dúvida se esta poderá adquirir ou não o vírus, o que pode fugir da capacidade da mãe.

Na maior parte dos casos o desejo de ser mãe existe e a gravidez é esperada e acompanhada pela família de forma bastante positiva (Galvão et al., 2010). O modo como é dado o diagnóstico e a concepção da severidade da doença são discutidos de forma individual com as mães infectadas, ou seja, existem casos em que as mulheres subestimam sua severidade (reforçado pelo 
não aparecimento de sintomas) e situaçōes que supervalorizam (ilustrado pela associação feita entre Aids e morte, principalmente no ato que é revelado o diagnóstico).

Por mais que haja um avanço tecnológico na parte medicamentosa de combate ao HIV, o seguimento do tratamento depende das informações dadas à paciente, do tipo de acolhimento realizado e do entendimento por parte das mulheres da importância de seguir o tratamento de forma adequada (Neves, 2007).

O uso profilático de AZT em estudos aplicados em lactentes de até 18 meses e crianças até 5,6 anos de idade mostrou-se sem efeito adverso para o desenvolvimento neuropsicomotor ou ponderal. Ou seja, o uso profilático de antirretrovirais nos momentos indicados como os mais adequados é a melhor estratégia para a prevenção da Aids na infância (Machado, 2010; Culname et al., 1999).

A terapia antirretroviral durante a gestação, no momento do parto e o uso oral do AZT (Zidovudine) nos recém-nascidos por cerca de seis semanas após o nascimento reduziu drasticamente a transmissão do tipo vertical e aumentou a sobrevida de crianças filhas de mulheres soropositivas, o que mostra a indiscutivel ação benéfica desses medicamentos. Vale ressaltar que, apesar da evolução da medicação antirretroviral, o uso do AZT permanece sendo indicado profilaticamente nestes casos, até os dias de hoje. 
A questão medicamentosa é parte fundamental, porém as práticas de cuidado realizadas em casa, na creche ou nos ambientes frequentados pelo lactente não são menos relevantes.

Pesquisas revelam que as práticas maternas interferem no curso de desenvolvimento, como é ilustrado pela posição que é deixado o lactente durante o dia (Silva et al., 2006), e que estas práticas mudam de acordo com a cultura local (De Vries, 1999; Santos, 2001; Capute, 1985; Mei, 1994). Por exemplo: lactentes norte-americanos ficam mais em prono, britânicos ficam mais em supino, africanos são estimulados a sentar e andar precocemente, mexicanos ficam muito no colo e brasileiros ficam mais em supino que em prono (Silva et al., 2001). Hábitos e culturas que estimulam de formas diversas o desempenho motor.

Para que possa ser melhor compreendido e acompanhado, o desenvolvimento motor de lactentes pode ser mensurado por uma série de escalas e parâmetros de observação. Com a finalidade de perceber precocemente se há algum desvio em seu curso, atraso ou ainda com a intenção de caracterizar minuciosamente sua sequência (Herrero et al., 2011).

A orientação de forma escrita torna a informação mais didática e de fácil memorização. Observou-se que a aplicação da escala Alberta durante a pesquisa nos favoreceu exatamente neste sentido. Profissional e cuidador dialogam sobre o desenvolvimento em um mesmo patamar de observação, informação e orientação para estimulação. 
Pois a escala é aplicada por meio de observação das posturas do lactente e a comparação com os desenhos dos posicionamentos e sua breve descrição motora. As mães e ou cuidadores puderam perceber de forma clara e objetiva quais eram as posturas mais evoluidas que seus filhos apresentavam e a provável postura a ser adquirida posteriormente.

Além do fato de a escala ter sido validada para a população gaúcha (Valentini e Saccani, 2010) e ter demonstrado ser fidedigna na avaliação das aquisições motoras de crianças brasileiras, o que a torna um instrumento útil a várias áreas da pesquisa científica e da clínica com bebês.

A área da fisioterapia possibilita o entendimento quanto às relações necessárias para as aquisições motoras, condição muscular, posicionamento mais adequado para a idade do lactente, brinquedos direcionados cronologicamente às posturas adequadas para o período que se encontra e sugestões de vivências motoras para aprimorar sua performance. 


\subsection{LACTENTES QUE APRESENTARAM ATRASO DO}

\section{DESENVOLVIMENTO MOTOR}

O atraso identificado em três, dos 30 lactentes, abarcava mais as variáveis ambientais que as biológicas. Destacando-se a escolaridade materna, ocorrência de epilepsia durante a gestação, número de moradores na casa maior que quatro, uso de álcool por familiar, não freqüentar creche e o local de permanência do lactente em casa ser o colo.

Quanto à escolaridade materna e a sua associação com o número de consultas do pré-natal, as mães com maior grau de instrução tinham o dobro de chances de completarem seis ou mais consultas (número ideal, segundo o Ministério da Saúde), dariam maior importância ao pré-natal e/ou teriam um acesso mais fácil ao acompanhamento de sua gestação, o que também foi demonstrado no estudo de Haidar et al. (2001).

No caso de mães com HIV, este acompanhamento torna-se ainda mais indispensável, pois necessita de medicação adequada após 16 semanas de gestação (reforçando sua aderência e regularidade), orientação quanto à escolha do tipo de parto (o mais indicado é o parto cesáreo, para que haja o menor contato possível com material sanguíneo materno), orientação quanto ao oferecimento de fórmula infantil (é contra-indicado o aleitamento materno por potencializar a transmissão vertical), deve ocorrer o acompanhamento do valor de carga viral do recém-nascido (sempre deve ser indetectável), dentre outras 
investigações clínicas e laboratoriais de mãe e filho (anemia, convulsões, toxicidade de medicamentos) (Bertolini, 2009).

O entendimento do porquê destes cuidados é de fundamental importância para que se tenha a aderência e o seguimento do tratamento, por parte da mãe, além do apoio dos familiares para que não se deixe de cumprir nenhuma estratégia para evitar a transmissão vertical (Instituto de Saúde, 2010).

Mothi et al. (2011) indicam, na índia, como alguns fatores podem estar relacionados com a não aderência ao tratamento, por exemplo, o diagnóstico infantil tardio, inadequação de nutrição correta e a falta de pessoal de saúde qualificado para informar corretamente sobre as estratégias de combate à trasnmissão vertical.

Este tipo de transmissão pode ser referida como sendo de fácil controle, caso as orientações sejam seguidas adequadamente. Orientações estas que podem ser complexas ou não, como é apontado em estudo na Nigéria, que sugere como medida de prevenção da TV que as agulhas usadas por mãe e filho sejam esterelizadas, demonstrando não haver o cuidado mínimo de não compartilhamento de agulhas por mãe infectada e filho não infectado (Okechukwu, 2011).

Na África Subsaariana, sugere-se que se houver o uso de HAART no programa de prevenção a TV, nas áreas com poucos recursos, o sucesso da estratégia pode alcançar taxas semelhantes aos dos países industrializados. Acrescenta ainda que a amamentação reduz a eficácia conseguida pela 
utilização de medicamentos antirretrovirais e conclui que a prestação de amplo acesso ao TARV, bem como o aconselhamento e o apoio adequados para práticas mais seguras de alimentação infantil são estritamente necessários (Ikechebelu et al., 2011).

Em contrapartida, no Canadá, pesquisas apontam alguns efeitos colaterais da exposição a HAART. Os resultados sugerem que o HIV e/ou somente a exposição a HAART está associada a um aumento da prevalência de mutações AC/TG no DNA mitocondrial em mães infectadas e mostram uma tendência semelhante em lactentes expostos durante a gravidez. Uma vez que - acúmulo de mutações do DNA mitocondrial tem sido associado ao envelhecimento e doenças associadas à idade, isto pode levantar preocupações a longo prazo para as populações de HIV e HAART- exposta (Jitratkosol et al., 2012).

Dentre outras questões abordadas no seguimento destes lactentes, há direções a serem seguidas durante o pré-natal, ou seja, indicação para que tenha seu início o mais precoce possível, cobertura universal, realização de forma periódica, integração com as demais ações preventivas e curativas, e deve ser observado um número mínimo de consultas. Como parâmetro é utilizado o número mínimo de consultas recomendado pelo American College of Gynecology and Obstetrics (ACOG), que varia entre onze e 14 consultas. Porém, a Organização Mundial de Saúde tem discutido se este número não é exagerado. O indicado é que o intervalo entre duas consultas não deve ultrapassar oito semanas (Coimbra et al., 2003). 
As mães em questão tiveram o número indicado de consultas, cerca de oito, e continuaram o acompanhamento com a pediatra para avaliação específica de seus lactentes, investigação de possiveis nódulos, exames laboratoriais, crescimento e desenvolvimento global.

Outra associação que sugere atraso do desenvolvimento seria entre o número de filhos e o grau de escolaridade, quanto maior o número de filhos menor a escolaridade; o que pode estar associado a um menor intervalo interparto, falta de informação ou falta de acesso aos serviços de saúde. A condição social é um forte condicionante da transmissão vertical, acrescenta Barcellos et al. (2009).

Em 2000, Halpern, Giugliani, Victora et al., verificaram que as crianças que tinham mais de três irmãos apresentavam um risco $90 \%$ maior de manifestar algum atraso no desenvolvimento neuropsicomotor.

O estudo mostrou que um dos lactentes que apresentou atraso era de uma família de cinco irmãos, sem a presença do pai. A mãe, além de levar as crianças para a escola, cozinhar e passar, ainda trabalhava lavando roupa para fora. Em relato, durante as perguntas do questionário, a mãe revelou que mantinha o lactente no colo, junto ao corpo com as pernas em abdução, para que pudesse fazer as atividades domésticas sem que tivesse o risco do lactente se machucar e a ela não estivesse por perto.

Este lactente apresentou percentil zero, já tinha 12 meses e não ficava em sentado ou bípede sem apoio. Rolava com bastante dificuldade, e ainda como se estivesse experimentando o movimento, não havia harmonia na 
movimentação. Foi sugerido acompanhamento pela fisioterapeuta responsável pelo estudo, de forma mais frequente e com estimulação essencial para que vivenciasse mais suas posturas e habilidades motoras. Após dois atendimentos, sendo um por semana, o lactente já apresentava maior independência em sentado e iniciava interesse por permanecer em bipede. Ou seja, parecia que o lactente apenas estava esperando o estímulo externo para que pudesse responder e vivenciar. A não oportunidade de descobertas e movimento também cessou sua evolução e/ou tentativas de sucesso ao iniciar preensão, de objetos de atividade de vida diária (escova de dente, pente) e/ou brinquedos (peças de encaixe, instrumentos musicais, livrinhos).

A presença materna, também primordial para o desenvolvimento, é discutida por Jelsma et al. (2011) quando abordam a criança institucionalizada e o lar adotivo. Neste contexto, os autores mesclam informações quanto ao conhecimento sobre desenvolvimento, apresentado pelas instituições, e a falta deste, pelos pais adotivos, além de informações quanto ao local de moradia. Sugerem que a instituição trouxe maior estimulação, pelo fato de a equipe conhecer melhor sobre o desenvolvimento infantil. Acrescentam ainda que os pais adotivos mais observavam as crianças do que as estimulavam.

Dos três lactentes em questão, as cuidadoras principais eram as mães, sendo que dois tinham suas mães empregadas e permaneciam em creche por meio período. Estes apresentaram percentil um e nove. E, como mencionado anteriormente, no caso do lactente de percentil zero, a mãe não trabalhava fora e o mesmo também não frequentava creche. 
Pela frequência na creche e o local de permanência durante o dia dos lactentes, podemos ter a informação do quanto ele é estimulado. Segundo Rezende et al. (2010), os lactentes melhoraram o desempenho motor depois da entrada na creche e Amorim et al. (2010) nos mostram que a não participação em creche somada à diminuição do tempo com a mãe estão relacionados ao atraso do desenvolvimento motor.

Dos lactentes estudados na presente pesquisa que frequentavam creche, um apresentou dificuldade em seguir o brinquedo oferecido durante a aplicação da escala. Para que o lactente tentasse se movimentar para pegar ou trocar de postura, o movimento do brinquedo deveria ser de forma bem lenta e com pouco estímulo verbal. A atenção deste lactente era precária e o estímulo tinha que ser dado de forma bem focal. Após algumas tentativas e repetições, ele conseguiu levantar de deitado para sentado, e sentado para bípede, segurando em um apoio.

O terceiro lactente tinha, como principal queixa da mãe, uma dificuldade em respirar e brincar por um tempo prolongado. Ela relatava que ele se sentia cansado. Informações do questionário evidenciavam que não batia sol no quarto do lactente, havendo mais de seis pessoas morando na casa e que o mesmo permanecia bastante tempo no chão, tanto na creche quanto em casa. O lactente com idade de um ano e dois meses na época da avaliação, ainda não apresentava marcha, engatinhando ou arrastando em piso frio. 
A mãe informou, ainda, que não houve necessidade de internações, mas que o acometimento respiratório aparecia como fator adverso às explorações do ambiente pelo lactente.

Dentre outros fatores discutidos no questionário estavam tipo de parto e uso de drogas por familiar.

O tipo de parto cesáreo ocorreu em três casos. Sabe-se que há influência no maior índice de transmissão vertical quando o parto é vaginal, sendo que o parto cesáreo associa-se ao seu menor risco (Yoshimoto, 2005) e é o indicado pelos profissionais da área de saúde que acompanham as mães infectadas.

O uso de drogas por pelo menos um familiar dos lactentes avaliados apareceu em sete das 30 avaliações, sem que houvesse atraso do desenvolvimento motor segundo a Escala Alberta. Uma das usuárias era a própria mãe biológica, mas neste caso a lactente estava sendo cuidada pela mãe adotiva.

No estudo de Negrini (2004), uma das mães estudadas fazia uso de crack durante a gestação, porém o lactente não apresentou atraso. Por outro lado, outras quatro mães interromperam o uso de maconha durante a gestação, e seus filhos apresentavam risco para atraso no desenvolvimento. Eyler et al. (1999) confirmam que pode haver prejuízo no desenvolvimento de lactentes cujas mães fizeram uso de droga na gestação e acrescentam que este fato pode ser uma abertura para o aparecimento de mais fatores de risco ao desenvolvimento. 
A escolaridade materna pode restringir o desenvolvimento infantil (MariaMengel, 2007; Golsdteins e Campbell, 2002; Amorim et al., 2009). Porém, a falta de didática ao orientar durante os atendimentos também pode ser vista como fator desfavorável no seguimento do que foi orientado. Cada consulta é uma grande oportunidade para o profissional orientar e supervisionar a estimulação, marcos motores e interação do lactente.

O acompanhamento deve ocorrer de forma multidisciplinar, sendo o fisioterapeuta um profissional capacitado e com potencial para identificar e avaliar as etapas de aquisição motoras, além de orientar sua estimulação e observação por parte de cuidadores e ambientes de convivência, por exemplo, as creches (Amorim et al., 2009; Mothi et al., 2011).

Não apenas o follow-up das fases motoras é de grande importância, mas também a aderência ao tratamento medicamentoso e hábitos de vida diária, como a questão da amamentação, por exemplo.

Paiva et al. '(2010) referem um período de decisões, conflitos e vivência da maternidade por mães com HIV, que pode ser vivido em diferentes espaços de tempo. Este período, no entanto, é recente ao nascimento e considera-se de extrema importância para a comunicação da mãe com o lactente e formação do vínculo.

Brazelton e Nugent (1994) especificam e ilustram este periodo. Ressaltam a linguagem complexa do comportamento infantil. Ainda que não possam falar a primeira palavra no primeiro ano de vida, os lactentes mostram- 
se prontos para se comunicar com um rico vocabulário de movimentos do corpo, gritos e respostas visuais.

Mesmo o lactente que acabara de nascer possui uma experiência motora dentro da barriga de sua mãe, conhece gostos, cheiros, sons e a sensação vestibular de balanço. $O$ recém-nascido se manifesta e se comunica frente ao rosto dos pais através, principalmente, do choro, além de ter uma capacidade de adaptação ao ambiente em que irá conviver (Brazelton e Nugent, 1994).

Foi percebido durante a pesquisa que o desenvolvimento motor dos lactentes nascidos de mães infectadas pelo HIV evidenciou algumas causas biológicas e ambientais como fatores de risco e/ou facilitadores para atingir o escore esperado para idade, na Escala Alberta (Marcondes, 1991).

O fato é que serem filhos de mães infectadas não sobressaiu às outras variáveis que pudessem trazer algum efeito facilitador à evolução do desenvolvimento motor. Ou seja, não foi apresentada diferença entre os lactentes com antecedentes de HIVIAids e os lactentes tidos como referência pela Escala Alberta.

Além disto, a escala ofereceu aos cuidadores a possibilidade de conhecimento por parte deles de qualquer desvio do desenvolvimento motor, sem trazer nenhum perigo ou desconforto à criança.

Torigoshi (2009) defende que o oferecimento de um serviço multidisciplinar especializado poderá, além de garantir uma atenção coordenada e centralizada ao lactente e cuidador, contribuir para estabelecer um follow-up continuo de grupos de risco para atraso do desenvolvimento. 
A escolha de avaliações, treinamento e monitoramento do seu uso requisita investimento técnico, humano e financeiro, agregando a possibilidade de um olhar menos subjetivo sobre as ações realizadas e as práticas propostas. 


\section{CONCLUSÃO}

O desenvolvimento motor de lactentes expostos ao vírus da imunodeficiência humana materno que fazem uso da medicação antirretroviral mostrou-se predominantemente adequado na idade de onze dias até 18 meses de vida, com apresentação da movimentação típica esperada para a idade.

Os fatores considerados ambientais (escolaridade materna, práticas de cuidado e posicionamento em domicílio, condição social, econômica e familiar e uso de drogas) sugeriram maior influência neste grupo de lactentes em relação a sua performance motora.

Os estímulos que provocaram melhor resposta por parte dos lactentes ao realizarem a movimentação espontânea, trocas posturais e manutenção da postura através de reações de equilíbrio e endireitamento foram os brinquedos com características visuais e auditivas, direcionados de acordo com a idade.

A Escala Motora Infantil Alberta (AIMS), no contexto de follow-up para este grupo de lactentes, mostrou-se pouco específica em seu seguimento clínico.

Os lactentes apresentaram necessidade de seguimento específico em suas diretrizes de atenção e cuidado, por exemplo: a questão nutricional onde há a substituição do aleitamento pelo oferecimento da fórmula infantil; $O$ uso adequado da medicação antirretroviral para a prevenção de transmissão vertical e a realização de exames clínicos e físicos de investigação de achados que possam interferir no crescimento ou desenvolvimento. 
O conhecimento e apropriação de questões relacionadas ao desenvolvimento motor por parte de mães/ cuidadores estreitaram a relação com seus filhos. O que fortalece situações propícias à movimentação, brincadeiras para estimulação cognitiva e o amadurecimento emocional deste binômio. 


\section{REFERÊNCIAS}

Albernaz EP, Menezes AM, Cesar JA, Victora CG, Barros FC, Halpern R. Fatores de risco associados à hospitalização por bronquiolite aguda no período pós-neonatal. Rev. Saúde Pública. 2003; 37(4): 485-93. Doi: http://dx.doi.org/10.1590/S0034-89102007000300005.

Amorim RCA, Laurentino GEC, Barros KMFT, Ferreira ALPR, Filho AGM, Raposo MCF. Programa de saúde da familia: proposta para identificação de fatores de risco para o desenvolvimento neuropsicomotor. Rev Bras Fisioterapia. 2010; 13(6): 506-13. Doi: http://dx.doi.org/10.1590/S141335552009005000065 .

Bagenda D, Nassali A, Kalyesubula I, Sherman B, Drotar D, Boivin M, Olness K. Health, Neurologic, and Cognitive Status of HIV-Infected, Long-Surviving, and Antiretroviral-Naive Ugandan Children. Pediatrics mar 2006; 117: 729-740. Doi: 10.1542/peds.2004-2699.

Barcellos C, Acosta LMW, Lisboa E, Bastos FI. Vigilância da transmissão vertical do HIV: indicadores socioeconômicos e de cobertura de atenção à saúde. Rev. Saúde Pública. 2009, 43(6): 1006-1014. Doi:

http://dx.doi.org/10.1590/S0034-89102009005000070.

Barret B, Tardieu M, Rustin P, Lacroix C, Chabrol B, Desguerre I, et al. Persistent mitochondrial dysfuntion in HIV-1 exposed but uninfected infants: clinical screening in a large prospective cohort. AIDS. 2003; 17: 1769-85. Doi:10.1097/01.aids.0000076284.54156.44

Beitune PE, Durte G, Quintana SM, Figueiró- Filho EA, Marcolin AC, Abduch R. Antiretroviral therapy during pregnancy and early neonatal life: consequences for HIV-exposed, uninfected children. BJID. 2004; 8:140-50. Doi: http://dx.doi.org/10.1590/S1413-86702004000200004

Beitune PE, Durte G, Campbell O, Quintana SM, Rodrigues LC. Effects of antiretroviral agents during pregnancy on liver enzymes and amylase in HIVexposed, uninfected newborn infants. BJID. 2007; 11:314-7. Doi: http://dx.doi.org/10.1590/S1413-86702007000300003.

Biggar R J, Janes M, Pilon R, Miotti P, Taha TET, Broadhead R et al. Virus levels in untreated African infants infected with human immunodeficiency virus type 1. J Infect Dis 1999;180: 1838-43. Doi: 10558939.

Bobath K. Um base neurofisiológica para o tratamento da Paralisia Cerebral. $2^{\mathrm{a}}$. ed. São Paulo: Manole Limitada; 1984, 1993. 110p. 
Brazelton TB. Momentos decisivos do desenvolvimento infantil. v.1. São Paulo: Martins Fonseca; 1994. 339p.

Brandão T, Silva KS, Sally EFO, Dias MA, Silva CVC, Fonseca VM. Características epidemiológicas e nutricionais de gestantes vivendo com o HIV. Rev Bras Ginecol Obstet. 2011; 33(8):188-95.

Brasil. Ministério da Saúde. Secretaria de vigilância em saúde. Programa Nacional de DST e AIDS. Recomendações para Terapia Antirretroviral em Crianças e Adolescentes Infectados pelo HIV. Brasília, 2009.

Brasil. Ministério da Saúde. Secretaria de vigilância em saúde. Programa Nacional de DST e AIDS. Recomendações para Profilaxia da Transmissão Vertical do HIV e Terapia Antirretroviral em Gestantes. Brasília, 2009.

Brasil. Ministério da Saúde. Secretaria de vigilância em saúde. Programa Nacional de DST/AIDS. Brasilia, 2006: 1-81.

Brasil. Ministério da Saúde.Plano Integrado de Enfrentamento da Feminização da Epidemia de Aids e outras DST. Programa Nacional de DST e Aids Brasilia, DF, 2007. 33p.

Brito AM; Sousa JL; Luna CF; Dourado I. Tendência da transmissão vertical de Aids após terapia anti-retroviral no Brasil. Rev Saúde Pública 2006;4,18-22. Doi: http://dx.doi.org/10.1590/S0034-89102006000800004.

Brocklhurst $P$, Volmink J. Antiretrovirals for reducing the risk of mother-to-child transmission of HIV infection. Cochrane Database Syst Rev.2005. Doi: 10.1002/14651858.CD003510.pub3.

Brum EHM, Scherman L. Vínculos iniciais e desenvolvimento infantil: abordagem teórica em situação de nascimento de risco. Ciência e saúde coletiva jun 2004; 9 (2). Doi: http://dx.doi.org/10.1590/S1413-

81232004000200021.

Capute AJ. Normal gross motor development: the influences of races, sex and socio- economic status. Dev Med Child Neurol 1985; 27: 635-43. Doi: 10.1111/j.1469-8749.1985.tb14136.x

Coimbra LC, Silva AAM, Mochel EG, Alves MTSS, Ribeiro VS, Aragão VMF, Bettiol $\mathrm{H}$. Fatores associados à inadequação do uso da assistência pré-natal. Rev Saúde Pública 2003;37(4):456-62. Doi: http://dx.doi.org/10.1590/S003489102003000400010.

Connolly K. Desenvolvimento motor: passado, presente e futuro. Rev Paul Educ Fis. 2000; 3: 6-15. 
Connor EM, Sperling RS, Gelber R, Kiselev P, Scott G, O'Sullivan MJ, et al. Reduction of maternal-infant transmission of human immunodeficiency virus type 1 with zidivudine treatment. Pediatric AIDS Clinical Trials Group Protocol 076 Study Group. N Engl J Med. 1994; 331(18): 1173-80. Doi: http://dx.doi.org/10.1590/S1519-38292008000400013.

Courpotin C. HIV infection in children: what's new in 1996. Place of pulmonary complications. Pediatr Pulmonol 1997; 16: 190-191. Doi: 9443269.

Culnane M, Fowler MG, Lee SS, McSherry G, Brady M, O'Donell K, et al. Lack of long-term effects of in utero exposure to zidovudine among uninfected children born to HIV-infected women. JAMA. 1999, 281:151-7. Doi: 9917118.

De Vries MW. Babies brain and culture: optimizing neurodevelopment on the savanna. Acta Pediatric Suppl. 1999; 429:43-8.

Eyler FD, Behnke M. Early development of infants exposed to drugs prenatally. Clin Perinatol (Gainesville). 1999; 26(1):107-50. Doi: 10214546.

Fernandes RCSC, Ribas GF, Pires SD, Gomes AM, Medina AE. Desafios operacionais persistentes determinam a não redução da transmissão maternoinfantil do HIV. J. Pediatr. (Rio J.). 2010; 86(6): 503-508. Doi: http://dx.doi.org/10.1590/S0021-75572010000600010.

Fernandes AMS, Antonio DG, Bahamondes LG, Cupertino CV. Conhecimento, atitudes e práticas de mulheres brasileiras atendidas pela rede básica de saúde em relação às doenças de transmissão sexual. Cad Saúde Pública 2000; 16 Suppl 1:S103-12. Doi: http://dx.doi.org/10.1590/S0102-311X2000000700009.

Galvão MTG, Cunha GH, Machado MMT. Dilemas e conflitos de ser mãe na vigência do HIVIAids. Rev. bras. enferm. 2010; 63(3): 371-376. Doi: http://dx.doi.org/10.1590/S0034-71672010000300004.

Goldstein LA, Campbell SK. Effectiveness of the Test of Infant Motor Performance as an educational tool for mothers. Pediatr Phys Ther. 2008 Summer;20(2):152-9. Doi: 10.1097/PEP.0b013e3181729de8.

Haidar FH, Oliveira UF, Nascimento LFC. Escolaridade materna: correlação com os indicadores obstétricos. Cad. Saúde Pública, Rio de Janeiro, 17(4):1025-1029, jul-ago, 2001. Doi: http://dx.doi.org/10.1590/S0102$311 \times 2001000400037$.

Halpern R. A influência das variáveis ambientais no desenvolvimento da linguagem em uma amostra de crianças. Revista da AMRIGS, Porto Alegre, 50 (4): 292-301, out.-dez. 2006. 
Halpern R, Giugliani ERJ, Victora CG, Barros FC, Horta BL. Fatores de risco para suspeita de atraso no desenvolvimento neuropsicomotor aos 12 meses de vida. Jornal de Pediatria, 2000, Rio de Janeiro, 76(6):121-128. Doi: 10.4067/S0370-41062002000500016.

Herdy GVH, Pinto CAM, Lopes VGS, Ribeiro RP, Gomes IM, Tchou HY, Melo $R$, Kurdin B, Tavares PA. Study of the cardiac alterations in hiv-nfected children consequent to the anti-retroviral therapy: prospective study of 47 cases. Arq Bras Cardiol 2003; 80 (3): 316-20. Doi: http://dx.doi.org/10.1590/S0066$782 \times 2003000300007$.

Holderbaum RM, Veeck EB, Oliveira HW, Silva CL, Fernandes A. Comparison among dental, skeletal and chronological development in HIV-positive children: a radiographic study. Braz Oral Res 2005;19(3):209-15. Doi: http://dx.doi.org/10.1590/S1806-83242005000300010.

Instituto de Saúde. Kalckmann S, Batista LE, Castro CM, Lago TDG, Souza SR. Nascer com equidade: humanização do parto e do nascimento: questões raciais/ cor e de gênero. São Paulo, 2010. Temas em Saúde Coletiva, 11.

Ikechebelu JI, Ugboaja JO, Kalu SO, Ugochukwu EF. The outcome of prevention of mother to child transmission (PMTCT) of HIV infection programme in Nnewi, southeast Nigeria. Niger J Med. 2011 Oct-Dec;20(4):421-5. Doi: 22288315.

Jelsma J, Davids N, Ferguson G. The motor development of orphaned children with and without HIV: Pilot exploration of foster care and residential placement. BMC Pediatr. 2011 Feb 7;11:11. Doi:10.1186/1471-2431-11-11.

Jerusalinsky J. Enquanto o futuro não vem: a psicanálise na clínica interdisciplinar com bebês. Salvador: Ágama, 2002. 306p.

Jitratkosol MH, Sattha B, Maan E, Gadawski I, Harrigan PR, Forbes J, Alimenti A, Van Schalkwyk J, Money D, Côté HC; and the CIHR Emerging team grant on HIV therapy and aging: CARMA. Blood mitochondrial DNA mutations in HIVinfected women and their infants exposed to highly active antiretroviral therapy during pregnancy. AIDS. 2012; 20. Doi: http://hdl.handle.net/2429/26035.

King SM and Committee on Pediatric AIDS. Evaluation and treatment of the human Immunodeficiency virus-1-expodes infant. Pediatrics. 2004; 114:497505. Doi: 15286240.

Lemes SO, Pedromônico MRM, Fisberg M, Succi RM. Caracterização do desenvolvimento mental e psicomotor de lactentes filhos de mães soropositivas para o HIV. Temas sobre o desenvolvimento. 2009; 9(53): 5-9. 
Machado DM, Fernandes SC, Succi RCM, Freire WS, Pannuti S, Gouveia AB, Levi JE, Diaz RS. Analysis of HIV-type 1 protease and reverse transcriptase in brazilian children failing highly active antiretroviral therapy (HAART). Rev. Inst. Med. Trop. jan-fev 2005; 47(1):1-5. Doi: http://dx.doi.org/10.1590/S003646652005000100001.

Machado MMT, Galvão MTG, Lindsay AC, Cunha AJLA, Leite AJM, Leite RD et al. Condições sociodemográficas de crianças de zero a dois anos filhas de mães com HIVIAids, Fortaleza, CE, Brasil. Rev. Bras. Saude Mater. Infant. 2010; 10(3): 377-382. Doi: http://dx.doi.org/10.1590/S151938292010000300011.

Magder LS, Mofenson L, Paul ME, Zorrilla CD, Blattner WA, Tuomala RE, et al. Risk factors for in utero and intrapartum transmission of HIV. J Acquir Immune Defic Syndr. 2005;38(1):87-95. Doi: 15608531.

Mancini MC et al. Perfil do desenvolvimento neuromotor do bebê de alto risco no primeiro ano de vida. Temas sobre o desenvolvimento 1992; 8: 3-8. Doi: http://dx.doi.org/10.1590/S0021-75572008000100010.

Marques HHS. Avaliação crítica dos efeitos adversos do tratamento antiretroviral no feto, recém-nascido e lactente. Rev Bras Ginecol Obstet. 2006; 28(7): 424-30. Doi: 0100-7203.

Manoel EJ. Desenvolvimento Motor: padrões em mudança, complexidade crescente. Rev Paul Educ Fis. 2000; 3: 35-54.

Marcondes E. Fatores ambientais do crescimento da criança. Rev Bras de Crescimento e Desenvolvimento Humano. 1991; 1(1): 15-43. Doi:

http://dx.doi.org/10.1590/S1519-38292004000100002.

Matida LH, Ramos AN, Moncau JEC, Marcopito LF, Marques HHS, Succi RCM, Negra MD, Haerst N. AIDS by mother-to-child transmission: survival analysis of cases followed from 1983 to 2002 in different regions of Brazil. Cad. Saúde Pública 2007; 23(3): s435-s444. Doi: http://dx.doi.org/10.1590/S0102$311 \times 2007001500011$.

Mehri LVA, Vilela MMS, Silva MN, Barros AA. Características do crescimento de crianças infectadas com o vírus da imunodeficiência humana. Pediatria 2001;1:17-26. Doi: 315088.

Maturana AP, Rizzo CV, Vasquez DF, Cavalheiro N, Holzer S, Morais VS. Avaliação da assistência ao parto em gestantes infectadas pelo HIV. Arq Med ABC. 2007;32(1):11-6. Doi: 455473. 
Matida LH, Ramos Jr NA, Moncau JEC, Marcopito LF, Marques HHS, Succi RMC et al. Aids por transmissão vertical: análise de sobrevivência dos casos acompanhados entre 1983 e 2002 nas diferentes regiões do Brasil. Cad. Saúde Pública. 2007:23 Sup 3:S435-S44. Doi: http://dx.doi.org/10.1590/S0102$311 \times 2007001500011$.

Mello EQ. Aplicabilidade da Escala Alberta em lactentes de risco social. Tese (Mestrado) - Departamento de Saúde Materno Infantil, Faculdade de Saúde Pública da USP 2003; 85p. Doi: 352120.

Mei J. The northern chinese custom of rearing babies in sandbags. In Van Rossum JHA, Laszlo JI. Motor Development: aspects of normal and delayed development. Amsterdã. VU University Press; 1994. Doi: 10.1111/j.14698749.1995.tb12017.x.

Moodley D, Moodley J. HIV-1 infection: an indication for caesarean section? International Journal of Obstetric Anesthesia. 2000;9:221-4. Doi: 15321074.

Maria-Mengel MRS, Linhares MBM. Fatores de risco para problemas de desenvolvimento infantil. Rev. Latino-Am. Enfermagem. 2007; 15(spe): 837-842. Doi: http://dx.doi.org/10.1590/S0104-11692007000700019.

Mothi SN, Karpagam S, Swamy VH, Mamatha ML, Sarvode SM. Paediatric HIV. trends \& challenges. Indian J Med Res. 2011; 134(6):912-9. Doi: 10.4103/09715916.92636 .

Neves LAS, Gir E. Mães portadoras do HIVIAids: percepções acerca da severidade da infecção. Rev. esc. enferm. USP. 2007; 41(4): 613-618. Doi: http://dx.doi.org/10.1590/S0080-62342007000400011.

Newell ML. Reducing childhood mortality in poor countries. Transactions of The Royal Society of Tropical Medicine and Hygiene. 2003;97:22-4.

Oliveira HW, Veeck EB, Sousa PHC, Fernandes A. Avaliação radiográfica da idade óssea em crianças infectadas pelo HIV por via vertical. Radiol. Bras. 2006; 39(1): 27-31.

Okechukwu AA, Okechukwu OI. Prevalence of paediatric HIV infection in Federal Capital Territory, Abuja. Niger J Med. 2011. 20(4):409-13. Doi: 22288313.

Paiva SS, Galvão MTG, Pagliuca LMF, Almeida PC. Comunicação não-verbal mãe/filho na vigência do HIV materno em ambiente experimental. Rev. LatinoAm. Enfermagem. 2010; 18(1): 41-47. Doi: http://dx.doi.org/10.1590/S010411692010000100007. 
Pedromônico MRM. A investigação do desenvolvimento da criança: problemas e enfrentamentos. Temas em psicologia da SBP (Florianópolis). 2002; 10(2): 113-120. Doi: 1413-389x.

Perrotti AC, Manoel EJ. Uma visão epigenética do desenvolvimento motor. Rev Bras Cien e Mov. 2001; 9(4) : 77-82.

Piper MC, Darrah J. Alberta Infant Motor Scale. Philadelphia: WB Sauders; 1994.

Pretti LC, Milan JC, Foschiani MA, Raniero EP, Pereira K. Caracterização dos fatores ambientais e o controle cervical de lactentes nascidos pré-termo.

Fisioter. mov. 2010; 23(2): 239-250. Doi: 10.1590/S0103-51502010000200008.

Rezende MA, Beteli VC, Santos JLF. Follow-up of the child's motor abilities in day-care centers and pre-schools. Rev. Latino-Am. Enfermagem . 2010; 13(5): 619-625. Doi: http://dx.doi.org/10.1590/S0104-11692005000500003.

Rezende CEB, Rodrigues REC, Haddad L, Yoshimura R, Rapoports PB. Manifestações otológicas em criança com sindrome da imunodeficiência adquirida. Rev Bras Otorrinolaringo jan-fev 2004; 70(1): 430-4. Doi: http://dx.doi.org/10.1590/S0034-72992004000100022.

Ribeiro J, Beltrame TS. Características neuromotoras e biopsicossocias de lactentes com histórico de risco biológico. Fisioter. mov. 2010; 23(1): 25-34. Doi: 0104-1282.

Rotta NT. Paralisia Cerebral, novas perspectivas terapêuticas. Jornal de Pediatria 2002; 78: 48-54. Doi: 10.1590/S0021-75572002000700008.

Rouquayrol MZ. Epidemiologia e Saúde. Rio de Janeiro: MEDSI; 2003. 527p.

Santos DCC. Desenvolvimento motor durante o primeiro ano de vida: comparação entre lactentes americanos e brasileiros. Tese de doutorado. Campinas. 2001. Doi: http://dx.doi.org/10.1590/S1413-35552006000200014.

Sapienza G, Pedromônico MRM. Risco, proteção e resiliência no desenvolvimento da criança e do adolescente. Psicologia em Estudo, Maringá, 2005; 10 (2): 209-216.

Shearer WT, Quinn TC, La Russa P, Lew JF, Mofensen L, Almy S et al. Viral load and disease progression in infants infected with human immunodeficiency virus type 1. N Engl J Med 1997;336:1337-42. Doi: 9134873.

Silva EB, Grotto HZW, Vilela MM. Aspectos clínicos e o hemograma em crianças expostas ao HIV-1: comparação entre pacientes infectados e soro- 
reversores. Jornal de Pediatria. 2001; 77(6): 503-511. Doi:

http://dx.doi.org/10.1590/S0021-75572001000600014.

Tecklin JS. Fisioterapia Pediátrica. Porto Alegre: Artmed; 2002. 570p.

Torigoshi, MF. Desfecho dos encaminhamentos de recém-nascidos internados na unidade de terapia intensiva neonatal do Hospital Municipal de Diadema. São Paulo; s.n; 2009. 102 p. Tese apresentada a Universidade de São Paulo. Faculdade de Saúde Pública. Departamento de Saúde Materno Infantil para obtenção do grau de Mestre.

Turner BJ, Mckee I, Pantel RH et al. Health care of children and adults with acquired immunodeficiency syndrome. Aech Pediatr Adolsc Med. 1996; 150: 615-622. Doi: 8646312.

UNICEF. Net, SP. 2009. AIDS. Disponivel em <www. unicef.org>. Acesso em: 20 fev 2012.

UNAids. A ONU e a resposta à Aids no Brasil. Joint United Nations Programme on Hiv/Aids, 2008, 32p.

Veloso GL, Vasconcelos AL, Grinsztejn B. Prevenção da transmissão vertical no Brasil. Bol Epidemiol Aids 1999;12(3).

Vigano A, Schineider L, Giacomet V, Bianchi R, Lo Cicero M, Soster EB, Bulgheroni $E$, Rusconi S. Efficacy and tolerability of multiple drug therapy in HIV-infected children. Journal of Infection 2004; 50: 404-411. Doi:

http://dx.doi.org/10.1016/j.jinf.2004.08.001

Yoshimoto CE, Diniz EMA, Vaz FAC. Evolução clínica e laboratorial de recémnascidos de mães HIV positivas. Rev Assoc Med Bras 2005; 51(2): 100-5. Doi: http://dx.doi.org/10.1590/S0104-42302005000200017.

Watts DH. Management of human immunodeficiency virus infection in pregnancy. N Engl J Med. 2002;346(24):1879-91. Doi: http://dx.doi.org/10.1016/j.bpobgyn.2004.10.007.

Zuccotti GV, Agostoni C, D'Auria E. Infant growth after in útero exposure to zidovudine. JAMA. 1999; 282: 527-9. 
ANEXOS 


\section{ANEXO 1: ROTEIRO ESTRUTURADO PARA AVALIAÇÃO DOS RECÉM-NASCIDOS E LACTENTES NO SERVIÇO DE ACOMPANHAMENTO DO CENTRO REFERÊNCIA E TRATAMENTO DE SÃO PAULO, BRASIL.}

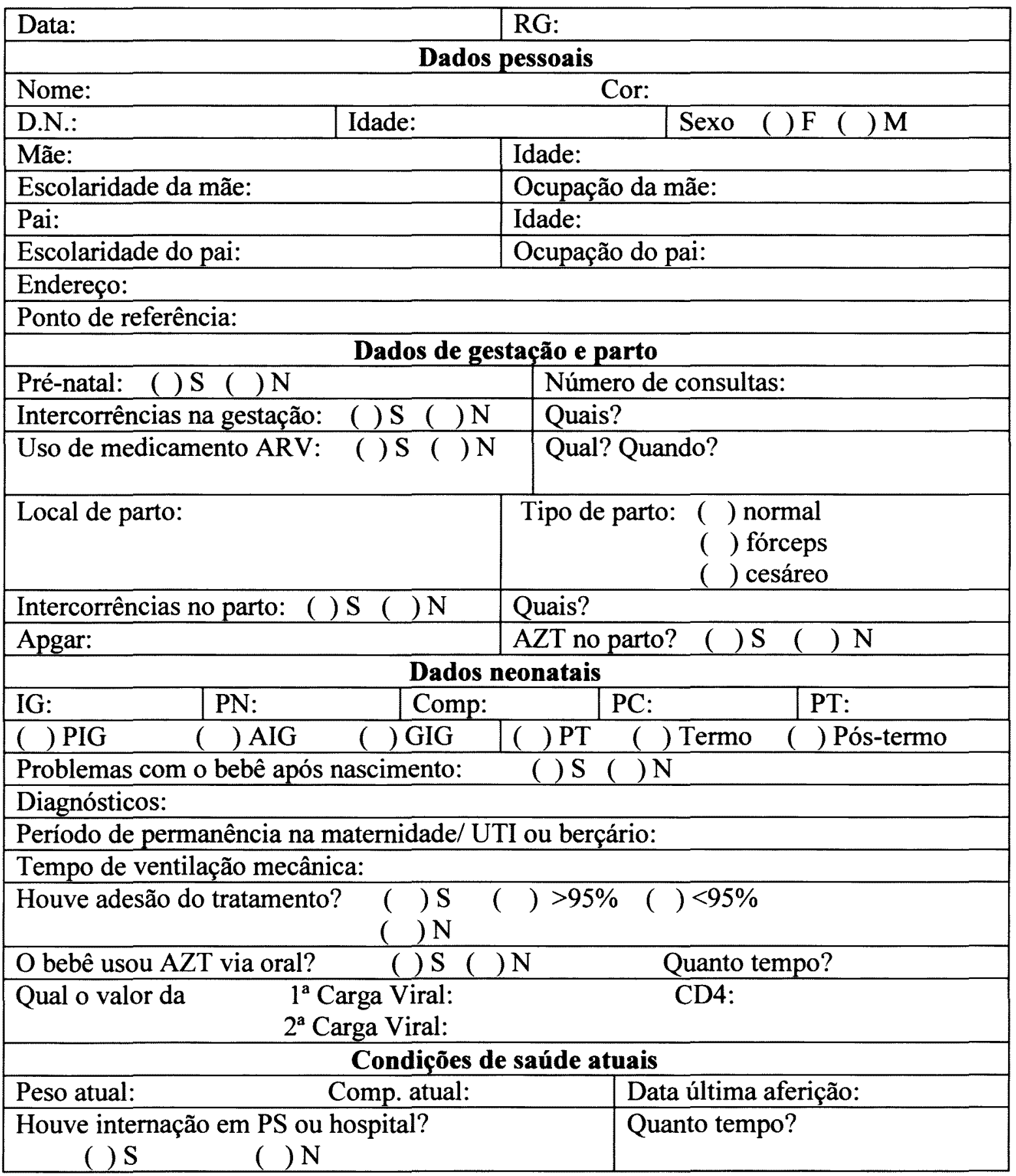




\begin{tabular}{|c|c|c|}
\hline \multicolumn{2}{|l|}{ Época do diagnóstico do HIV materno: } & Outras doenças: \\
\hline \multicolumn{3}{|c|}{ 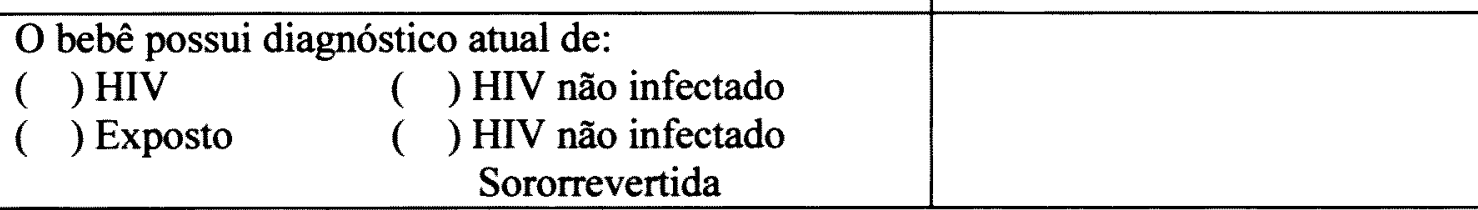 } \\
\hline \multicolumn{3}{|c|}{$\begin{array}{l}\text { Condições de moradia } \\
\end{array}$} \\
\hline $\begin{array}{ll}\text { Tipo de moradia: } & \text { ( ) alvenaria } \\
& \text { ( ) madeira } \\
& \text { ( ) outros }\end{array}$ & \multicolumn{2}{|c|}{$\begin{array}{ll}\text { Sol no quarto: } & (\text { ) manhã } \\
& (\text { ) tarde }\end{array}$} \\
\hline Umidade no quarto: ( ) S ( ) N & \multicolumn{2}{|c|}{ Mofo na casa: () $\mathrm{S}(\mathrm{)}) \mathrm{N}$} \\
\hline No. de cômodos: & \multicolumn{2}{|c|}{ Pessoas habitando local: } \\
\hline \multicolumn{3}{|l|}{ Tipo de piso: } \\
\hline Água encanada na cozinha: ( ) S ( ) N & \multicolumn{2}{|c|}{ Energia elétrica: ( ) S ( ) $\mathrm{N}$} \\
\hline \multicolumn{3}{|c|}{ Banheiro: ( ) próprio interno ( ) próprio externo ( ) comunitário } \\
\hline \multicolumn{3}{|c|}{ Familia e situação de estimulação } \\
\hline No. de filhos: & $\begin{array}{l}\text { Pai empregado? } \\
\text { ( ) } \mathrm{S}(\text { ) } \mathrm{N}\end{array}$ & $\begin{array}{l}\text { Mãe empregada? } \\
\text { ( ) } \mathrm{S}(\mathrm{C}) \mathrm{N}\end{array}$ \\
\hline $\begin{array}{l}\text { Alcoólatra na família? } \\
\begin{array}{ll}\text { ( ) } \mathrm{S} & (\mathrm{C}) \mathrm{N}\end{array}\end{array}$ & $\begin{array}{l}\text { Usuário de drogas? } \\
\text { ( ) } \mathrm{S} \quad(\text { ) } \mathrm{N}\end{array}$ & $\begin{array}{l}\text { Parentesco com o } \\
\text { bebê: }\end{array}$ \\
\hline Cuidador do bebê durante o dia: & Grau de parentesco: & \\
\hline $\begin{array}{l}\text { Onde permanece a maior parte do tempo? } \\
\begin{array}{ll}(\quad) \text { casa } & (\text { ) escola } \\
(\quad) \text { abrigo } & (\text { ) outros }\end{array}\end{array}$ & $\begin{array}{l}\text { Na casa fica aonde? } \\
\text { ( ) cercadinho } \\
\text { ( ) berço } \\
\text { ( ) cama }\end{array}$ & $\begin{array}{l}\text { ( ) sofá } \\
\text { ( ) carrinho }\end{array}$ \\
\hline Utiliza andador: ( ) S ( ) N & Desde quando? Quan & o tempo? \\
\hline
\end{tabular}




\section{ANEXO 2: TERMO DE CONSENTIMENTO LIVRE E ESCLARECIDO}

Título do Projeto: Desenvolvimento motor de lactentes expostos ao Vírus da Imunodeficiência Humana/AIDS

Pesquisadora Responsável: Dafne Herrero

Seu bebê está sendo convidado a participar de um projeto que tem por objetivo avaliar as etapas do desenvolvimento motor (capacidade que ele tem de rolar, sentar, ficar de pé...) de crianças expostas ao HIV/AIDS. Sabe-se que pode ocorrer um atraso motor neste grupo de crianças portanto é importante a investigação precoce para que entre em atendimento.

Para tanto será necessário realizar 2 procedimentos: a avaliação observacional do bebê pela Escala Alberta e a coleta de dados por questionário direcionado ao pai/mãe ou responsável. Além de informações complementares retiradas do prontuário.

Esta avaliação não causará dano ou desconforto ao bebê, pois o mesmo será, na maior parte do tempo, apenas observado. Se ao final da avaliação observacional for identificado algum atraso na criança, o pai/mãe ou responsável será orientado a procurar o serviço de estimulação (atendimento em que a fisioterapeuta ajuda o bebê a desenvolver-se mais rápido) oferecido pela APAE-SP (telefone: 11 5080-7123, falar com Cátia ou Juliana).

Após ler e receber explicações sobre a pesquisa, e ter meus direitos de:

1. receber resposta a qualquer pergunta e esclarecimento sobre os procedimentos, riscos, benefícios e outros assuntos relacionados à pesquisa;

2. retirar o consentimento a qualquer momento e deixar de participar do estudo;

3. não ser identificado e ser mantido o caráter confidencial das informações.

Caso haja alguma dúvida você poderá ligar para o número 2684-7798 e falar com a pesquisadora Dafne Herrero (responsável pela pesquisa) ou procurar esclarecimentos com o coordenador do Comitê de Ética em Pesquisa do Centro de Referência e Treinamento DST/AIDS: Dr. Eduardo Ronner Lagonegro, no telefone 11 5087-9837, Rua Santa Cruz, 81 - Vila Mariana, São Paulo - SP.

Declaro estar ciente do exposto e concordo com a participação do menor

Nome do pai/mãe ou responsável:

Assinatura:

Data:________

Pesquisadora responsável : Dafne Herrero

Assinatura:

Data:___ 


\section{ANEXO 3: APROVAÇÃO NOS COMITÊS DE ÉTICA DA FACULDADE DE SAÚDE PÚBLICA DA UNIVERSIDADE DE SÃO E DO CENTRO DE REFERÊNCIA E TREINAMENTO DE HIVI AIDS DE SÃO PAULO)}

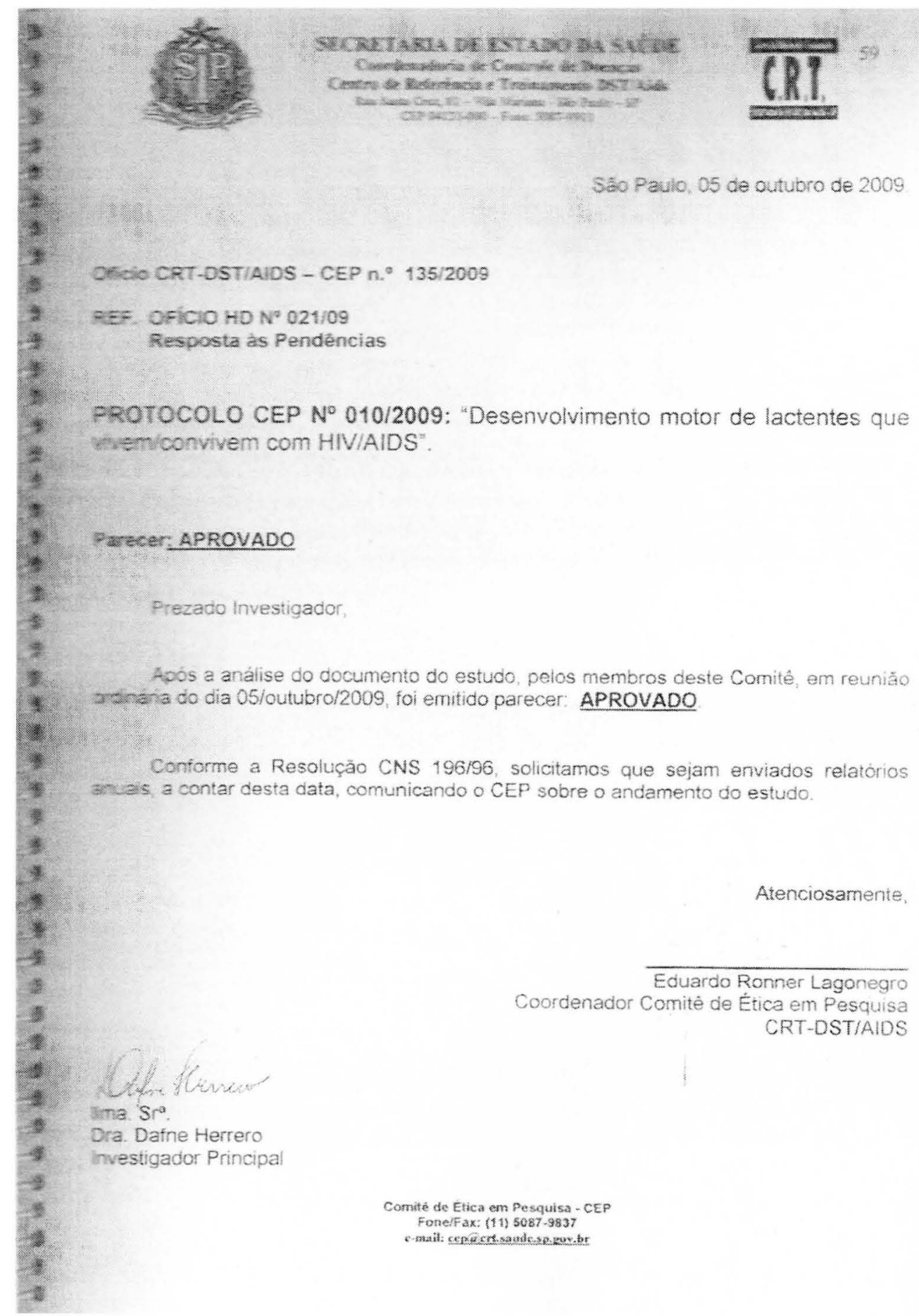


of.COEP/350/09

3 de dezembro de 2009

Prezado(a) Pesquisador(a) e Orientador(a),

o Comitê de Ética en Pesquisa da Faculdade de Saúde Pública da Universidade de Sä́o Paulo - COEP/FSP, analisou, de acordo com a Resoluçăo N. ${ }^{\circ} 196 / 96$ do Conseltho Nacional de Saúde - CNS e suas complementares o protocalo de pesquisa n. ${ }^{\circ} 1991$. intitulado "DESENVOLVIMENTO MOTOR DE LACTENTES QUE VIVEM/CONVIVEM COM HIV/AIDS", área temática GRUPO III, sob responsabilidade do(a) pesquisador(a) Dafne Herrero e orientaçăo do(a) professor(a) Luiz Carlos de Abreu, e considerou que a pendência anteriormente apresentada por este COEP foi atendida. Protocolo de pesquisa APROVADO "AD-REFERENDUM".

Cabe lembrar que conforme Resolucão CN $/ 196 / 96$, são deveres do (a) pesquisador (a): 1. Comunicar, de imediato, qualquer alteracão no projeto e aguardar manifestação deste CEP (Comitê de Etica em Pesquisa), para dar continuidade à pesquisa; 2. Manter sob sua quarda e em local segura, pelo prazo de 5 (cinco) anos, os dados da pesquisa, contendo fichas individuais e todos os demais documentos recomendados pelo CEP, no caso eventual auditoria; 3. Comunicar formaimente a este Comitê, quando do encerramento deste projeto; 4. Elaborar e apresentar relatónios parciais e final; 5 . Justificar, perante o CEP, interrupção do projeto ou a não publicação dos resuitados.

Atenciosamente,

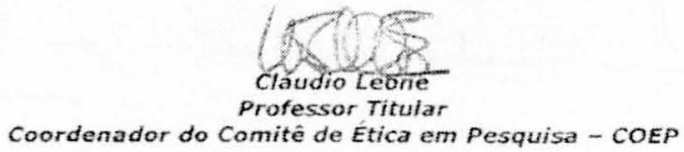

$\operatorname{Iim} .^{\circ} \mathrm{Sr}$.

Dr. Luiz Carlos de Abreu

Departamento de Saúde Materno-Infantil

Faculdade de Saúde Pública/USP

\footnotetext{
Av. Dr. Arnaldo, 715 - Assessoria Acadêmica - CEP: 01246-904 - São Paulo - SP Telefones: (55-11) 3061-7779? e-mail: coep@fsp.usp.br site www.fsp.usp.br
} 


\section{ANEXO 4: ESCALA MOTORA INFANTIL ALBERTA UTILIZADA PARA A AVALIAÇÃO DO DESEMPENHO MOTOR DE RECÉM- NASCIDOS E LACTENTES ATÉ O 18 MÊS DE VIDA.}

\section{ESCALA MOTORA INFANTIL ALBERTA}

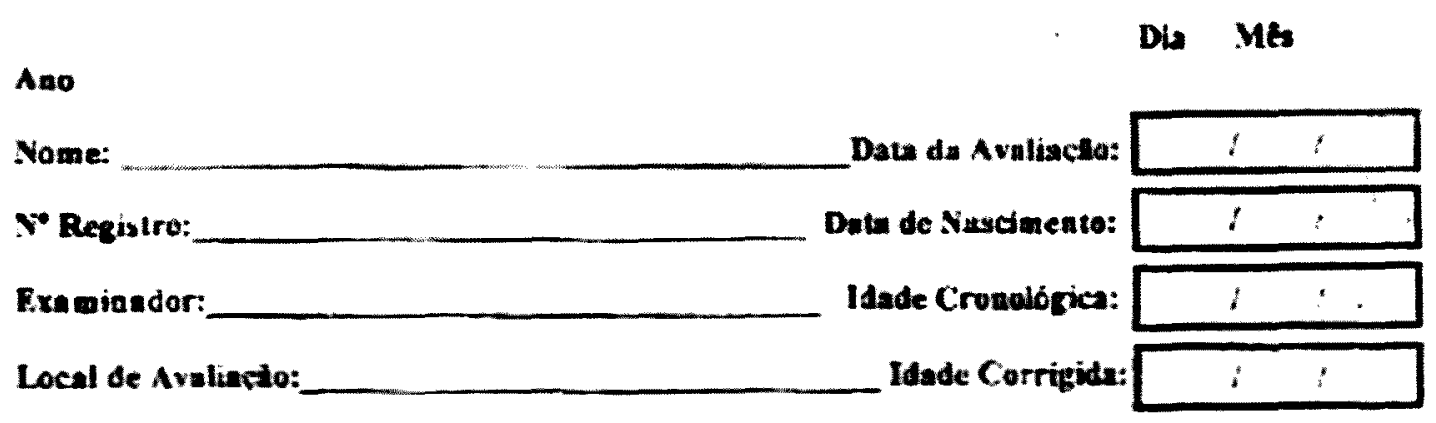

\begin{tabular}{|l|l|l|l|}
\hline & $\begin{array}{l}\text { Lteas Anteriores } \\
\text { Creditudo }\end{array}$ & $\begin{array}{l}\text { Iteas Creditades } \\
\text { lan Janela }\end{array}$ & Recore da Subescals \\
\hline Prono & & & \\
\hline Supios & & & \\
\hline Sestudo & & & \\
\hline Em pé & & & \\
\hline
\end{tabular}

Escore Total:

Pereentit:

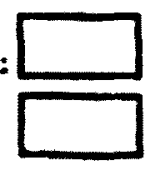

Comentírios e Recomendaples: 


\section{ESCALA ALBERTA}

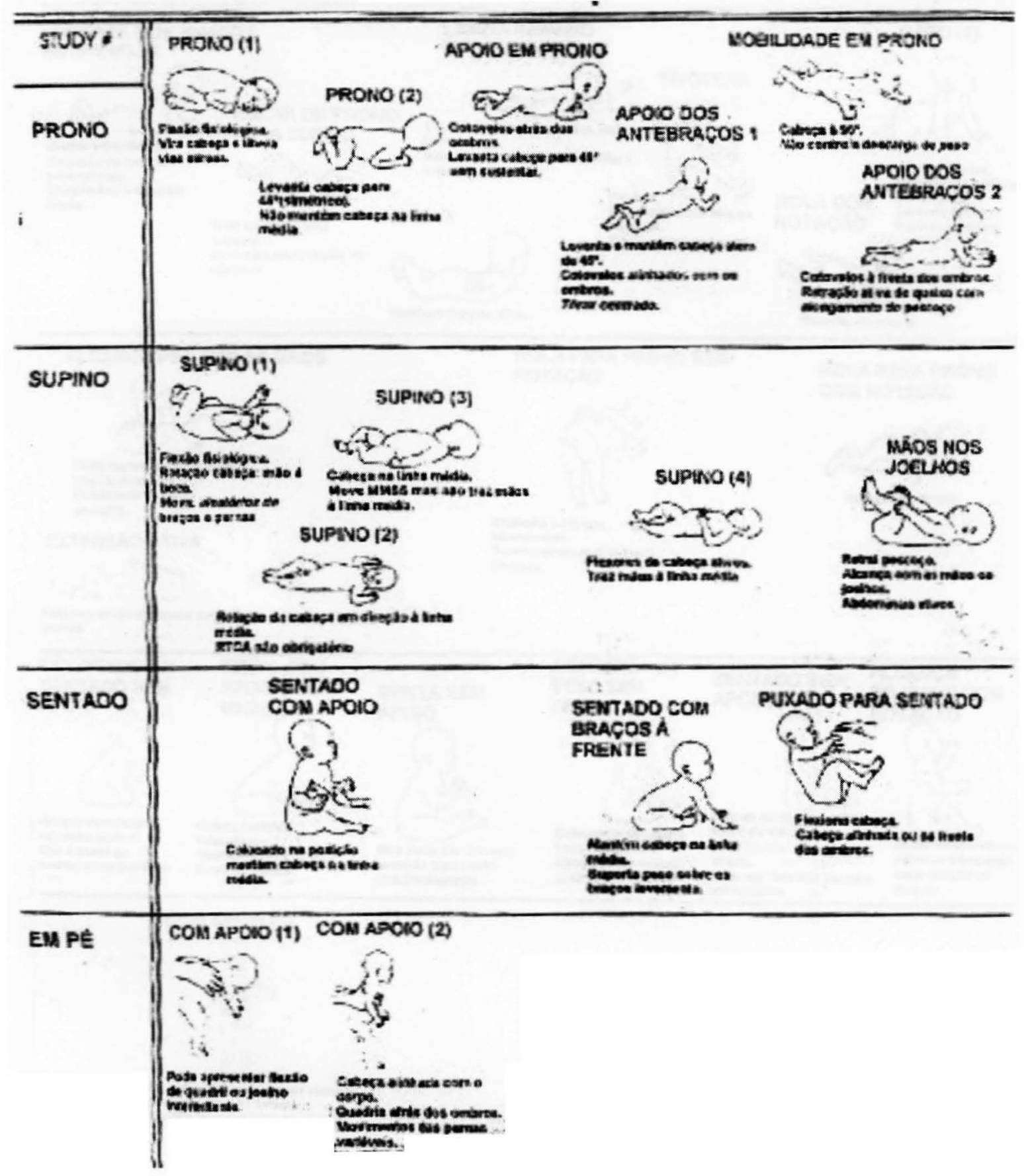




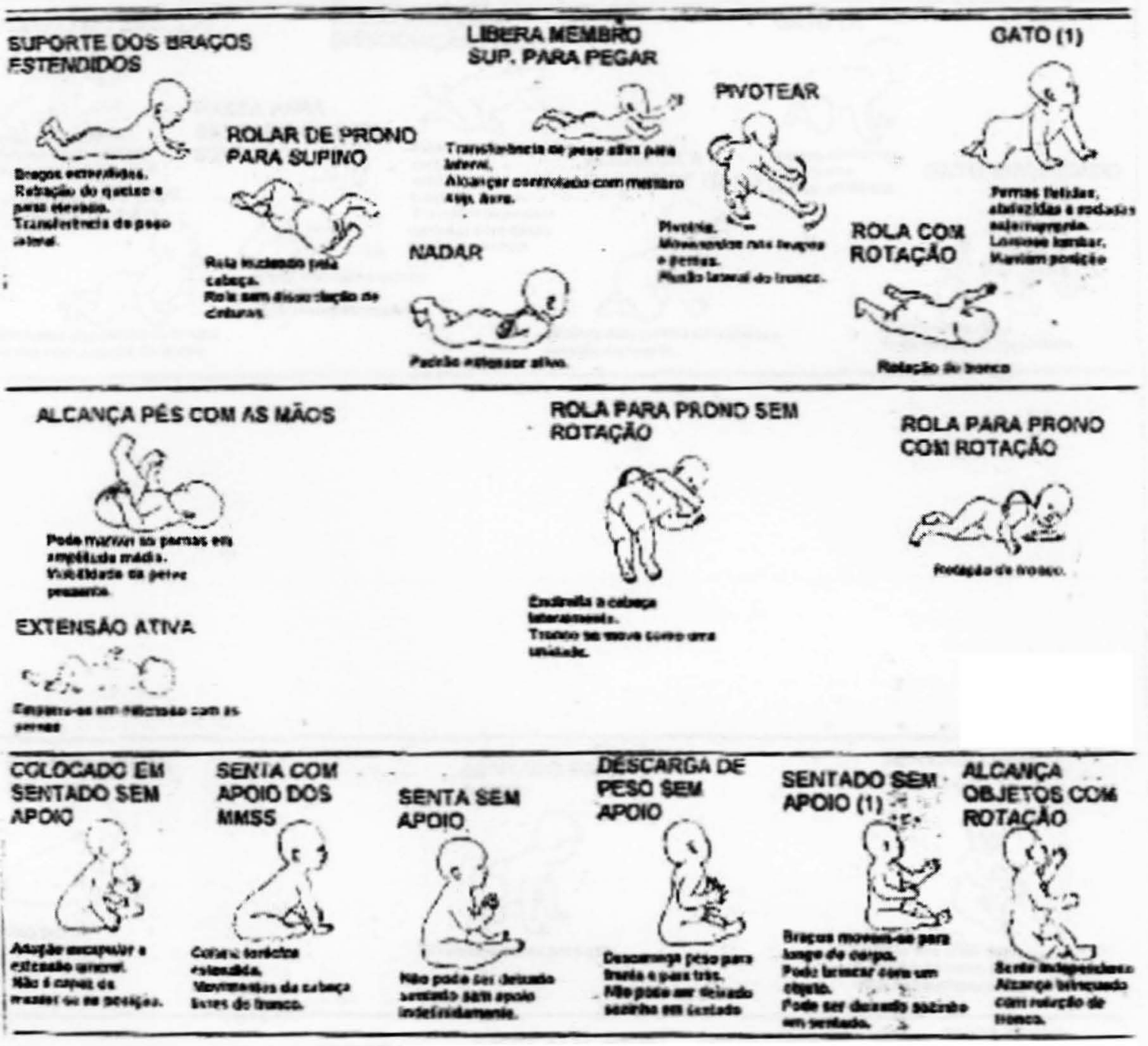

CON APOIO (3)

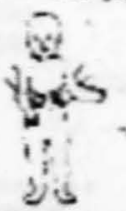

Gasirie ateknedas stmes omtwes.

Corwive esves ab vmex.

Mastrnesecos varions do pemes. 


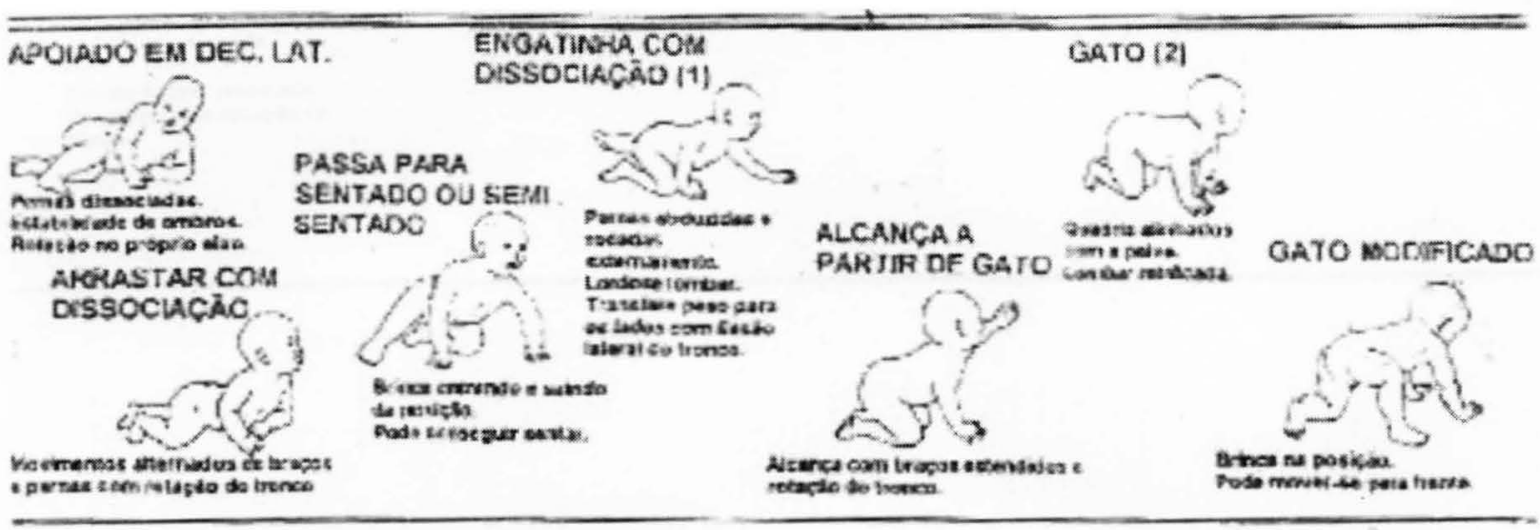

SENTADO PARA
PRONO
PASSA PARA
EAT PE OONA
APOIO




\section{ENGATINHAR COM}

DISSOCIACAO

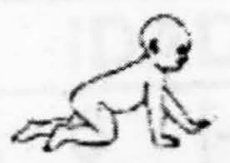

Cotures lomter reteficedia

Eneacine con rocacilo de

trones.

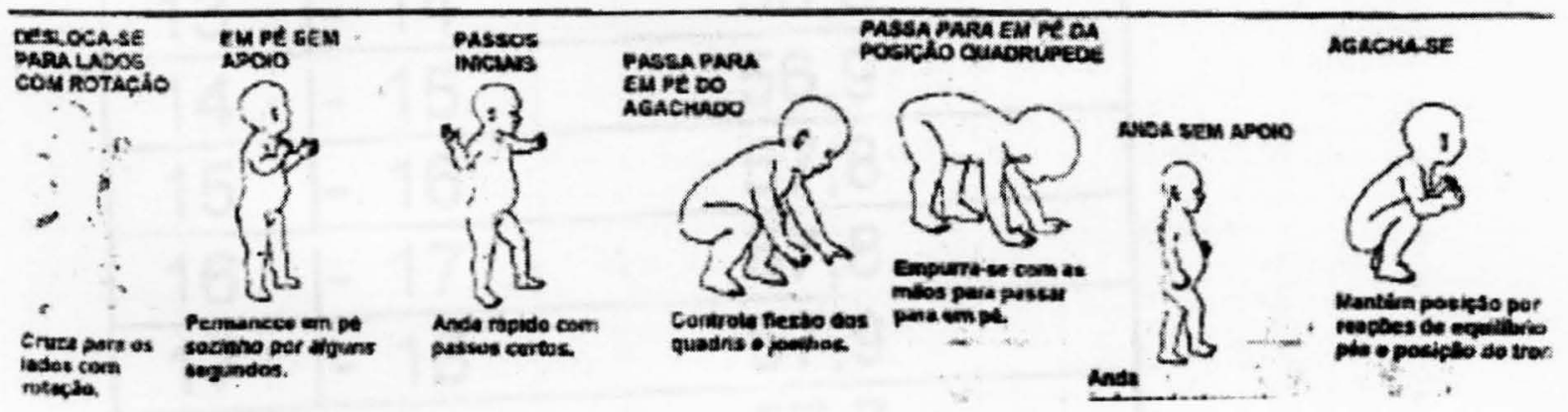




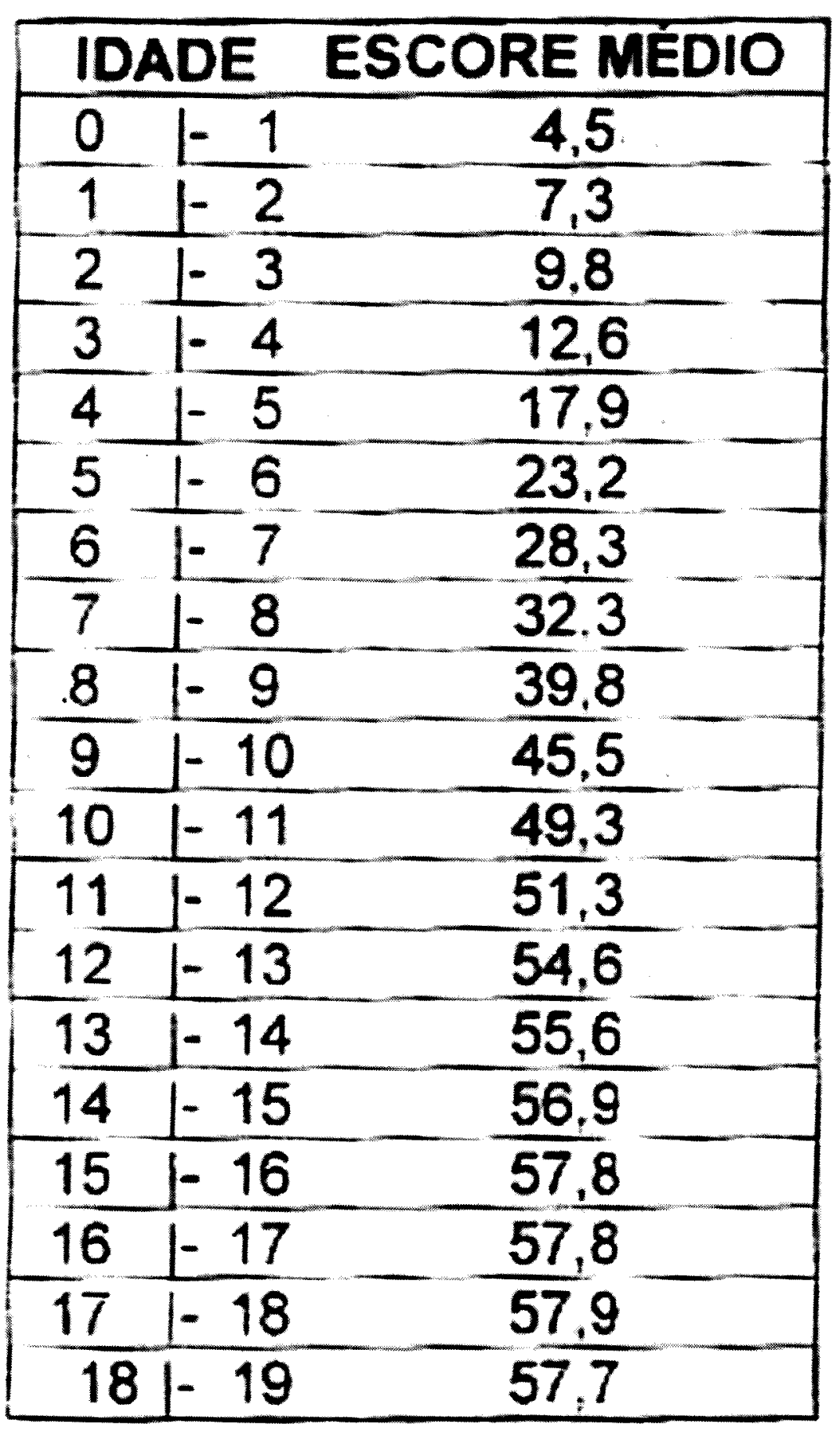




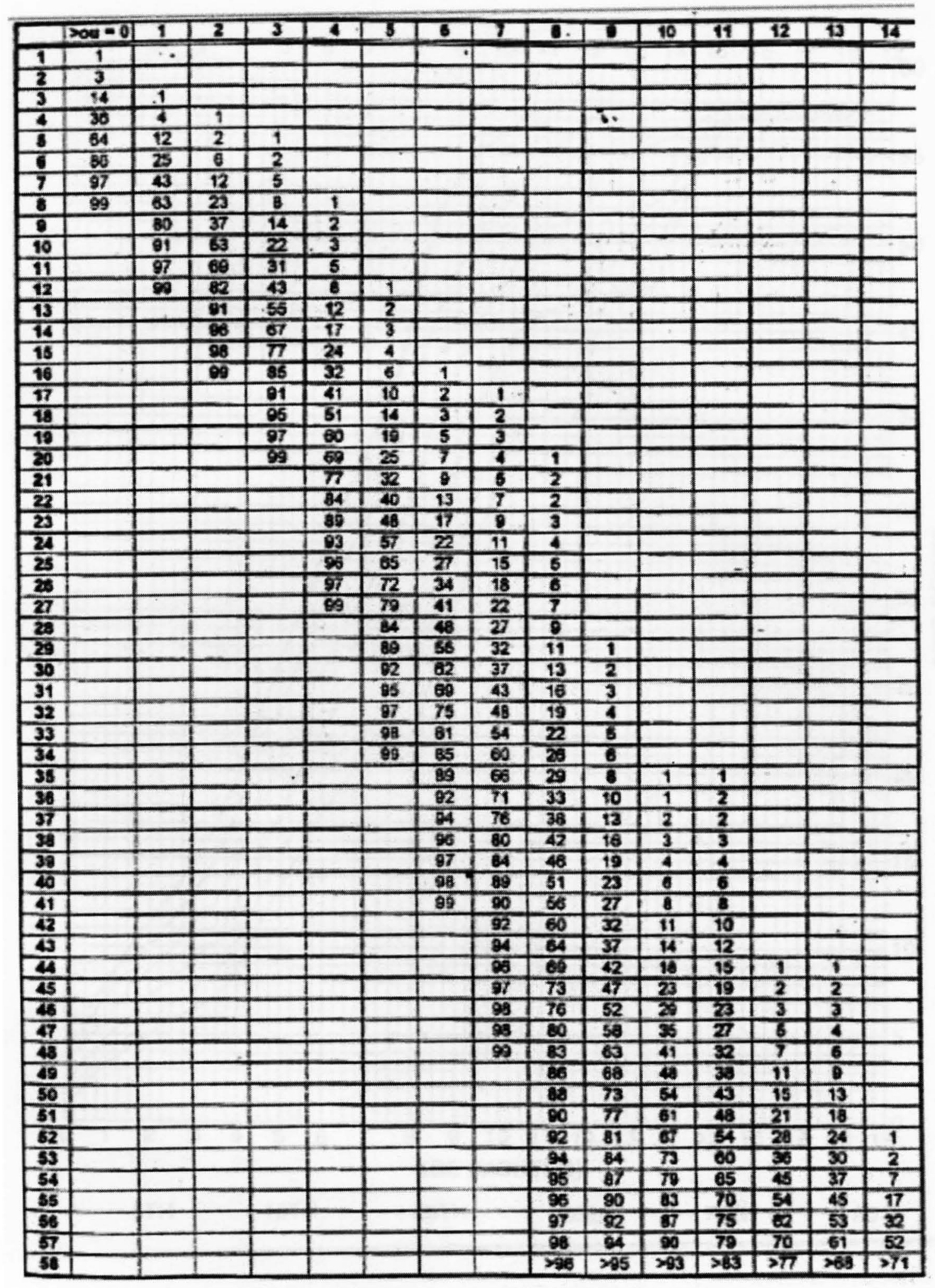




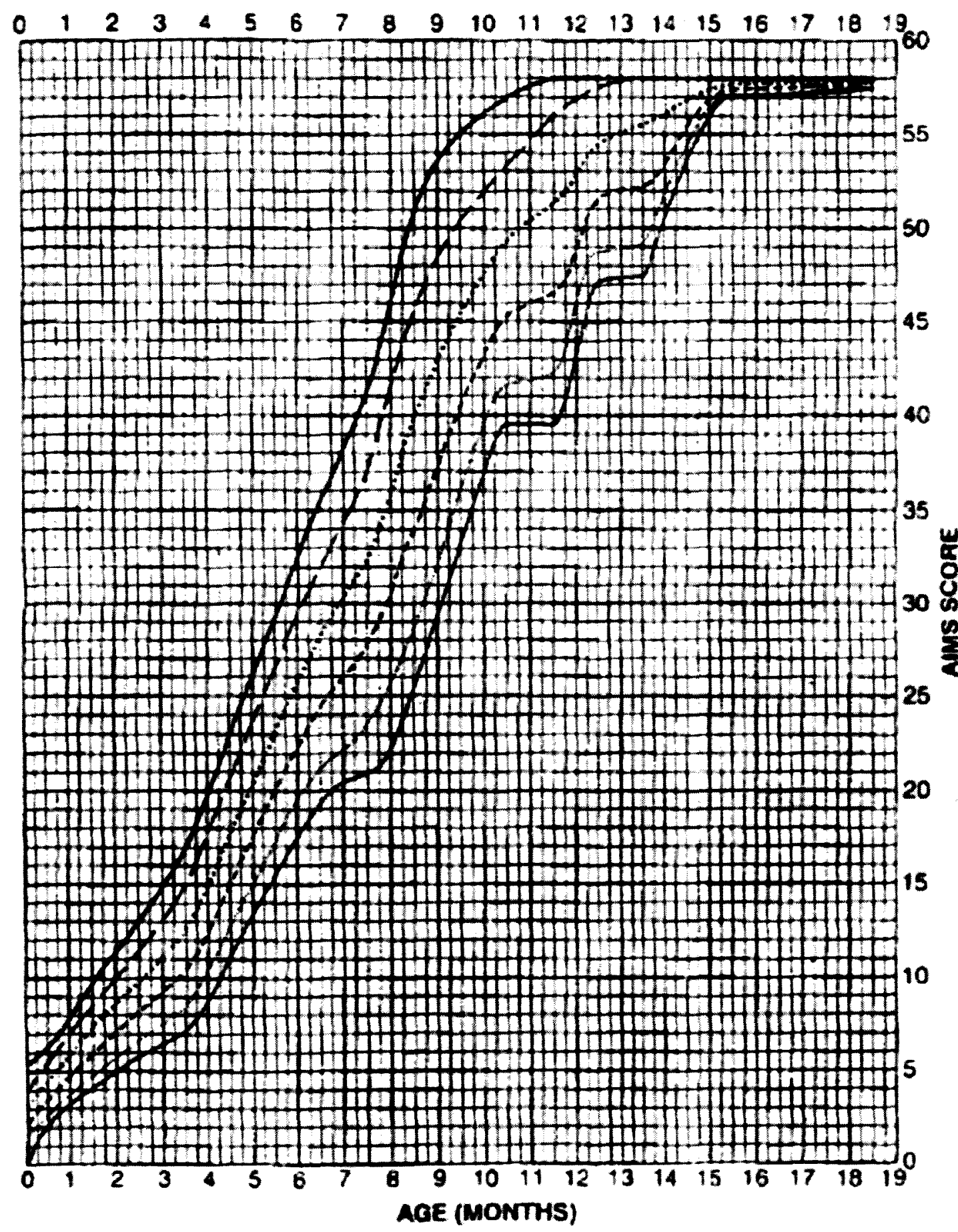




\title{
ANEXO 5: ARTIGO SUBMETIDO PARA PUBLICAÇÃO NA REVISTA "EUROPEAN JOURNAL OF MEDICAL RESEARCH"
}

\section{Motor Development of Infants Exposed to HIV in Brazil}

\author{
Dafne Herrero ${ }^{1}$, Luiz Carlos de Abreu ${ }^{1,2}$
}

1. Programa de Pós-graduação em Saúde Pública. Área de concentração: Saúde, Ciclos de Vida e Sociedade da Faculdade de Saúde Pública da USP.

2. Laboratório de Escrita Científica do Departamento de Morfologia e Fisiologia, Faculdade de Medicina do ABC.

Corresponding author: dafneh@uol.com.br

\section{Abstract}

Background: To assess the motor development of infants exposed to maternal human immunodeficiency virus (HIV).

Methods: 30 infants were assessed in the period from November 2009 to March 2010 at the AIDS Reference and Training Center, in São Paulo, Brazil. The assessment instrument used in the research was the Alberta Infant Motor Scale (AIMS). All 30 infants used the antiretroviral drug properly for 42 consecutive days, in accordance with the protocol of the World Health Organization.

Results: Out of the total number of infants 27 (90\%) had proper motor performance and $3(10 \%)$ presented motor delay, according to the AIMS.

Discussion: This work demonstrated that only $10 \%$ of the assessed group had developmental delay and no relation with environmental variables was detected, such as maternal level of education, social and economic issues, maternal practices, attendance at the day care center, and drug use during pregnancy. It is important to emphasize the necessity of studies with a larger number of participants.

Key words: motor development, assessment, HIVIAIDS, early intervention, physiotherapy. 


\section{Introduction}

Motor development has been discussed and more intensively dealt with since the 70's. Theories try to explain whether the main influence on its progress is the biological maturation or the environmental experience ${ }^{1}$, taking into account the importance of the initial bond of the infant with the reference caregiver $^{2}$, and the factors that may cause cultural and clinical interference ${ }^{3}$.

The study of development provides us with information on the direction of its progress, the expected sequence, the changes of common behavior, the search for improvement of action, and knowledge about motor acquisition milestones ${ }^{4}$. The latter makes it possible for the parents themselves, caregivers or the follow-up health team to identify the motor delay ${ }^{4-6}$.

As to the group of the main genetic and environmental issues that interfere in the child development, it is known that the causes of morbidity related to pregnancy and labor appear more intensively in the first week ${ }^{7}$. During the neonatal period, however, the environmental causes start to appear more frequently in the statistics, expressed mainly through infections ${ }^{8}$. Neonatal anoxia, low birth weight, neonatal tetanus, and intrauterine infections ${ }^{7}$, such as Aids, are among the main causes of morbidity and mortality of infants.

Acquired immune deficiency syndrome (Aids) is a progressive disorder of the immune system characterized by selective destruction of CD4 T cells by the human immunodeficiency virus (HIV) ${ }^{9}$.

Until the end of the 80's, it was believed that the infection through the Human Immunodeficiency Virus - HIV and the consequent Acquired Immune Deficiency Syndrome - AIDS, was limited to a specific group of people. However, in this same decade, the first cases of children with this diagnosis were reported, making such infection one of the biggest problems of public health not only in Brazil but in the whole world.

In developing countries, mainly Latin America countries, HIV infections spread more intensively among women, which consequently increased the vertical transmission rate, that is, the percentage of infections from mother to 
child. In Brazil, more specifically in 1985, the first case of a child with HIV was reported by the Ministry of ${ }^{10-12}$. Currently 30 thousand new cases of AIDS appear every year in Brazil and the Vertical Transmission account for $80 \%-90 \%$ of the cases of HIV in children ${ }^{13,14}$.

There are more vulnerable groups in the population. In order to identify such groups, social, political and institutional, and behavioral aspects are taken into account. These are analyzed together with individual aspects and specific conditions (Matida, 2010) ${ }^{15}$. The transmission rate in developing countries remains increased due to factors such as difficulty of diagnosis during pregnancy, failure to follow the antiretroviral therapy or the prophylaxis, and failure to total replacement of the breastmilk with infant formula ${ }^{16,17,40}$. It should be noted that in $1999,39 \%$ of the infants of a mother with confirmed diagnosis were still breastfed and Silva et al, (2001) ${ }^{18}$ say that in a study conducted with two groups of infected and non-infected infants breastfeeding appears as an additional risk of postnatal transmission. Ivers et al suggest, in their study, that breast milk substitution was safe, acceptable and feasible for HIV-infected women choosing this option ${ }^{41}$.

This vertical or mother-to-child transmission may occur during the intrauterine life, labor, postpartum, mainly during breastfeeding ${ }^{18}$. Statistics show that approximately $65 \%$ of the cases occur during labor, $35 \%$ occur during the intrauterine period, mainly in the last weeks of pregnancy, and breastfeeding represents an additional risk of transmission of $7 \%$ to $22 \%{ }^{19,40}$. Yoshimoto, $(2005)^{13}$ also says that the transmission occurs mainly during labor and emphasizes that $70 \%-90 \%$ of the cases are characterized by the late appearance of symptoms in children and adolescents.

Currently, there are investigations on the biochemical changes that may occur in infants born to HIV-infected mothers that use antiretroviral drugs in order to prevent vertical infection, from mother to child. Among the infected infants and children there may be manifestations such as weight-height deficit (clinical finding in $69.5 \%$ of the cases before one year of age), anemia, 
hypochromia (paleness due to deficiency of hemoglobin), macrocytosis (increase of the size of the red blood cells), atypical lymphocytes, lymphopenia (reduction in the number of lymphocytes), and mononucleosis (increase of the number of monocytes) (Smith et al, 2000) ${ }^{20}$. However, the action of the medication on the development and growth of exposed children is still controversial and more research is needed in order to determine what the real risks and benefits are. Therefore, the aim of this study is to verify the motor characteristics of non-infected children born to mothers with medical diagnosis of Aids and that went through antiretroviral treatment. 


\section{Methods}

\section{Study Population}

The research was carried out after approval by the Independent Ethics Committee of the AIDS Reference and Training Center and by the Ethics Committee of the Public Health College of USP, in accordance with the rules governing research on human beings of Resolution No. 196/96 and No. 251/97 of the National Health Council.

The aims of the research as well as the procedures were previously explained to all parents or legal representatives. The research was conducted only after the consent forms were obtained from those responsible.

It was a cross-sectional study conducted in an outpatient clinic specialized in assisting patients with HIVIAids, from November 2009 to March 2010.

\section{Infant profile}

30 full term newborns were assessed with age between 20 days and 18 months, out of which 19 were male and 11 were female. Most of them, 25, were born by cesarean section and 5 were born by normal delivery (the latter being contraindicated in cases of infected mothers). At the moment of assessment, the viral load of the assessed infants was undetectable. They were using or had already made use of the antiretroviral for 42 days after birth (AZT, oral route). The medication received by mothers during pregnancy was the combination of three of the following antiretroviral drugs: tenofovir, neviparine, kaletra, biovir, ritonavir, atazanavir, and $A Z T$, depending on each patient and the acceptance of the combination of such drugs. Mothers who had already been diagnosed with Aids before pregnancy (10) were already using ARVs. Five out of the remaining (20) used the medication from the first quarter on, thirteen from the second quarter on, and two of them did not use it. 


\section{Assessment tools}

Initially, a structured questionnaire was used. It contained important information, such as gender, age, adhesion to the treatment with antiretroviral, number of people living in the same house, place where the infant remains at home, and use of drugs.

The Alberta Infant Motor Scale, an observational scale made by Piper and Darrah (1994) ${ }^{21}$ to assess the motor development of infants since their birth until they are 18 months old, was used to verify the motor development. Some of the objectives of such scale are: (1) to identify restrictions of the neuromotor development of infants; (2) to inform parents about the motor activities that the baby performs, the activities that the infant does not perform, and the activities that are being developed; (3) to analyze the motor development in a certain period of time or before and after hospitalization; (4) to measure the very small changes in the motor development which cannot be identified through more traditional methods; (5) to act as a research instrument in order to identify the effectiveness in stimulation programs for infants with motor disorders. After the questionnaire and tests were applied, data were verified through descriptive analysis. 


\section{Results}

The characteristics of patients and the results achieved are shown in table 1 , where it can be seen that out of the 30 infants assessed only $3(10 \%)$ had score below the 10th percentile and the remaining 27 (90\%) had the percentile expected for the age.

Table 1: Data obtained from the structured questionnaire and assessment through Alberta Scale.

\begin{tabular}{|c|c|c|c|c|c|c|c|}
\hline & $\begin{array}{l}\text { Maternal } \\
\text { Educatio } \\
\text { nal Level }\end{array}$ & $\begin{array}{c}* \\
\text { A to } \\
T\end{array}$ & $\stackrel{* *}{\text { PSH }}$ & $\begin{array}{l}\text { *** } \\
\text { PIH }\end{array}$ & $\begin{array}{l}\text { Day } \\
\text { Care } \\
\text { Center }\end{array}$ & $\begin{array}{l}\text { Use of } \\
\text { Drugs }\end{array}$ & $\begin{array}{l}\text { Result } \\
\text { AIMS }\end{array}$ \\
\hline 1 & $\begin{array}{l}\text { finished } \\
\text { college }\end{array}$ & $Y$ & 5 & floor & $\mathrm{Y}$ & $\bar{N}$ & Adequate \\
\hline 2 & $\begin{array}{l}\text { finished } \\
\text { college }\end{array}$ & $Y$ & 3 & cradle & $\mathbf{N}$ & $\mathbf{N}$ & Adequate \\
\hline 3 & $\begin{array}{l}\text { finished } \\
\text { high } \\
\text { school }\end{array}$ & $Y$ & 3 & floor & $\mathbf{N}$ & $\mathrm{N}$ & Adequate \\
\hline 4 & $\begin{array}{l}\text { finished } \\
\text { high } \\
\text { school }\end{array}$ & $Y$ & 9 & floor & $\bar{Y}$ & $N$ & Adequate \\
\hline 5 & $\begin{array}{l}\text { finished } \\
\text { high } \\
\text { school }\end{array}$ & $Y$ & 4 & floor & $\bar{Y}$ & $\mathbf{N}$ & Delay \\
\hline 6 & $\begin{array}{l}\text { finished } \\
\text { high } \\
\text { school }\end{array}$ & $Y$ & 3 & floor & $\mathbf{N}$ & $\mathbf{N}$ & Adequate \\
\hline 7 & $\begin{array}{l}\text { unfinished } \\
\text { high } \\
\text { school }\end{array}$ & $Y$ & 4 & cradle & $\mathbf{N}$ & $\mathrm{N}$ & Adequate \\
\hline 8 & $\begin{array}{c}\text { finished } \\
\text { high } \\
\text { school } \\
\end{array}$ & $Y$ & 4 & stroller & $\mathrm{N}$ & $\mathrm{N}$ & Adequate \\
\hline 9 & $\begin{array}{c}\text { unfinished } \\
\text { college } \\
\text { degree }\end{array}$ & $Y$ & 8 & stroller & $\mathrm{N}$ & $\mathrm{N}$ & Adequate \\
\hline 10 & $\begin{array}{l}\text { unfinished } \\
\text { college } \\
\text { degree }\end{array}$ & Y & 3 & stroller & $\mathrm{N}$ & $\mathbf{N}$ & Adequate \\
\hline
\end{tabular}




\begin{tabular}{|c|c|c|c|c|c|c|c|}
\hline 11 & $\begin{array}{l}\text { unfinished } \\
\text { high } \\
\text { school }\end{array}$ & $Y$ & 4 & floor & $N$ & $\mathrm{~N}$ & Adequate \\
\hline 12 & $\begin{array}{l}\text { unfinished } \\
\text { high } \\
\text { school }\end{array}$ & $Y$ & 7 & floor & $N$ & $N$ & Adequate \\
\hline 13 & $\begin{array}{l}\text { finished } \\
\text { college }\end{array}$ & $Y$ & 6 & floor & $\mathbf{N}$ & $\mathbf{N}$ & Delay \\
\hline 14 & $\begin{array}{l}\text { finished } \\
\text { high } \\
\text { school }\end{array}$ & $Y$ & 3 & floor & $N$ & $N$ & Adequate \\
\hline 15 & $\begin{array}{l}\text { finished } \\
\text { high } \\
\text { school }\end{array}$ & $Y$ & 6 & floor & $\mathbf{N}$ & $\mathrm{N}$ & Adequate \\
\hline 16 & $\begin{array}{l}\text { finished } \\
\text { high } \\
\text { school }\end{array}$ & $Y$ & 4 & floor & $N$ & $\mathbf{N}$ & Adequate \\
\hline 17 & $\begin{array}{l}\text { finished } \\
\text { college }\end{array}$ & $Y$ & 5 & stroller & $N$ & $N$ & Adequate \\
\hline 18 & $\begin{array}{l}\text { finished } \\
\text { high } \\
\text { school }\end{array}$ & $N$ & 5 & floor & $\mathbf{N}$ & $\bar{Y}$ & Adequate \\
\hline 19 & $\begin{array}{l}\text { finished } \\
\text { high } \\
\text { school }\end{array}$ & $Y$ & 3 & floor & $\bar{Y}$ & $\mathbf{N}$ & Adequate \\
\hline 20 & $\begin{array}{l}\text { unfinished } \\
\text { high } \\
\text { school }\end{array}$ & $Y$ & 4 & floor & $\mathrm{Y}$ & $\mathbf{N}$ & Adequate \\
\hline 21 & $\begin{array}{l}\text { finished } \\
\text { high } \\
\text { school } \\
\end{array}$ & $Y$ & 6 & bed & $\bar{Y}$ & $\mathrm{Y}$ & Adequate \\
\hline 22 & $\begin{array}{c}\text { finished } \\
\text { primary } \\
\text { school }\end{array}$ & $Y$ & 6 & bed & $\mathrm{Y}$ & $\mathrm{N}$ & Adequate \\
\hline 23 & $\begin{array}{c}\text { unfinished } \\
\text { primary } \\
\text { school }\end{array}$ & $Y$ & 6 & lap & $\mathrm{Y}$ & $\mathbf{N}$ & Delay \\
\hline 24 & $\begin{array}{c}\text { unfinished } \\
\text { primary } \\
\text { school }\end{array}$ & $Y$ & 6 & floor & $\bar{Y}$ & $\bar{N}$ & Adequate \\
\hline 25 & $\begin{array}{l}\text { did not } \\
\text { study }\end{array}$ & $\mathrm{N}$ & 3 & stroller & $N$ & $\bar{Y}$ & Adequate \\
\hline 26 & $\begin{array}{c}\text { finished } \\
\text { high }\end{array}$ & $Y$ & 2 & stroller & $\mathrm{N}$ & $N$ & Adequate \\
\hline
\end{tabular}




\begin{tabular}{|c|c|c|c|c|c|c|c|}
\hline & school & & & & & & \\
\hline 27 & $\begin{array}{c}\text { unfinished } \\
\text { college } \\
\text { degree }\end{array}$ & Y & 3 & stroller & $\mathbf{N}$ & $\mathbf{N}$ & Adequate \\
\hline 28 & $\begin{array}{l}\text { finished } \\
\text { high } \\
\text { school }\end{array}$ & Y & 5 & floor & $\mathbf{N}$ & $\mathbf{N}$ & Adequate \\
\hline 29 & $\begin{array}{l}\text { finished } \\
\text { primary } \\
\text { school }\end{array}$ & $\mathbf{Y}$ & 12 & lap & $\bar{N}$ & $\bar{Y}$ & Adequate \\
\hline 30 & $\begin{array}{l}\text { unfinished } \\
\text { high } \\
\text { school }\end{array}$ & Y & 4 & bed & $\mathbf{N}$ & $\mathbf{N}$ & Adequate \\
\hline
\end{tabular}

$\mathrm{Y}=$ yes, $\mathrm{N}=$ no, ${ }^{*} \mathrm{~A}$ to $\mathrm{T}=$ adhesion to treatment, ${ }^{* *} \mathrm{PSH}=$ people living in the same house as the infant, ${ }^{\star \star *} \mathrm{PIH}=$ place where the infant remains at home. 


\section{Discussion}

The population comprised of infected mothers and infants exposed to HIV during pregnancy and breastfeeding brings, in specific or global terms, certain demands that involve environmental and biological factors related to child development, which are considered harmful or facilitators of such process (Negrini, 2004) ${ }^{22}$.

Ribeiro and Beltrane $(2010)^{23}$ explain that biological risk factors can interfere in the neuromotor development, especially if there is a history risk at the age of up to 18 months. Pretti et al., $(2010)^{24}$, however, advocate that the environmental risk factors are the main harmful effects for motor development.

The mother-child relationship is considered a determining factor for full development of the child and family involvement in the care dedicated to the infant. Paiva et al., $(2010)^{25}$ show us that the non-verbal communication present in the situation of the mother with HIV and her child causes attachment to the infant and the possibility of identifying abnormalities in their development. The uncertainty of waiting for the serology results and the overprotection of their children are mentioned by Galvão et al., $(2010)^{26}$ as some of the dilemmas and conflicts present in the life of the infected mother.

Fernandes $(2010)^{16}$ demonstrates that, in Brazil, there was not a reduction of the mother-to-child HIV transmission rate in the period from 2004 to 2007 and characterized the following as determining obstacles of such nonreduction: the low coverage for anti-HIV testing during prenatal care, preventing treatment or efficient maternal prophylaxis; and the incorrect use of rapid testing in the admission for delivery. Although there is prenatal exposure to a drug, it is not possible to determine the immediate results in a child, but such exposure can be a marker for a number of variables that can have impact on development. Proper intervention strategies require investigations to determine which factors that expose children to the risk and protect the ideal development ${ }^{27,40}$. 
Ribeiro and Beltrane, $(2010)^{23}$ mention that children with biological risk history may have some impairment regarding development aspects. According to Jelsma et al., (2011) ${ }^{28}$ children with HIV were significantly delayed when compared to their HIV negative counterparts. Attention, motor function, and executive function were particularly compromised among individuals with $\mathrm{HIV}^{29}$.

In the data shown in this study, it was identified that only $3(10 \%)$ out of the 30 infants presented delay in the assessment instrument used and the influence of the use of antiretroviral was not detected. That is, the prophylactic use of antiretrovirals at the periods pointed as the most suitable is one of the best strategies for preventing Aids in childhood ${ }^{30,31}$ and probably it does not imply delays in motor development. Yoshimoto, 2005 suggests that the prophylaxis with AZT in all recommended periods and long term follow-up of infants born to HIV positive mothers constitutes one of the best strategies for preventing Aids in childhood.

The use of drug associated to the stimulus received at home, at the day care center, or places attended by the infant are the allies to prevent delay in motor and full development. The environmental factors were also assessed and are discussed below

a) maternal educational level: according to Haidar et al., $(2001)^{32}$, the maternal educational level can be considered an obstetric marker of risk for the mother and the newborn. Knowing the maternal perceptions about Aids can provide health professionals with more understanding about their behavior. The group also demonstrates that the educational level is related to nutritional matters. Infant formula is offered to replace breastmilk in order to prevent Vertical Transmission ${ }^{26}$. However, information and family participation are fundamental. Machado, $(2010)^{30}$ mentions that it is important to investigate the vulnerability to possible infant food deficit and probably issues such as proper information to mothers, understanding the guidance provided by health professionals, care when preparing the formula, access in the quantity indicated by the Ministry of Health, and availability at the points of delivery are factors that 
contribute to make proper nutrition difficult. In this study, the maternal educational level was investigated. The three infants with developmental delay had mothers with different educational levels and such fact which does not justify any relationship.

b) social and economic issues: unemployment, poverty, difficult access to health services and education, and the number of people living in the house are factors that may contribute to characterize economic difficulties. Barcellos et al., $(2009)^{33}$ mention that urban poverty represents a strong conditioning factor for vertical transmission of HIV. However, the action of health surveillance services in association with the basic attention can overcome this tendency. In Brazil, it is necessary to have prevention strategies and health promotion, taking into account the social context of the families living with HIVIAids ${ }^{30}$ During the investigations of these factors, the possibility of any relationship between social and economic issues and the three infants with developmental delay (Table 1) was not detected either.

c) maternal practices and attendance at the day care center: maternal practices can influence the progress of infant development, for example, the position in which the infant stays during the day ${ }^{3}$ and these practices change according to the local culture ${ }^{34-37}$. North-American infants stay more in prone, the British in supine, the Africans are encouraged to sit and walk early, the Mexicans stay much time on the lap, and the Brazilians stay more in supine than in prone ${ }^{3}$. Mei, $(1994)^{37}$ demonstrates that behavioral manifestations observed in infants in the North of China lead to a restriction of child mobility causing interference in motor development. The act of attending a day care center should also be taken into account in the infant development. Identifying whether the infant goes to a day care center provides information on how stimulated he/she is. According to Rezende et al., $(2010)^{38}$, infants improve their motor development after they start to attend the day care center and Amorim et al., $(2010)^{39}$ show us that the non-participation in a day care center associated to the decrease of the time spent with the mother are linked to the delay in motor 
development. By analyzing the results of this study, questions related to the most frequent position of the infant at home and whether the infant spends certain time at the day care center enabled different answers and it was not possible to detect any relationship.

d) use of drugs: in the study conducted by Negrini, (2004) ${ }^{22}$ and Eyler et al., (1999) ${ }^{27}$ it was observed that there may impairment in the development of infants whose mothers use drugs during pregnancy. They add that such fact can be an opening for the appearance of more factors of risk to the development. The use of drugs by at least one family member of the assessed infants appeared in seven out of the 30 assessments. However, there was no delay in the motor development of these infants, according to the Alberta Scale.

Although environmental influence is crucial to the development of the infant, it is important to emphasize that some of these factors were verified in this work, but the number of individuals with delay did not enable any correlation test. In the descriptive analysis, there was not any possible inference relationship between the assessed environmental factors, maternal educational level, social and economic issues, maternal practices, attendance at day care center, and the use of drugs with the delay in development. 


\section{Conclusion}

This study aimed to verify the motor characteristics of infants born to mothers with medical diagnosis of Aids and that had gone through antiretroviral treatment. Out of the 30 infants assessed through Alberta Infant Motor Scale three $(10 \%)$ had delay in motor development. It was not possible to verify the influence in the development delay of the assessed group based on the environmental variables assessed (maternal level of education, social and economic issues, maternal practices, attendance at the day care center, and use of drugs).

\section{Acknowledgments}

The authors received the financial support from Public Health College of Universidade de São Paulo and thank those who contributed substantially to its completion. 


\section{REFERENCES}

1. Manoel EJ. Desenvolvimento Motor: padrões em mudança, complexidade crescente. Rev Paul Educ Fis. 2000; 3: 35-54.

2. Brum EHM, Scherman L. Vínculos iniciais e desenvolvimento infantil: abordagem teórica em situação de nascimento de risco. Ciência e saúde coletiva. $2004 ; 9(2)$ : 457-467.

3. Silva PL, Santos DCC, Gonçalves VMG. Influência de práticas maternas no desenvolvimento motor de lactentes do $6^{\circ}$ ao $12^{\circ}$ meses de vida. Rev Bras fisioter. 2006; 10(2): 225-231.

4. Flehmig I. Desenvolvimento normal e seus desvios no lactente. São Paulo: Livraria Atheneu, 2000. p.09-45. (v.1)

5. Brazelton TB. Momentos decisivos do desenvolvimento infantil. São Paulo: Martins Fonseca, 1994. 339p. (v.1)

6. Tecklin JS. Fisioterapia Pediátrica. Porto Alegre: Artmed, 2002. 570p.

7. Rouquayrol MZ. Epidemiologia e Saúde. Rio de Janeiro: MEDSI, 2003. 527p.

8. Marcondes E. Fatores ambientais do crescimento da criança. Rev Bras de Cresc e Desenvolv Hum. 1991; 1(1): 15-43.

9. Al-Khindi $T$, Zakzanis KK, van Gorp WG. Does antiretroviral therapy improve HIV-associated cognitive impairment? A quantitative review of the literature. J Int Neuropsychol Soc. 2011;17(6):956-969. DOI: http://dx.doi.org/10.1017/S1355617711000968

10. Maturana AP, Rizzo CV, Vasquez DF, Cavalheiro N, Holzer S, Morais VS. Avaliação da assistência ao parto em gestantes infectadas pelo HIV. Arq Med ABC. 2007;32(1):11-16.

11. Newell ML. Reducing childhood mortality in poor countries. Transactions of The Royal Society of Tropical Medicine and Hygiene. 2003;97:22-4.DOI: http://dx.doi.org/10.1016/S0035-9203(03)90008-3

12. Moodley D, Moodley J. HIV-1 infection: an indication for caesarean section? International Journal of Obstetric Anesthesia. 2000;9:221-4. 
13. Yoshimoto CE, Diniz EMA, Vaz FAC. Evolução clínica e laboratorial de recém-nascidos de mães HIV positivas. Rev Assoc Med Bras. 2005; 51(2): 100105.

14. UNAids. A ONU e a resposta à Aids no Brasil. Joint United Nations Programme on Hiv/Aids, 2008. 32p.

15. Matida LH. Transmissão do HIV, da Sífilis e da Hepatite B no estado de São Paulo. Instituto de Saúde. São Paulo, 2010, p.203.

16. Fernandes RCSC, Ribas GF, Pires SD, Gomes AM, Medina AE. Desafios operacionais persistentes determinam a não redução da transmissão maternoinfantil do HIV. J Pediatr. 2010; 86(6): 503-508.

17. Matida LH, Ramos Jr NA, Moncau JEC, Marcopito LF, Marques HHS, Succi RMC, et al. Aids por transmissão vertical: análise de sobrevivência dos casos acompanhados entre 1983 e 2002 nas diferentes regiões do Brasil. Cad Saúde Pública. 2007; 23(3):435-444.

18. Silva EB, Grotto HZW, Vilela MM. Aspectos clínicos e o hemograma em crianças expostas ao HIV-1: comparação entre pacientes infectados e sororeversores. Jornal de Pediatria. 2001; 77(6): 503-511.

19. Brito AM, Sousa JL, Luna CF, Dourado I. Tendência da transmissão vertical de Aids após terapia anti-retroviral no Brasil. Rev Saúde Pública. 2006;4:18-22.

20. Smith R, Malee K, Charurat M, Magder L, Mellins C, Macmillan C, Hittleman J, Lasky T, Llorente A, Moye J. Timing of perinatal human immunodeficiency virus type 1 infection and rate of neurodevelopment. The Women and Infant Transmission Study Group. Pediatr Infect Dis J. 2000 Sep;19(9):862-71.

21. Piper MC, Darrah J. Alberta Infant Motor Scale. Philadelphia: WB Sauders; 1994.

22. Negrini SFBM. Estudo do desenvolvimento neuropsicomotor de crianças filhas de mães soropositivas para o HIV no município de Ribeirão Preto, SP. (Mestrado em Medicina), 2004.

23. Ribeiro J, Beltrame TS. Características neuromotoras e biopsicossocias de lactentes com histórico de risco biológico. Fisioter mov. 2010; 23(1): 25-34.

24. Pretti LC, Milan JC, Foschiani MA, Raniero EP, Pereira K. Caracterização dos fatores ambientais e o controle cervical de lactentes nascidos pré-termo. Fisioter mov. 2010; 23(2): 239-250. 
25. Paiva SS, Galvão MTG, Pagliuca LMF, Almeida PC. Comunicação nãoverbal mãe/filho na vigência do HIV materno em ambiente experimental. Rev Latino-Am Enfermagem. 2010; 18(1): 41-47.

26. Galvão MTG, Cunha GH, Machado MMT. Dilemas e conflitos de ser mãe na vigência do HIVIAids. Rev Bras Enferm. 2010; 63(3): 371-376.

27. Eyler FD, Behnke M. Early development of infants exposed to drugs prenatally. Clin Perinatol. 1999; 26(1):107-50.

28. Jelsma J, Davids N, Ferguson G. The motor development of orphaned children with and without HIV: Pilot exploration of foster care and residential placement. BMC Pediatr. 2011;11:11. DOI: 10.1186/1471-2431-11-11.

29. Reger M, Welsh R, Razani J, Martin DJ, Boone KB. A meta-analysis of the neuropsychological sequelae of HIV infection. Journal of the International Neuropsychological Society. 2002; 8: 410-424. DOI: http://dx.doi.org/10.1017/S1355617702813212.

30. Machado MMT, Galvão MTG, Lindsay AC, Cunha AJLA, Leite AJM, Leite $\mathrm{RD}$, et al. Condições sociodemográficas de crianças de zero a dois anos filhas de mães com HIVIAids, Fortaleza, CE, Brasil. Rev Bras Saúde Mater Infant. 2010; 10(3): 377-382.

31. Culnane M, Fowler MG, Lee SS, McSherry G, Brady M, O'Donell K, et al. Lack of long-term effects of in utero exposure to zidovudine among uninfected children born to HIV-infected women. JAMA. 1999, 281:151-7.

32. Haidar FH, Oliveira UF, Nascimento LFC. Escolaridade materna: correlação com os indicadores obstétricos. Cad. Saúde Pública. 2001; 17(4): 1025-1029.

33. Barcellos C, Acosta LMW, Lisboa E, Bastos FI. Vigilância da transmissão vertical do HIV: indicadores socioeconômicos e de cobertura de atenção à saúde. Rev Saúde Pública. 2009; 43(6): 1006-1014.

34. De Vries MW. Babies brain and culture: optimizing neurodevelopment on the savanna. Acta Pediatric Suppl. 1999; 429:43-48. DOI: 10.1111/j.16512227.1999.tb01289.x.

35. Santos DCC. Desenvolvimento motor durante o primeiro ano de vida: uma comparação entre um grupo de lactentes brasileiros e americanos. [Doutorado] Campinas (SP): Universidade Estadual de Campinas; 2001. 
36. Capute AJ. Normal gross motor development: the influences of races, sex and socio- economic status. Dev Med Child Neurol. 1985; 27: 635-643. DOI: 10.1111/j.1469-8749.1985.tb14136.x.

37. Mei J. The northern chinese custom of rearing babies in sandbags. In Van Rossum JHA, Laszlo Jl. Motor Development: aspects of normal and delayed development. Amsterdã. VU University Press; 1994.

38. Rezende MA, Beteli VC, Santos JLF. Follow-up of the child's motor abilities in day-care centers and pre-schools. Rev Latino-Am Enfermagem. 2010; 13(5): 619-625.

39. Amorim RCA, Laurentino GEC, Barros KMFT, Ferreira ALPR, Filho AGM, Raposo MCF. Programa de saúde da família: proposta para identificação de fatores de risco para o desenvolvimento neuropsicomotor. Rev Bras Fisioterapia. 2010; 13(6): 506-513.

40. Hermanides HS, Vught LA, Voigt R, Muskiet FD, Durand A, Osch GV, Wever SK, Gerstenbluth I, Smit C, Duits AJ. Developing quality indicators for the care of HIV-infected pregnant women in the Dutch Caribbean. AIDS Research and Therapy 2011, 8:32. DOI:10.1186/1742-6405-8-32.

41. Ivers LC, Appleton SC, Wang B, Jerome JG, Cullen KA, Smith Fawzi MC. HIV-free survival and morbidity among formula-fed infants in a prevention of mother-to-child transmission of HIV program in rural Haiti. AIDS Res Ther. 2011 Oct 12;8(1):37. DOI: 10.1186/1742-6405-8-37. 


\title{
ANEXO 6: ARTIGO SUBMETIDO PARA PUBLICAÇÃO NA REVISTA "INTERNATIONAL BREASTFEEDING JOURNAL"
}

\section{Brazilian and international guidance on breastfeeding for infants of hiv- infected mothers \\ D Herrero ${ }^{1}$, SR Souza ${ }^{2}$, CBM Monteiro ${ }^{3}$, MT Blake $^{4}$, DV Bertolini $^{5}$, LC Abreu ${ }^{6}$}

\begin{abstract}
1, 2, 3, 6 Programa de Pós-graduação em Saúde Pública. Área de concentração: Saúde, Ciclos de Vida e Sociedade da Faculdade de Saúde Pública da USP

${ }^{4}$ Laboratório de Escrita Científica, Faculdade de Medicina do ABC

${ }^{5}$ Centro de Referência e Treinamento em DSTIAIDS - Programa Estadual de São Paulo DST/Aids - Programa Municipal de SP
\end{abstract}

Corresponding author: dafneh@uol.com.br

\section{ABSTRACT}

INTRODUCTION: the moment of breastfeeding becomes one of the first contacts between mother and infant. Breastfeeding in infants of mothers living with AIDS is oriented divergently from the United Nations Children's Fund (UNICEF) and the Ministry of Health of Brazil, regarding the current information provided by the World Health Organization. OBJECTIVE: To describe adopted practices in the process of breastfeeding for infants exposed to vertical transmission of HIV. METHODS: A search has been conducted for articles and materials on breastfeeding in infants exposed to HIV. Information has been collected from Medline, Lilacs, Cochrane Library databases, and direct research in guidebooks distributed in the health services in Brazil. The keywords used were: breastfeeding, AIDS, monitoring maternal-infant health. RESULTS: the information collected indicates that breastfeeding can contribute effectively to the vertical transmission depending on the conduct adopted in relation to the use of antiretroviral therapy, length of medication and level of maternal viral load. CONCLUSION: it will be up to the health professionals involved and the government policy adopted the direction to be followed on the issue of breastfeeding for neonates and infants exposed to vertical HIV transmission. 
Keywords: breastfeeding, child development., AIDS, vertical transmission of infectious disease, infant.

\section{INTRODUCTION}

From the moment that a mother brings the newborn baby close to her breast for the very first time, she will instinctively know that the loving messages that come along with breastfeeding are so important to the well-being, as the milk itself. Without these messages, the food would not be enough to stimulate the child emotional and even physical development ${ }^{1}$. The timing of breastfeeding becomes one of the first contacts between mother and infant, strengthening the bond started during pregnancy. According to Brazelton, child development ends up depending heavily of this connection.

In the cases of mothers living with AIDS, such practice is guided not to occur by UNICEF and the Ministry of Health of Brazil. And the current orientation of World Health Organisation ${ }^{2}$ is having exclusive breastfeeding until six months of life with the use of antiretroviral therapy for mother and infant.

This lack of mother-infant contact involves essentially important issues concerning AIDS and the family relationship, such as: bond formation, the practical and nutritional issue guaranteed by the offering of maternal milk, social deprivation not to share this moment in public nappy-changing facilities and the self-realization of the mother to continue serving the infant nutritionally beyond the nine months of pregnancy.

Additionally, it is worth mentioning the growing concern about the increasing rate of HIVIAIDS infection among women, which is called phenomenon of "feminisation"10, having the representation of this group been highlighted in recent years and appears as one of the focuses of the current study. 
Specifically in 1985 it was reported the first case of HIV in children by the Ministry of Health ${ }^{3,4.5}$. Over the recent years there has been no significant increase in mortality due to the prevention and combating of the virus. According to the São Paulo State Secretary of Health.-Brazil ${ }^{6}$, considering data from SEADE - Foundation State System of Data Analysis, the transmission of AIDS in São Paulo state decreased by $64.4 \%$ in the last decade.

Aiming at gathering information on the subject matter, breastfeeding and AIDS, the current study has the objective to describe conducts adopted in the process of breastfeeding for infants exposed to HIV vertical transmission. 


\section{METHODS}

It is a manuscript in the form of data synthesis. Major international databases have been searched: Medical Literature Analysis and Retrieval System Online (Medline), Latin American and Caribbean Health Sciences (Lilacs), Scientific Electronic Library Online (Scielo), Cochrane Library and direct research has been made in guide books distributed by the health service in Brazil.

The search has covered the years 1994 to 2011, using the keywords: breastfeeding, AIDS, monitoring of infants and maternal and child health. These descriptors (DECs) were investigated in the Virtual Health Library (Biblioteca Virtual em Saúde - BVS) of the Regional Library of Medicine (Biblioteca Regional de Medicina - BIREME).

As inclusion criteria were considered: the representativity of the samples, scientific journals, objective answered in the conclusion, clarity of the data provided and references for guidelines. 


\section{RESULTS}

The articles and chapters gathered together to compose this article follow in the table below, describing brief summaries of the topics addressed by the mentioned authors.

\begin{tabular}{|c|c|}
\hline The Petra $^{16}$ & $\begin{array}{l}\text { Experimental results provide strong evidence that } \\
\text { during childbirth and postpartum, ARV ZDV/3TC and } \\
\text { NVP early prophylaxis can reduce substantially the VT } \\
\text { of HIV among populations who breastfeed. }\end{array}$ \\
\hline Nolan $M$ L et al ${ }^{17}$ & $\begin{array}{l}\text { The substantial decrease in maternal viral load and / or } \\
\text { changes in viral load in breast milk may decrease the } \\
\text { risk of transmission during breastfeeding. }\end{array}$ \\
\hline Bulterys $\mathrm{M}$ et $\mathrm{al}^{18}$ & $\begin{array}{l}\text { The prolonged breastfeeding contributes substantially } \\
\text { to the HIV-1 transmission, even in the presence of an } \\
\text { effective early intervention with intensive counseling } \\
\text { and continuous support by the research team. }\end{array}$ \\
\hline Miotti PG et al ${ }^{19}$ & $\begin{array}{l}\text { Suggest that without antiretroviral drugs the rate of } \\
\text { transmission attributable to breastfeeding is higher in } \\
\text { the first weeks after birth and, then, declines at a } \\
\text { constantly low or regressive rate. }\end{array}$ \\
\hline Leroy $V$ et $\left.a\right|^{20}$ & $\begin{array}{l}\text { There is an important finding of a strong relationship } \\
\text { between maternal disease stage and viral load in } \\
\text { breast milk. }\end{array}$ \\
\hline Embree JE et $\mathrm{al}^{21}$ & $\begin{array}{l}\text { High power antiretroviral therapy allows the continued } \\
\text { promotion and support for the practice of breastfeeding } \\
\text { for all women (including the majority of women infected } \\
\text { with HIV and reduces morbidity and mortality. }\end{array}$ \\
\hline $\mathrm{WHO}{ }^{22}$ & $\begin{array}{l}\text { All women who choose to breastfeed should be } \\
\text { encouraged to breastfeed exclusively for the first six } \\
\text { months of the infant life. Since the study results } \\
\text { suggest that breastfeeding should occur in a guided } \\
\text { way and with effective antiretroviral intervention to } \\
\text { reduce VT and promote the survival of the infant. }\end{array}$ \\
\hline Jones et $\mathrm{al}^{23}$ & $\begin{array}{l}\text { According to the Division of Policy and Planning of } \\
\text { UNICEF, the interventions needed to achieve the } \\
\text { millennium development goal of reducing child mortality } \\
\text { by two thirds by } 2015 \text { are available but are not being } \\
\text { provided to the mothers and children who need them. }\end{array}$ \\
\hline Brito et $\mathrm{al}^{8}$ & $\begin{array}{l}\text { Suggest a favorable response to the implementation of } \\
\text { intervention policies for the prevention of vertical } \\
\text { transmission of HIV in Brazil, as it occurred in other }\end{array}$ \\
\hline
\end{tabular}




\begin{tabular}{|c|c|}
\hline & parts of the world. \\
\hline Matida et $\mathrm{al}^{24}$ & $\begin{array}{l}\text { This Brazilian analysis shows to be possible for a } \\
\text { developing country to establish an effective system of } \\
\text { free and universal access to antiretroviral therapy, even } \\
\text { with regional difficulties for the organization of an ideal } \\
\text { infrastructure for health, resulting in a significant } \\
\text { increase in survival. }\end{array}$ \\
\hline Brazelton $^{1}$ & $\begin{array}{l}\text { If food is fundamental to survival, the infant's future } \\
\text { quality of life also depends on the affection that he } \\
\text { receives from parents along with the food. }\end{array}$ \\
\hline $\begin{array}{l}\text { Ministério da Saúde } \\
\text { do Brasil }^{15}\end{array}$ & $\begin{array}{l}\text { Current rates and guidance regarding breastfeeding } \\
\text { being contraindicated in cases of maternal HIV. }\end{array}$ \\
\hline $\begin{array}{l}\text { Organização Mundial } \\
\text { da Saúde }\end{array}$ & $\begin{array}{l}\text { Current rates and information on breastfeeding and } \\
\text { HIV }\end{array}$ \\
\hline $\mathrm{UNICEF}^{13}$ & $\begin{array}{l}\text { Current rates and information on breastfeeding and } \\
\text { HIV }\end{array}$ \\
\hline $\begin{array}{l}\text { Maturana et } \mathrm{al}^{3} \text {, } \\
\text { Moodley }\end{array}$ & $\begin{array}{l}\text { The first reported case of AIDS in Brazil was in } 1985 \\
\text { and that, according to the Ministry of Health of Brazil, } \\
\text { the period between } 1980 \text { and } 2006 \text { the route of vertical } \\
\text { transmission was responsible for } 78.1 \% \text { of cases in } \\
\text { children of less than } 13 \text { years. }\end{array}$ \\
\hline Newell $^{4}$ & $\begin{array}{l}\text { The persistence of high rates of perinatal and neonatal } \\
\text { mortality in many developing countries reinforces the } \\
\text { need to improve perinatal care in homes and major } \\
\text { local public health centers. }\end{array}$ \\
\hline Silva et al $^{7}$ & $\begin{array}{l}\text { The clinical and hematological aspects of children } \\
\text { exposed to vertical transmission of HIV-1 and } \\
\text { comparison between the infected and the } \\
\text { seroreverting children. }\end{array}$ \\
\hline Herdy et $\mathrm{al}^{9}$ & $\begin{array}{l}\text { The HIV-infected child who receives a combination of } \\
\text { antiretroviral drugs has better progress than those } \\
\text { receiving isolated medication. }\end{array}$ \\
\hline Veloso et $\mathrm{al}^{10}$ & $\begin{array}{l}\text { The intimate relationship between prevention of vertical } \\
\text { transmission of HIV and prenatal and childbirth care } \\
\text { requires joint action to be implemented by STD/AIDS } \\
\text { and Women's Health programs at the federal, state and } \\
\text { municipal levels. }\end{array}$ \\
\hline Marques et $\mathrm{al}^{11}$ & $\begin{array}{l}\text { It is suggested a routine of clinical-laboratory } \\
\text { monitoring during the first } 18 \text { months and then annually } \\
\text { until the end of adolescence. }\end{array}$ \\
\hline
\end{tabular}




\section{DISCUSSION}

HIV infection in developing countries, especially in the Latin American countries, spreads more strongly among women, a process called "feminization" of the epidemic ${ }^{12}$ and, consequently, leads to an increased possibility of cases of vertical transmission from mother to child.

The Vertical Transmission (VT) or maternal-infant may occur during intrauterine life, at birth, and in the postpartum through breastfeeding ${ }^{7}$, current focus of this review. Statistics indicate that about $65 \%$ of the cases of vertical transmission occur during labor and childbirth itself, 35\% occur in the womb, especially during the last weeks of pregnancy and breastfeeding represents an additional risk of transmission of $7 \%$ to $22 \%^{8}$.

In Brazil, approximately $90 \%$ of children living with AIDS were vertically infected $^{9}$. This type of contamination presents bimodal clinical course, early, with a median age of onset of symptoms at four months and later, at age six. It is estimated that $20 \%$ of infants in the absence of effective antiretroviral therapy have early progression of the disease.

Considering the growth of the epidemic in the female population, and, consequently, the possibility of increasing the rate of vertical transmission, the Ministry of Health of Brazil published in 1995, specific regulations on the prevention of vertical transmission, establishing it as a priority by the STD and AIDS National Program ${ }^{10}$. After the publication of the regulation, the state of São Paulo has created the first adaptations for the implementation of Protocol ACTG-076.

However, the use of injectable AZT as an indicator of this prophylactic practice implementation, demonstrated that this procedure was performed with only $40 \%$ of HIV positive pregnant women expected for the year $1998^{11}$. Such fact has occurred because of a protocol implementation problem in the institutions. 
Aiming at the strengthening of this control action, another strategy to assess the implementation of the vertical HIV transmission prophylaxis protocol was the inclusion of monitoring the HIV positive pregnants and children exposed to diseases of compulsory notification since 2000 (Ordinance MS $\mathrm{Nr}$. 993/2000) ${ }^{8}$.

After the implementation of these epidemiological measures and the supply of milk (infant formula), it was observed a decrease of about $70 \%$ of cases of vertical transmission ${ }^{9}$. Significant changes in the clinical prognosis of the children were also observed decreasing the index of morbidity and mortality by opportunistic infections.

Given the number of children living or cohabiting with HIV, the issue of breastfeeding has been receiving attention and new guidelines since December 2009.

According to $\mathrm{WHO}^{2}$, the new guidelines to improve health and save lives have recommended, for the first time, breastfeeding for infants of mothers with AIDS to make use of antiretroviral therapy during breastfeeding to prevent vertical transmission. This guidance is directed primarily to places where there is no distribution of infant formula and the possibility of death due to malnutrition or diarrhea is very high.

"These new recommendations are based on the most current data available," said Hiroki Nakatani, Assistant General Director for HIV / AIDS, tuberculosis, malaria and neglected tropical diseases in the World Health Organization "The widespread adoption will help more people in areas with a high incidence of the virus have long and healthy lives ", adds Nakatani.

Among the new guidelines is the use of antiretroviral therapy earlier in pregnancy from the 14 th week until the end of breastfeeding ${ }^{2}$.

The breastfeeding time is raised until the infant complete 12 months of age under the condition that both are on antiretroviral therapy. According to WHO surveys, this process will reduce the risk of HIV transmission and improve the infant's chance of survival. 
"In the new recommendations, we are sending a clear message that breastfeeding is a good option for the baby, even those with HIV positive mothers, when they have access to antiretroviral drugs," said Daisy Mafubelu, general director of Family and Community Health, World Health Organization.

National health authorities are encouraged by WHO to identify the most appropriate feeding practices of infants (breastfeeding with antiretroviral or use of infant formula) for their communities. The chosen practice should be used as the unique standard of care.

According to the UNICEF ${ }^{13}$ guidance, the infant formula should be offered. There is no cost and its supply to the infant may occur with the emotional commitment that would happen in a situation of exclusive breastfeeding. Moreover, it provides for the pregnant women living with AIDS the "Practical Guide to Food for Children under 12 months who cannot be breastfed," offering suitable options for full nutrition of infants.

It still guides that the breastfeeding by infected mother should be inhibited postpartum by bandaging or the use of lactation inhibitor, as soon as it happens to preserve the mother's emotional state at the very moment. It also emphasizes the importance of the aid by the medical team and family in supporting this decision without discrimination.

As for the Ministry of Health of Brasil ${ }^{15}$, in order to achieve the maximum reduction in the rate of vertical transmission, together with the State Program for STD/AIDS in São Paulo, the guidance is for the breastfeeding does not occur, but the replacement by the infant formula distributed free of charge, after counseling, thereby ensuring an adequate nutritional development.

There is also contra-indication for mixed breastfeeding, crossed breastfeeding (breastfeeding by another woman), so that the child is not exposed to other infectious agents, or home pasteurization of human milk because this milk is not tested.

When considering global data, especially in the regions most affected by the infection, the reducing of the number of deaths by infections among 
breastfed children reinforces the many factors that encourage breastfeeding exclusively ${ }^{22}$. Approximately $13 \%$ of deaths of children under five years can be avoided $^{23}$. "No other single strategy achieves the impact that breastfeeding has in reducing deaths of children under five years." According to information by the World HealthOrganisation ${ }^{2}$ and UNICEF ${ }^{13}$, six million children's lives are being saved every year because of the increasing rates of exclusive breastfeeding in children with HIV.

The alarming rates of malnutrition are among the 30 poorest countries in the world, where at least 21 are African. In this region, unfavorable economic conditions, state of disrespect for the rights of the child and lack of protection for their development and growth, reflect an exposure to HIV virus more strongly ${ }^{13}$.

The latest international estimates that more than $25 \%$ of the population lives on less than US\$1.25 per day, being one of the most unequal situations in the whole world ${ }^{25}$. In 2007, approximately $18 \%$ of adults between 15 and 49 years old lives with HIV. The young people represent $4 \%$ of the men and $13 \%$ of the women between 15 and 24 years. Teenage girls are likely two to 4.5 times of becoming infected with AIDS, when compared to boys, because of their anatomy.

Regarding children, 1.4 million children under 18 years, $8 \%$ located in South Africa have been orphaned by one or both parents due to AIDS. Approximately $20 \%$ of them are not registered at birth, which hinders access to basic services.

In the current situation, the rights to survival, development and health are affronted daily in environments lacking sufficient resources to social welfare and health of this population. This region is among the only ones that possessed the mortality rate of children under five years above 50 per thousand live births in 2008.

UNICEF $^{13}$ data confirm that over $90 \%$ of children live in Africa and Asia, with one third of deaths in infancy of this group is due to malnutrition. Compared to the risk of vertical HIV transmission through exclusive breastfeeding, $7-22 \%$, 
the survival of infants prevails when receiving milk through the mother, ensuring their nutrition. Moreover, the access to antiretroviral drugs decreases the risk of further vertical transmission, what justifies the WHO guidance for its global operation.

Bulterys' data $^{18}$ state that prolonged breastfeeding contributes substantially to HIV transmission, even in the presence of an effective early intervention, intensive counseling and continuous support by the research team. Miotti ${ }^{19}$ suggests that without antiretroviral drugs the rate of transmission attributable to breastfeeding is higher in the first weeks after birth and, then, declines at a consistently low or decreasing rate.

$E$ mbree ${ }^{21}$ underlies that the high potency antiretroviral therapy allows the continued promotion and support to the breastfeeding practice for all women (including the majority of women infected with HIV) and reduces morbidity and mortality associated with the use of formulas.

On this same theme, in Brazil, studies that evaluated mortality of children vertically infected have verified that there was a decrease of approximately $67 \%$ in the mortality rate of these children, parallel to an increase in the use of antiretroviral drugs between 1998 and $2002^{16,17-24}$.

After the compulsory notification, the services have been able to provide more information about the exams, practices and care of mothers for their infants. Among this guidance is the artificial breastfeeding and nutritional status.

The distribution of the "Guide to Clinical Treatment of HIV Infection" to all pediatricians in the Public Health Network helps access to information. They are prepared based on the knowledge in the literature on viral dynamics, intervention guidelines (in countries like the United States and others in Europe) and the experience of professionals involved in their elaboration.

The referral services provide follow-up for mothers and children. It is performed during pregnancy through monthly visits in the first year of life of the infant, following on a yearly basis, according to each case individually. Children receive kits of infant formula, ensuring nutrition and protection to their exposure 
to HIV. Justifying the guidelines of the Ministry of Health, since in Brazil there is the possibility to offer and ensure the kit formula for all children.

As for the support and explanations given to the mother to understand the decision of the local health services and their recommendations, it can be emphasized the unique moment of attention and emotional commitment during the feeding of infants, by offering the breast or the formula.

According to Brazelton ${ }^{1}$, as previously mentioned, "the food would not be enough if there was no affection in the act of breastfeeding". That is, the time of breastfeeding can be broken in the act of sucking (the chest or in this case, the bottle), in visual contact with the mother when breastfeeding the infant, the approach with the mother's body (sensing temperature, texture, heartbeat and breathing) and mother-infant interaction by speaking or singing.

The quality of life of infants and their interaction with adults rely on previous enjoyable experiences. Allowing an infant to look an adult, let be packed and snug when being fed, makes him stop playing behind or avoid eye contact with people. From this point on infants gain weight and have a healthy development. If food is fundamental to survival, quality of future life also depends on the affection that he receives from parents along with food ${ }^{1}$. Either being exclusive breastfeeding or bottle with infant formula.

Both counseling situations are based on different justifications related to the rate of HIV transmission increased through breastfeeding, which may give protection to the infant with the formula and nutritional process in economically disadvantaged countries without guaranteed access to health services and infant formula.

In this way, it will be for the health professionals involved and the government policy adopted the direction to be followed on the issue of breastfeeding in newborns and infants exposed to HIV through vertical transmission. 


\section{REFERENCES}

1. Brazelton TB. Momentos decisivos do desenvolvimento infantil. São Paulo: Martins Fontes. 1994. 1, 347-52.

2. UNICEF. Net, NY. 2008. Children and AIDS: Third stocktaking report, p. 16. Disponivel em <www.unicef.org>. Acesso em: 20 fev 2011.

3. Maturana AP, Rizzo CV, Vasquez DF, Cavalheiro N, Holzer S, Morais VS. Avaliação da assistência ao parto em gestantes infectadas pelo HIV. Arq Med ABC. 2007; 32(1):11-6.

4. Newell ML. Reducing childhood mortality in poor countries. Transactions of The Royal Society of Tropical Medicine and Hygiene. 2003; 97:22-4.

5. Moodley D, Moodley J. HIV-1 infection: an indication for caesarean section? International Journal of Obstetric Anesthesia. 2000; 9:221-4.

6. Secretaria do Estado de Saúde, 2009.

7. Silva EB; Grotto HZW; Vilela MM. Aspectos clínicos e o hemograma em crianças expostas ao HIV-1: comparação entre pacientes infectados e sororeversores. Jornal de Pediatria 2001; 77(6): 503-511.

8. Brito AM; Sousa JL; Luna CF; Dourado I. Tendência da transmissão vertical de Aids após terapia anti-retroviral no Brasil. Rev Saúde Pública 2006; 4,18-22.

9. Herdy GVH; Pinto CAM; Lopes VGS; Ribeiro RP; Gomes IM; Tchou HY; Melo R; Kurdin B; Tavares PA. Study of the cardiac alterations in hiv-nfected children consequent to the anti-retroviral therapy: prospective study of 47 cases. Arq Bras Cardiol 2003; 80 (3): 316-20.

10. Veloso GL; Vasconcelos AL; Grinsztejn B. Prevenção da transmissão vertical no Brasil. Bol Epidemiol Aids 1999;12(3).

11. Marques HHS. Avaliação crítica dos efeitos adversos do tratamento antiretroviral no feto, recém-nascido e lactente. Rev Bras Ginecol Obstet. 2006; 28(7): 424-30.

12. Programa Nacional de DST/AIDS do Ministério da Saúde 2009 - Secretaria de Vigilância Sanitária em Saúde; 1-81.

13. UNICEF. Net, SP. 2011. AIDS. Disponivel em <www.unicef.org>. Acesso em: 22 set 2011.

14. Machado MMT, Galvão MTG, Kerr-Pontes LRS, Cunha AJLA, Leite AJM, Lindsay AC, Leite RD, Leite CAC. Acesso e utilização de fórmula infantil e 
alimentos entre crianças nascidas de mulheres com HIVIAIDS. Rev. Eletr. Enf. [Internet]. 2007;9(3):699-11.

15. UNICEF. Net. 2011. Situação mundial da infância. Disponivel em <www.unicef.org>. Acesso em: 20 ago 2011.

16. The PETRA study team. Efficacy of three short-course regimens of zidovudine and lamivudine in preventing early and late transmission of HIV-1 from mother to child in Tanzania, South Africa and Uganda (PETRA study): a randomised, double-blind, placebo-controlled trial. Lancet 2002, 359:1178-1186.

17. Nolan ML, Greenberg AE, Fowler MG. A review of clinical trials to prevent mother-to-child HIV-1 transmission in Africa and inform rational intervention strategies. 2002; 16 (15), 1991-9.

18. Bulterys $M$, Nolan M, Jamieson D, Dominguez K, Fowler MG. Advances in the prevention of mother-to-child HIV-1 transmission: current issues, future challenges. AIDScience 2002, 2.

19. Miotti PG, Taha TE, Kumwenda NI, et al. HIV transmission through breastfeeding. A study in Malawi. JAMA 1999, 282:744-749.

20. Leroy V, Karon J, Alioum A, et al. 24-month efficacy of a maternal shortcourse zidovudine regimen to prevent mother-to-child transmission of HIV-1 in West Africa: A pooled analysis of two randomized clinical trials. AIDS 2002, 16:631-641.

21. Embree JE, Njenga $S$, Datta $P$, et al. Risk factors for postnatal mother-child transmission of HIV-1. AIDS 2000, 14:2535-2541.

22. WHO Collaborative Study Team on the Role of Breastfeeding on the Prevention of Infant Mortality. Effect of breastfeeding on infant and child mortality due to infectious diseases in less developed countries: a pooled analysis. Lancet $2000,355: 451-455$

23. Jones, G. et al. How many child deaths can we prevent this year? Lancet, [S.I.],v. 362, p. 65-71, 2003.

24. Matida LH; Ramos AN; Moncau JEC; Marcopito LF; Marques HHS; Succi RCM; Negra MD; Haerst N. AIDS by mother-to-child transmission: survival analysis of cases followed from 1983 to 2002 in different regions of Brazil. Cad. Saúde Pública 2007; 23(3): s435-s444.

25. Mirochnick M, Fenton T, et al.,for the Pediatric AIDS Clinical Trials Group Protocol 250 Team. Pharmacokinetics of nevirapine in HIV type 1 infected pregnant women and their neonates. J Infect Dis 1998, 178:368-374. 
26. Musoke $P$, Guay LA, Bagenda D, et al. A phase 1/11 study of the safety and pharmacokinetics of nevirapine in HIV-1 infected pregnant Ugandan women and their neonates. AIDS 1999, 13:479-486.

27. Comitê Assessor das Recomendações para Profilaxia da Transmissão Vertical do HIV e Terapia Antirretroviral em Gestantes. Recomendações para profilaxia da transmissão vertical do HIV e terapia antirretroviral em gestantes 2006. 